Portland State University

PDXScholar

$11-30-2020$

\title{
Smoking Behaviors in Patients Offered Lung Cancer Screening
}

Sara Elizabeth Golden

Portland State University

Follow this and additional works at: https://pdxscholar.library.pdx.edu/open_access_etds

Part of the Health Communication Commons, and the Public Health Commons Let us know how access to this document benefits you.

\section{Recommended Citation}

Golden, Sara Elizabeth, "Smoking Behaviors in Patients Offered Lung Cancer Screening" (2020). Dissertations and Theses. Paper 5620.

https://doi.org/10.15760/etd.7492

This Dissertation is brought to you for free and open access. It has been accepted for inclusion in Dissertations and Theses by an authorized administrator of PDXScholar. Please contact us if we can make this document more accessible: pdxscholar@pdx.edu. 
Smoking Behaviors in Patients Offered Lung Cancer Screening

by

Sara Elizabeth Golden

A dissertation submitted in partial fulfillment of the requirements for the degree of

\author{
Doctor of Philosophy \\ in \\ Sociology
}

\begin{abstract}
Dissertation Committee:
Hyeyoung Woo, Chair

Ginny Garcia-Alexander

Christopher Slatore

Melissa Thompson

Jeffrey Robinson
\end{abstract}

Portland State University

2020 
(C) 2020 Sara Elizabeth Golden 


\begin{abstract}
In the United States, smoking causes preventable diseases, including lung cancer, which is the leading cause of cancer deaths. Improving smoking cessation rates is important to decrease lung cancer deaths. Health care visits with a discussion about lung cancer screening (LCS) may help in increasing prevalence of smoking cessation. Importantly, insurers now require clinicians to have a shared decision-making discussion with patients that includes discussion of smoking abstinence before they can receive an LCS scan (i.e., a low-dose computed tomography scan). This discussion may represent a unique opportunity to encourage smoking cessation since it may prompt positive smoking behavior change. However, it is less known whether, and to what extent, factors are important for current smoking status or improving smoking cessation before and within the LCS decision-making discussion.

This three-paper dissertation aims to understand patterns of successful smoking cessation focusing on socioeconomic, sociodemographic, and psychosocial factors among patients offered LCS at three sites: VA Portland Health Care System, VA Minneapolis Health Care System, and Duke University Medical Center. I utilize both quantitative and qualitative approaches to examine data from an existing longitudinal dataset compiled by the VA Portland Health Care System, which includes patient survey responses, electronic health records, and patient and clinician interviews. For the first paper, I describe the socioeconomic and sociodemographic factors of patients offered LCS and compare factors of those who had successfully quit smoking prior to being offered LCS with the factors of those who were not successfully able to quit. For the second paper, I examine
\end{abstract}


how patient-reported presence of patient-clinician communication is associated with smoking cessation (measured at one-year follow-up). For the third paper, I qualitatively evaluate how clinicians and patients communicate about smoking in the context of the LCS decision-making discussion. With this analysis, I can explore the nuances of how patients and clinicians communicate about smoking in the context of lung cancer screening.

Given that conversations between patients and clinicians pertaining to smoking may serve as a unique opportunity for smoking cessation, this dissertation provides better understandings about roles of communications with clinicians in smoking cessations among patients. First, I found that hardened smokers offered LCS differed in important social factors based on their smoking status at baseline. Second, discussing smoking cessation during the LCS decision-making discussion may not lead to successful smoking cessation at least in the short term. There may be other more important aspects that affect smoking cessation. Lastly, in support of previous findings, communication about smoking during the LCS decision-making discussion is unlikely to influence smoking behavior. Findings of the three analytic chapters can offer some insights for how the LCS decision-making discussion is helpful to encourage cessation, which would improve public health by reducing deaths from lung related diseases. 


\section{Acknowledgements}

I would like to acknowledge the assistance of support of all the research assistants, project managers, and site-PIs at each site, the study participants, and my doctoral committee members.

$\underline{\text { Lead Site Investigators }}$

VA Portland Health Care System

Christopher Slatore, MD, MS

VA Minneapolis Health Care System

Anne Melzer, MD, MS

Duke University Medical Center

Santanu Datta, PhD, James Davis, MD

$\underline{\text { Research and Clinical Teams }}$

VA Portland Health Care System

Sara Golden, Sarah Ono, Leah Miranda, Tara Thomas, Philip Tostado, Molly Davis, Cynthia Sadak

VA Minneapolis Health Care System

Angela Fabbrini, Megan Campbell, Ruth Balk, Miranda Deconcini

Duke University Medical Center

Jillian Dirkes, Leah Thomas, Betty Tong, MD

$\underline{\text { Committee Members }}$

Portland State University

Hyeyoung Woo, $\mathrm{PhD}$, Melissa Thompson, $\mathrm{PhD}$, Jeffrey Robinson, $\mathrm{PhD}$ 


\section{University of Texas- San Antonio}

Ginny Garcia-Alexander, $\mathrm{PhD}$

VA Portland Health Care System

Christopher Slatore, MD, MS

\section{Declaration of Conflicting Interests}

All authors declare no conflicts of interest with the work presented in this manuscript.

The Department of Veterans Affairs did not have a role in the conduct of the study, in the collection, management, analysis, interpretation of data, or in the preparation of the manuscript. VA Health Services Research and Development declined to fund this study multiple times. The views expressed in this article are those of the authors and do not necessarily represent the views of the Department of Veterans Affairs or the U.S.

Government.

\section{Funding}

This study was funded by a Research Scholar Grant, 128737-RSG-155-01-CPPB from the American Cancer Society for Christopher G. Slatore. The study was supported by resources from the VA Portland Health Care System, Portland, OR; the Edith Nourse Rogers Memorial VA Hospital, Bedford, MA; Portland State University Sociology Department, Portland, OR; and Duke University School of Medicine, Durham, NC 


\title{
Table of Contents
}

\author{
Page Content \\ i Abstract \\ iii Acknowledgements \\ vi List of Tables \\ vii List of Figures \\ 1 Chapter 1. Introduction \\ 58 Chapter 2. Description of hardened smokers offered lung cancer screening \\ 86 Chapter 3. The association of patient-clinician communication in smoking \\ cessation in patients offered lung cancer screening \\ 112 Chapter 4. Patient and clinician perspectives on lung cancer screening \\ decision-making discussions and smoking cessation \\ 143 Chapter 5. Conclusion \\ 176 Appendix A: VA Decision Aid \\ 177 Appendix B: Duke University Decision Aid \\ 178 Appendix C: Published Study Protocol \\ 180 Appendix D: Selected Surveys \\ 182 Appendix E: Interview Guides \\ 185 Appendix F: Human Subjects Approvals
}




\section{List of Tables}

\section{Page Chapter 1.}

27 Table 1. Research Question 1 Variables

29 Table 2. Research Question 2 Variables

\section{Chapter 2.}

75 Table 1. Self-reported Descriptive Statistics of All Subjects

76 Table 2. Descriptive and Bivariate Statistics Reporting Differences between Current and Former Smokers

\section{Chapter 3.}

102 Table 1. Characteristics of Patients who are Currently Smoking Offered Lung Cancer Screening

104 Table 2. Odds Ratios for the Association of Patient-Clinician Communication about Smoking Cessation and Cessation Outcomes

\section{Chapter 4.}

135 Table 1. Self-reported Patient Characteristics

136 Table 2. Clinician Self-reported Characteristics 


\section{List of Figures}

\section{Page Chapter 1.}

19 Figure 1. Patient-Centered Communication Model

\section{Chapter 3.}

101 Figure 1. Patient-Centered Communication Model 


\section{Chapter 1. Introduction}

It is well known that cigarette smoking undermines health (Centers for Disease Control and Prevention 2018a; Cesar Neto et al. 2012; Dunga et al. 2015; Feirman et al. 2016; Sanner and Grimsrud 2015; Taylor 2015; U.S. Department of Health and Human Services 2014; Warnakulasuriya et al. 2010; Warren and Cummings 2013). Smoking remains the leading cause of preventable disease in the United States (Centers for Disease Control and Prevention [CDC] 2018a) and is associated with 80-90\% of all lung cancers. Indeed, while lung cancer is the third most commonly diagnosed cancer, the fatality rate of lung cancer is the highest among all cancers (Siegel, Miller, and Jemal 2016).

Smoking cessation can significantly reduce morbidity and mortality risks (CDC 2018b; U.S. Department of Health and Human Services 2014). However, approximately $14 \%$ of US adults continue to smoke (CDC 2018c), despite widespread knowledge about its harmful effects. Lung cancer screening (LCS) using an annual low-dose computed tomography (LDCT) scan is another avenue to reduce morbidity and mortality from cigarette smoking (herein, 'LCS' refers to the process of screening while 'LDCT' refers to the scan itself). Importantly, insurers now require a shared decision-making discussion (herein, referred to as the "decision-making discussion") to occur prior to patient receipt of the LDCT that includes discussion of smoking cessation and abstinence. It is unknown what factors are important for improving smoking cessation among patients offered the LDCT for LCS during the decision-making discussion. 
The purpose of this dissertation is to describe and examine patterns of successful smoking cessation using socioeconomic, sociodemographic, and psychosocial factors, while understanding use of the LCS decision-making discussion as an opportunity to encourage cessation. Given that conversations between patients and clinicians pertaining to smoking may serve as a unique opportunity for smoking cessation, this dissertation provides better understandings about roles of communications with clinicians in smoking cessations among patients. Findings of the three analytic chapters can offer insights for how the LCS decision-making discussion is helpful to encourage cessation, which would improve public health by reducing deaths from lung related diseases.

For this purpose, I aim to address three research questions in this dissertation. My first research question examines whether patients who were able to successfully achieve smoking cessation differ from patients who were not able to successfully achieve smoking cessation in terms of socioeconomic and sociodemographic factors. My second research question investigates the role of communication within the LCS decisionmaking discussion in smoking cessation. To address this question, I look at patientclinician communication (assessed by patient's perceptions of the presence of communication about smoking) during the LCS decision-making discussion associated with smoking cessation. Finally, I address a question of how clinicians and patients communicate about smoking within the LCS decision-making discussion.

To address my first research question, I describe and compare various social factors of patients participating in LCS programs at three separate sites. Patients offered LCS can be classified as hardened smokers (those who have a difficult time quitting). I 
describe the role of the socioeconomic status (SES), measured by educational attainment, employment status, and income, as well as sociodemographic factors among the patients. I then perform bivariate analysis to compare those who were able to successfully quit smoking with those who were not able to successfully quit prior to being offered LCS, in terms of SES and sociodemographic factors. Given the large body of research connecting higher SES and certain demographics to improved health outcomes (Kawachi et al. 1997; Mirowsky and Ross 2015; Phelan et al. 2004; Phelan, Link, and Tehranifar 2010; Schnittker 2004; Subramanian and Kawachi 2004), it is expected that individuals of less education, who are not employed, have lower income, are of minority racial/ethnic status, are not married, and are male, would be less likely to report successful smoking cessation compared to those who have more education, who are employed, have higher income, are non-minorities, are married, and are female (Gorini et al. 2018; Jha et al. 2006; Royal College of Physicians 2016). Because differences in SES exist among patients at the study sites, I also expect that patients at the VAPORHCS or Minneapolis sites are less likely to report successful smoking cessation, compared to those who are at the Duke site.

After I describe and compare these social factors in terms of smoking cessation for the first research question, I examine the independent contribution of an important psychosocial resource on successful smoking cessation by looking at patient-clinician communication. Because treatment compliance and improved health outcomes can be improved with communication, and communication is prompted by shared decisionmaking, I assess the contribution of patient-clinician communication. Patient-clinician communication is a psychosocial factor that is increasingly recognized as an important 
determinant of health. High-quality communication can improve patient-centered outcomes like smoking cessation and abstinence, as well as increased exercise and other positive health behaviors (Institute of Medicine [IOM] 2013; Mead and Bower 2000; Simpson et al. 1991; Weiland et al. 2012). Thus, I expect that individuals reporting communication about smoking cessation with their clinician will be more likely to evidence successful smoking cessation at the end of the study period.

Finally, Research Question 3 (RQ3) undertakes a qualitative examination of the nuances of how patients and clinicians communicate about smoking in the context of LCS. RQ3 thus sheds light on the previous quantitative RQ2. This study asks: How do clinicians and patients communicate about smoking during the LCS decision-making discussion? The qualitative examination uses conventional content analysis to add to the richness of the prior research questions. Additionally, the qualitative methods allow for more detailed questions to be asked about patient and clinician experience with communicating about smoking cessation in the context of the LCS decision-making discussion.

The data I examine provide unique access to patients who undergo an LCS decision-making discussion for two reasons. First, these data are unique because it is the largest prospective study of patients offered LCS to date. Second, I have unique access to all aspects of the study, from study design to data collection to analysis, through my work as a Research Associate at the VA Portland Health Care System (VAPORHCS). Findings of this dissertation contribute to the existing literature about smoking cessation and hardened smokers. Importantly, these findings will add to the knowledge base and 
sociological theory about fundamental causes, unique populations (e.g., hardened smokers), and patient-clinician communication.

\section{Sample and Setting}

We recruited patients from three sites: the VAPORHCS, Portland, OR; the Minneapolis VA Medical Center, Minneapolis, MN; and Duke University Medical Center, Durham, North Carolina. Participants were outpatients who were eligible for LCS based on age, smoking history, and comorbid diseases. Clinical criteria based on the National Lung Screening Trial (NLST) included: men and women who are current or former smokers (within 15 years) aged 55 to 77 with $\geq 30$ pack-years of smoking (NLST Research Team et al. 2011). Additional clinical criteria included patients who were asymptomatic in terms of lung cancer symptoms, not undergoing active treatment for cancer, had no history of lung cancer, and were physically able to tolerate surgical resection for lung cancer. In addition to these clinical criteria, we did have research eligibility criteria. First, patients must have been offered the LDCT for LCS by a provider. Patients could accept or decline the LDCT. Second, we excluded those with severe dementia, severe, uncontrolled schizophrenia or other mental illness, and severe hearing impairment. Finally, no exclusions were made based on race/ethnicity, but we limited enrollees to English speakers, either as a primary or secondary language. The research team did not verify clinical eligibility.

The majority of this study population are Veterans, but about one-third are not. Since two of the sites that contribute most of the sample are VA hospitals, it is important to discuss Veteran status. Veteran cohorts are different from the general population in 
several key areas. For instance, Veterans are predominately male, more educated, and have higher incomes than the general population. Importantly, however, users of VA Hospitals like those included in our study, are generally poorer, older, less well educated, less likely to be employed, and have more chronic health conditions than either the general population or Veterans who do not use VA hospitals (Morgan 2005).

National smoking rates for Veterans have declined about 15\% from 2010 to 2015; however, Veterans are still more likely to be current smokers compared to the civilian population (21.6\% vs. 14\%) (Department of Veterans Affairs, Veterans Health Administration 2015; CDC 2019). Similarly, $42 \%$ of US adults and $74 \%$ of Veterans are current or former cigarette smokers (Mariolis et al. 2006), indicating that Veterans are less likely to successfully quit smoking. Despite the availability of smoking cessation programs in the VA healthcare system, smoking remains "accepted, accommodated, and promoted" during active military service (Smith et al. 2014). As a result, almost half (49\%) of military service members reported using nicotine in the past year (Department of Defense 2013) and almost one-third started smoking after joining the military (Bray et al. 2006). One previous study found VA Hospital users were actually more likely to have ever smoked (McKinney et al. 1997). Veterans are important to include in this study because of their higher smoking prevalence, and the fact that lung cancer disproportionately affects Veterans. Veterans have a higher lung cancer incidence (Harris, Hebert, and Wynder 1989) and mortality (Campling et al. 2005) than the general population, making it important to include them in studies of smoking cessation. 
Importantly, although all Veterans in this study were enrolled in VA health care, the LDCT was not paid for by this study for any participant. Veteran participants may have had a small co-pay (no more than \$50) for the scan, but non-Veterans either had insurance or paid out of pocket. Because access to care has been shown to be associated with various health outcomes (Andersen 1995; Hoffman and Paradise 2008), and because Veterans may have better access to care, this study will incorporate site location in the RQ1 and RQ2 analyses.

\section{Hardened Smokers}

Patients offered LCS are by definition at high-risk of developing lung cancer. They are eligible based on age (55-77 years), smoking history (either currently smoking or a $\geq 30$ pack-year history), and comorbidities. This population can generally be considered as "hardened" smokers (note that we recognize the pejorative nature of the term "hardened smokers," but to date there has been no other agreed-upon term). Hardened smokers are individuals who smoke that are "less likely to be influenced by cessation measures" (Ney et al. 1989), and have no intention to quit and/or find it very difficult to quit (Docherty and McNeill 2012). Hardened smokers are also more likely to be from disadvantaged backgrounds (Lund, Lund, and Kvaavik 2011). These individuals are difficult to reach but are equally as important to target for smoking cessation. Sometimes hardened smokers may have given up on cessation, but it is important to remember that it is never too late to quit smoking and even quitting later in life has significant health benefits (Peto et al. 2000). 
Because this study is focused on hardened smokers, it provides a unique opportunity to examine the potential for socioeconomic, sociodemographic, and psychosocial factors to improve rates of smoking cessation in this population. In addition, all patients in this study have an added benefit of a decision-making discussion to include smoking, which may alter patients' knowledge and desire to quit. Therefore, there may be differences in smoking behavior changes compared to those not in LCS programs. It is important to determine if traditional well-correlated socioeconomic, sociodemographic, and psychosocial factors remain significant in this potentially different population.

\section{Literature Review}

\section{Socioeconomic and Sociodemographic Variations in Smoking and Smoking Cessation}

I considered several socioeconomic and sociodemographic factors in this study, including educational attainment, employment status, income, racial/ethnic status, marital status, age, gender, and study site location. Income, educational attainment, and employment status are components of SES and are well-known correlates to smoking. Components of SES are, "factors that involve a person's relationships to other people" (Link and Phelan 1995:81), mainly involving economic positions in society. SES is "a key underlying factor" that influences health. Indeed, smokers that come from socioeconomically disadvantaged backgrounds tend to have more smoking-related illness. This is a result of their almost three-fold higher prevalence of smoking compared with those in higher socioeconomic brackets (Drope et al. 2018). Formally, I expect that those with lower educational attainment, who are not employed, and have lower income, will be more likely to smoke. 
Sociologists like Kawachi et al. (1997), Frohlich, Chabot, and Corin (2002), and Williams (2003), have widely examined the importance of SES as a single measure and separately, as being important correlates with health behaviors, like smoking. SES may influence smoking cessation indirectly, however. For instance, those with lower educational attainment are less likely to feel self-efficacy or control over their life. They may lack in resources such as knowledge of health and problem-solving skills. Education produces self-efficacy (Mirowsky and Ross 2003) since education is not something that can be lost or eliminated with a downturn in the economy. Via self-efficacy, education can help people "cope actively and flexibly, avoid problems, and prepare for those that cannot be avoided" (Mirowsky and Ross 2015:299). For these reasons, those with lower levels of educational attainment may experience more stress and be less likely to utilize preventive healthy behaviors, leading them to have higher smoking rates (Ross and Mirowsky 1999).

Additionally, education typically leads to higher status occupations, more money, better health insurance, and higher quality health care (see below for discussion about occupation). Interestingly, though, people with lower educational attainment tend to have poorer health than those with higher educational attainment even with access to the same quality of care (Robert Wood Johnson Foundation 2014). The association with poorer health may be due to increased stress (as above) or because of health literacy discrepancies (van der Heide et. al 2013). Prior research has shown that educational attainment affects decisions about smoking, including the decision to start smoking and the decision to quit smoking (de Walque 2007; Jürges, Reinhold, and Salm 2011). For 
instance, $26.2 \%$ of males who smoked who did not graduate from high school were able to quit smoking, while $57.6 \%$ of males who smoked who graduated from college were able to quit smoking (de Walque 2007). Another study found that for people with at least a high school education, regular smoking did not occur until 19-24 years of age, compared with those who did not graduate from high school, who started regularly smoking at 18 years of age or less (Pierce et al. 1991).

Occupation is difficult to measure. Occupation is an "ambiguous term," making it hard to categorize into analytic components since it can be defined in different ways (Royeen 2002). Occupation and employment status can, however, provide a marker of self-efficacy since those with presence of an occupation, or higher status occupations, generally have greater autonomy and control over their circumstances. The Whitehall studies showed that SES defined by occupation is strongly and inversely related to mortality, a claim supported by several studies since (Marmot et al. 1991). Lower ranked occupations, and having no occupation at all, can limit autonomy and self-efficacy. Deficiencies in autonomy and self-efficacy can increase stress, which is linked with negative health behaviors, like smoking.

In addition, occupational differences can expose individuals to differing occupation-related lifestyle factors. There are deeply rooted psychosocial attitudes and effects of occupation that seem to persist despite knowledge about the detrimental effects of smoking (Sterling and Weinkam 1990). For instance, blue collar occupations have a history of allowing smoking and individuals in these occupations continue to smoke at a higher rate ( $41 \%$ of farm laborers vs $28 \%$ of managers). Similarly, a higher proportion of 
professionals and those in higher status occupations who do smoke, are able to successfully stop smoking compared with those in blue collar occupations (50\% vs. 35\%, respectively) (Sterling and Weinkam 1978).

Similarly, individuals with higher incomes generally have higher-paying jobs and people in these positions generally have a greater sense of autonomy and self-efficacy, thereby leading to better health. Frohlich and colleagues (2002), for instance, explored how aspects of social structures, like income, influence smoking and community norms surrounding health behaviors. People in poverty when measured by income are more likely to continue to smoke (i.e., not successfully quit), for instance. This holds for Veterans and civilians (Golden et al. 2018; Marmot and Wilkinson 2006). Income provides key resources like the ability to purchase health care and more nutritious foods (Adler and Newman 2002), access safer housing, and have greater technological access. Thus, people with higher incomes can garner health information more easily, utilize preventive medicine appropriately, and avoid risks more successfully.

Several other studies show strong associations between SES and health. In fact, "people in lower social class positions have higher rates of virtually every disease" (Syme and Yen 2000). Shishehbor et al. (2006) found that people with lower SES also had greater physical disability and higher all-cause mortality. Those with the lowest income and least educational attainment are consistently less healthy than those in the higher income and educational brackets (Braveman et al. 2010), in part due to lack of resources like knowledge and life skills that are important for health. The infamous Black Report out of the UK in 1980 (Bartley, Blane, and Smith 1998) exemplified that even 
when using multiple measures of social position, the gradational association of SES with mortality remained. The three main SES components discussed here each provide similar resources to each other, which is why they are often seen as proxies for measures of SES as a whole. I will look at each well-correlated component separately in order to describe this sample population

I also examine racial/ethnic status, marital status, age, gender, and study site. Some minority racial groups such as American Indian/Alaska Natives (Nollen 2019) are more likely to smoke compared with other racial groups, although this is not consistent across all minority groups. For instance, African Americans have been found to be three times more likely to be light smokers vs. heavy smokers when compared with whites, and the differences were not explained by other sociodemographic features (Kabat, Morabia, and Wynder 2011). Further, whites typically initiate smoking earlier compared to minorities (Kandel et al. 2004), although prevalence of smoking among white adults is about the same as for African American adults. Also, research shows that African American adults are less successful at smoking cessation compared to white adults (CDC 2020). The U.S. Department of Health and Human Services (1998) notes this may be due to lower utilization of cessation treatments and less access to preventive health services.

Reasons for the effects of race on health behaviors, like smoking, are likely multifactorial. Racial categories comprise differing socioeconomic, political, occupational, and educational components that can each affect health differently (Williams 1997). For example, different racial and ethnic groups have important power and status differences, which can be illustrated by differences in SES. Williams (1997) 
points out the three-fold higher rate of poverty for African Americans, Latinos, American Indians, and many Asian subgroups compared with Whites. These SES differences lead to disparities in health through multiple avenues, as discussed above. Of course, there is also the history of racism in America, which "created a set of norms that required the differential treatment (discrimination)" of minority groups (Williams 1997), leading to unequal health care, education, occupations, etc.

Rates of smoking are also elevated among those who are unmarried. Married individuals are less likely to smoke than those who are divorced/separated/widowed and those who are single (12.5\% vs. $18.1 \%$ vs. $13.9 \%$, respectively) (CDC 2020; Vannimenus 2018). Marital status and its association with positive health outcomes have also been found, such as decreased stress, better overall self-reported health (Lorenz et al. 2006; Osler et al. 2008), and others (Umberson and Montez 2010). For men, especially, marriage is associated with an increased probability of successful smoking cessation $(\mathrm{OR}=1.69)$ (Broms et al. 2003).

One aspect of marriage that may improve health is the social support the dyad provides. It has been well documented that the social support gleaned via the marriage dyad improves health outcomes in areas such as lupus (Mazzoni and Cicognani 2011), mental health (Tajvar et al. 2013), and diabetes (Strom and Egede 2012), to name a few. The importance of social support for health outcomes has been documented in various types of cancer (Banik et al. 2016; Carpenter et al. 2010; Ikeda et al. 2013; Kroenke et al. 2013; Luszczynska et al. 2013; Nausheen et al. 2009; Pinquart and Duberstein 2010) as well. Clinical benefits of social support in cancer include mortality benefits, protection 
against disease progression and incidence, and mitigation of mental health issues

(Carpenter et al. 2010; Ikeda et al. 2013; Kroenke et al. 2013; Nausheen et al. 2009; Pinquart and Duberstein 2010).

Social support is important for both biological and behavioral reasons for health. Some studies show that higher levels of social support equate to lower levels of certain hormones that are deleterious to cancer cells. Also, having the social support provided by a spouse affects behavior since the spouse can encourage treatment seeking or be a motivator for positive health changes (Pinquart and Duberstein 2010), like quitting smoking. There are four main types of supportive actions: emotional, instrumental, informational, and appraisal. Emotional actions are often the most widely discussed. This type of support includes showing empathy, sympathy, love, caring, and listening. Instrumental support includes more functional aspects of support like taking patients to appointments, as well as providing concrete supplies or materials to assist with practical issues (Thoits 2010). Informational support is any advice or information that others can provide to an individual. Often this type of support comes from health care providers. Appraisal support is generally the least discussed and possibly the least commonly measured, but it involves any assistance from others that may aid in self-esteem or selfevaluation (Heaney and Israel 2008). This type of support can also come from health care providers. Social support often comes from a spouse, but of course clinicians may be an important part of the circle of people providing social support for hardened smokers offered LCS. 
Between the ages of 25 and 64 current smoking rates are about the same, around $16 \%$. Over the age of 64 , however, it drops to $8.4 \%$ (CDC 2020). This could be due to the historical use of targeted tobacco advertising to minors, or the influence on youth of role models who use cigarettes (Steinberg and Delnevo 2013). Additionally, one study found that among older smokers, heavier smokers who used equal to or more than 25 cigarettes per day were the most likely to successfully quit smoking, whereas for younger smokers, those who used less than 25 cigarettes per day were more likely to stop (Coambs, Li, and Kozlowski 1992). This finding may relate to an increase in desire to quit as tobaccorelated and other health or financial effects produce a heavier burden during aging (Steinberg and Delnevo 2013; Golden et al. 2020). I do not expect much variation in smoking based on age since our population is within a rather narrow 55-75-year age range.

Males have a higher smoking rate than females (15.6\% vs $12.0 \%$, respectively) (CDC 2020) in the general population and generally have a higher smoking intensity (McClure et al. 2020). Females have a worse quit rate though, where they are $31 \%$ less likely to quit successfully compared to males (National Institute on Drug Abuse 2020). A large, multi-national, retrospective study used a comparative risk framework to determine the prevalence of smoking by sex and age (GBD 2015 Tobacco Collaborators 2017). This study supported other findings that the general prevalence of smoking for women is less than for men, but so were successful reductions in smoking. I would expect males to be more likely to currently smoke based on the higher smoking rates and the population of hardened smokers and Veterans being studied. 
There is a rather large body of literature describing gender inequality and the relationship with women's smoking and changing gender roles, mostly centered around popular culture's portrayal of smoking. Cessation interventions are also often thought to work the same across genders (Bottorff et al. 2014), or may only differ based on biological factors, ignoring social gender-specific issues. This assumption is in contrast to the evidence that quit rates differ significantly between men and women. Thus, it is important to be aware of and document the differences between genders in the reasons and theory behind their smoking behaviors in order to develop and implement effective interventions.

All site locations selected for this study serve relatively large rural populations also, who also have higher smoking rates compared to their urban counterparts (Atkins, Kim, and Munson 2017; Robert, Doogan, and Kurti 2016). Reasons for the increased smoking rates are likely related to differences in SES between rural and urban divisions, however even among all income levels. For instance, Roberts et al. (2016) found that people in rural areas still had higher rates of tobacco use compared to their urban counterparts. Income differences though, do seem to have an additive effect on smoking prevalence (Higgins et al. 2016). Reasons for increased smoking in rural populations could be due to targeted marketing by tobacco companies or differences in education (Roberts, Doogan, and Kurti 2016). Even though all sites in this study include large rural populations in their catchment areas, patients from our Duke University site self-selected 
for smoking cessation assistanceso I expect them to have more individuals who were able to successfully quit smoking.

Certainly, specific subgroups of people are more likely to initiate and continue smoking compared to others, and these differences are largely based on SES and sociodemographic factors. Undoubtedly, there is evidence that the results of all studies are showing an association of SES, sociodemographics, and health based on lack of resources like reduced access to health behavior/cessation techniques or knowledge, lack of motivation or control, reduced social capital, or chronic stress (Elo 2009; Thoits 2010; Umberson, Crosnoe, and Reczek 2010). Psychosocial Resources: Self-efficacy

House (2002) provides a comprehensive background on the emerging role of psychosocial factors, like self-efficacy, in health. Interestingly, it was spurred by the 1964 Surgeon General's report (U.S. Department of Health and Human Services 1964) on smoking that identified psychosocial factors as being important in smoking and smokingrelated diseases. House noted that negative psychosocial factors like stress, anxiety, low self-esteem, or low self-efficacy are chronic, can lead to negative health behaviors, like smoking (House 2002). Self-efficacy emerged as one of the most significant psychosocial factors involved in smoking cessation (Strecher 1986), providing a reliable measure of abstinence from smoking (Gwaltney et al. 2009) and successful cessation (DiClemente, Prochaska, and Gibertini 1985).

Self-efficacy refers to "beliefs in one's capabilities to organize and execute the courses of action required to produce given attainments" (Bandura 1997). That is, self- 
efficacy is a mechanism whereby a person senses control (Bandura 1997), or mastery, over their circumstances and health. Self-efficacy sustains confidence and is often associated with lower reports of anxiety and depression (Mirowsky and Ross 2003). Selfefficacy is part of a positive self-experience contributing to health and well-being. The sense of control or mastery is related to the likelihood of developing and dying of chronic disease. Environment, social supports, and other psychosocial aspects of one's life influence levels of self-efficacy (Marmot and Wilkinson 2006) and may change over time.

\section{Psychosocial Resources: Communication}

Patient-clinician communication is widely regarded as a key component of high quality care that can improve patient-centered outcomes (IOM 2013; Mead and Bower 2000; Simpson et al. 1991; Weiland et al. 2012), like improved health behaviors. The patient-centered communication model posited by Street et al. (2009), identifies five domains of health communication. The patient-centered communication domains include: information exchange (sharing information about risks, benefits, etc.); patient as person (consideration of patients' feelings, preferences, and values); sharing power and responsibility (shared decision-making); therapeutic alliance (the need for patient and clinician to be "on the same page"); and clinician as person (taking the clinicians' limitations and knowledge into consideration) (Figure 1). Since shared decision-making is mandated as part of the LCS decision-making discussion and is a domain of highquality patient-centered communication, (Mead and Bower 2000), I examine the presence of communication to determine the association with smoking cessation. 
Figure 1. Patient-Centered Communication Model

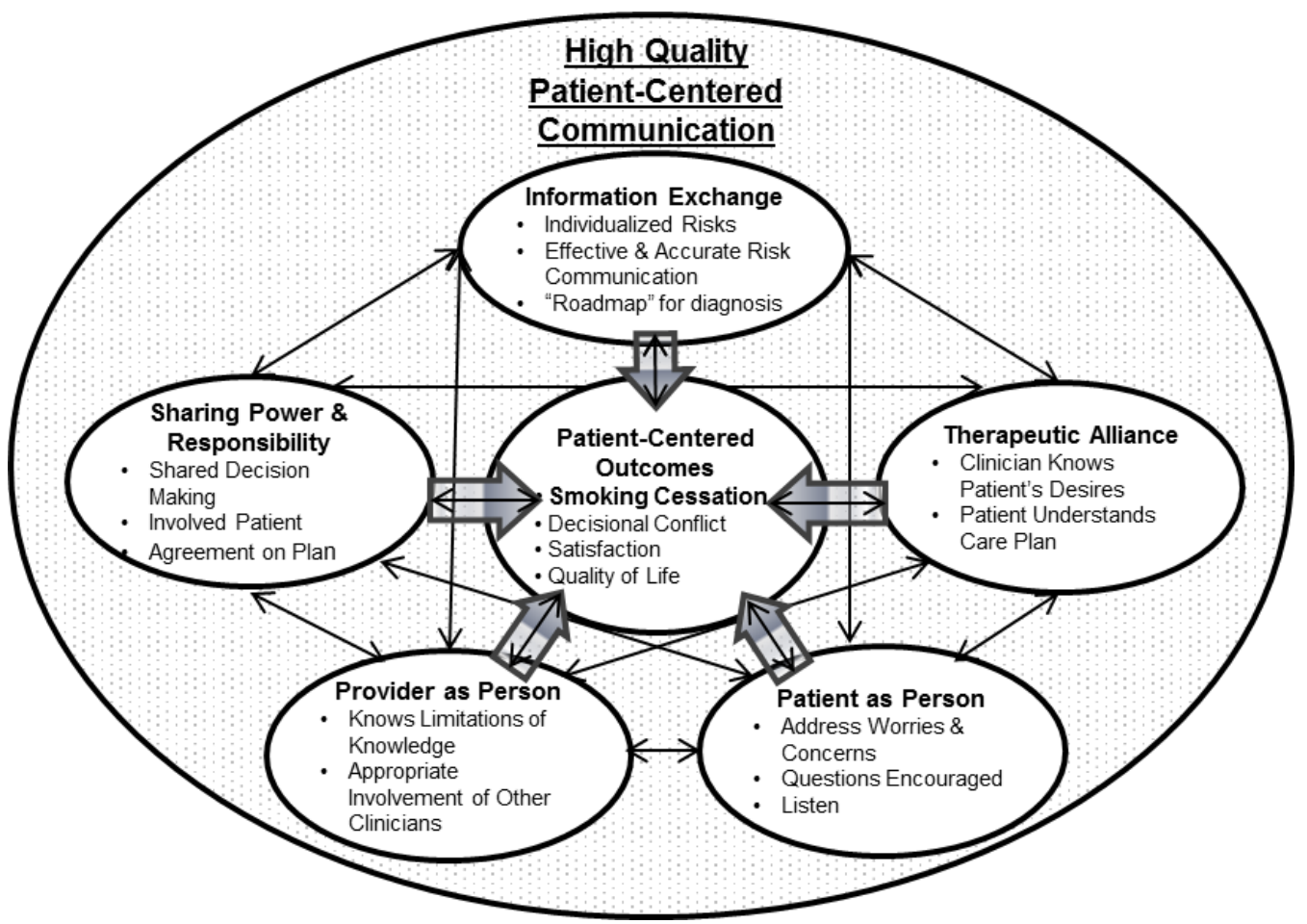

In addition, a 2008 report published by the Agency for Healthcare Research and

Quality (AHRQ) recommends that "every individual entering a health care setting"

should have their smoking status assessed and clinicians should advise their patients who smoke to quit (2008 PHS Guideline Update Panel, Liaisons, and Staff 2008). The AHRQ recommendation was based on a meta-analysis showing evidence that even brief advice given by a physician (Lancaster and Stead 2004), or other clinicians (Bao, Duan, and Fox 2006), can significantly increase cessation rates. One central method of communicating about smoking cessation is through use of the 5A's. The 5A's are Ask, Advise, Assess, Assist, and Arrange, and should be used at every clinical encounter. "Ask" refers to 
identifying a patient's smoking status (never, former, or current); “Advise” refers to encouraging cessation in a "clear, strong, and personalized manner"; "Assess" refers to determining the patient's willingness to quit; "Assist" refers to offering tailored smoking cessation strategies, such as referrals to counseling, medications, or other resources; and "Arrange" refers to scheduling follow-up to assess treatment outcomes and provide ongoing care (Agency for Healthcare Research and Quality 2012). The US Department of Veterans Affairs and other medical systems have adopted use of the 5A's via guidelines put forth by the US Public Health Service (The Clinical Practice Guideline Treating Tobacco Use and Dependence 2008 Update Panel, Liaisons, and Staff 2008). While the LCS decision-making discussion seems an opportune time to utilize techniques like the $5 \mathrm{~A}$ 's to communicate about smoking behaviors, it is unknown how or if they are applied in the LCS context.

Communication, therefore, has significance in eliciting successful smoking cessation, and is explored herein using quantitative surveys. Additionally, I explore the nuances of this communication qualitatively.

\section{Lung Cancer Screening}

In 2020, approximately 228,820 people in the U.S. are expected to be diagnosed with lung cancer (American Cancer Society 2020), and this number is likely to increase with further emerging evidence recommending LCS (Bach et al. 2012; Humphrey et al. 2013; Jaklitsch et al. 2012; Jensen et al. 2015; Moyer 2014). Large numbers of people at increased risk of lung cancer. Veterans, in particular, have a disproportionately higher lung cancer incidence (Harris, Hebert, and Wynder 1989) and mortality (Campling et al. 
2005) than the general population. VA facilities diagnose about 7,700 Veterans every year with lung cancer and almost 900,000 Veterans are at risk (Sprey 2020). This is likely attributable to environmental exposures, but maybe more importantly, prior policies enabling the Department of Defense to supply cigarettes to troops and include them in basic rations until 1975. Though this policy is no longer in place, $30 \%$ of Veterans continue to smoke, twice the amount of the general population (Food and Drug Administration 2020).

The goal of LCS, like any screening, is to detect disease early in people who do not have any symptoms of disease. LCS is now recommended by several organizations such as the United States Preventive Services Task Force (U.S. Preventive Services 2004; Moyer 2014), the American Cancer Society (Wender et al. 2013), and others (Bach et al. 2012; Jaklitsch et al. 2012; Samet et al. 2012; Wood 2015). It is estimated that up to 7 million US adults may be eligible for screening (NLST Research Team [NLST] et al. 2011). These determinations were made on the basis of the largest clinical trial in American history, the NLST. The NLST showed that using the LDCT (compared to a normal x-ray) could improve lung cancer and overall mortality by $20 \%$ and $7 \%$, respectively, in the eligible population (NLST Research Team et al. 2011).

While receipt of the LDCT has not been shown to impact smoking cessation (Slatore et al. 2014), high quality communication has been shown to impact cessation (Bailey et al. 2018; Bao, Duan, and Fox 2006; Lancaster and Stead 2004; LindsonHawley, Thompson, and Begh 2015).This may be especially true within an LCS decision-making discussion given that communication may be improved within shared 
decision-making contexts. Notably, all patients in this sample received a decision-making discussion. For the purposes of this dissertation, I utilize LCS as the context in which the decision-making discussion and smoking conversations are conducted.

\section{The LCS Decision-Making Discussion}

Importantly, the United States Preventive Services Task Force gave LCS a grade B recommendation, meaning they recommend the intervention and require private insurers to extend coverage for this screening. The Centers for Medicare and Medicaid Services (CMS) has also agreed to pay for LCS (Jensen et al. 2015). These recommendations, however, came with conditions (Jensen et al. 2015). For instance, insurers require a decision-making discussion to occur prior to receipt of the LDCT; the first time such a requirement has been made.

To facilitate decision-making and communication for LCS, a qualified practitioner must use a decision aid recognized by a national professional medical organization. In this study, clinicians from the two VA sites typically used the VAproduced decision aid (Appendix A), while at Duke University they used a decision aid created by the Agency for Healthcare Research and Quality (AHRQ) (Appendix B). Within the decision-making discussion, there is also a requirement to provide smoking cessation counseling and provision of cessation services as appropriate, since discussions of LCS often address current and past smoking behaviors. It unknown though, if the decision-making discussion improves rates or opinions of smoking cessation through communication.

\section{Methods}


Overview

This dissertation uses existing data from a longitudinal, observational, mixedmethods cohort study of patients offered LCS in three institutions: VAPORHCS, Portland, OR; Minneapolis VA Medical Center, Minneapolis, MN; and Duke University Medical Center, Durham, NC. We strategically chose these sites to include patients with demographic diversity across economic, racial, and urban/rural domains. We also included clinicians who discussed LCS with patients to obtain the clinician perspective. The study Principal Investigator is Christopher Slatore, MD, MS at VAPORHCS, the coordinating site.

LCS may uniquely influence patient-centered outcomes given the distress about lung cancer since it has a high mortality compared to other cancers. Patient-centered outcomes from screening trials have been described (Harris et al. 2014; Humphrey et al. 2013) but many questions regarding the occurrence and magnitude of the expected risks and benefits, such as continued smoking, in routine care settings remain.

\section{Lung Cancer Screening as a Process}

LCS is usually initiated by clinicians asking eligible patients if they are interested. Since LCS is still in the beginning stages, and since it was not widely publicized at the time of this study, patients were unlikely to ask for LCS themselves. Upon confirmation of patient interest, the patient and clinician are required to undergo the decision-making discussion, which ends in the patient deciding either to accept, decline, or postpone the LDCT. The LDCT in both VA sites was generally performed within one to two weeks of the decision-making discussion, however patients were able to schedule the scan for 
whenever was convenient for them., The VAPORHCS began walk-in appointments for the LDCT toward the end of enrollment so patients could come in any time MondaySaturday to obtain their scan, which made LDCT timing more variable. At Duke University, the LDCT was usually performed approximately one month after the decision-making discussion, however this was variable depending on patient and hospital imaging department scheduling.

\section{Study Eligibility}

We prospectively recruited subjects from March 2016-April 2019; follow-up visits concluded in May 2020. We recruited outpatients eligible for LCS based on age, smoking history, and comorbid diseases. Clinical criteria based on the NLST included: men and women who are current or former smokers (within 15 years) aged 55 to 77 with $\geq 30$ pack-years of smoking (NLST Research Team et al. 2011). Additional clinical criteria included patients who were asymptomatic in terms of lung cancer symptoms, not undergoing active treatment for cancer, had no history of lung cancer, and were physically able to tolerate surgical resection for lung cancer. In addition to these clinical criteria, patients must have been offered LCS by a provider. Patients could accept or decline the LDCT. Our research criteria excluded those with severe dementia, severe, uncontrolled schizophrenia or other mental illness, and severe hearing impairment. No exclusions were made based on race/ethnicity, but we limited enrollees to English speakers, either as a primary or secondary language. The research team did not verify clinical eligibility. We utilized IRB-approved research methods at each site (VAPORHCS \#3482; Minneapolis VA \#4645-B; Duke \#Pro00073394). Of note, patients 
without personal phones were still eligible and we coordinated study visits with times they were seen in clinic. The complete protocol has been published previously (Miranda et al. 2017) (Appendix C).

\section{Research Question 1 Overview}

RQ1 is a quantitative study designed to describe and compare patients offered LCS who formerly smoked and those who currently smoked at the time of the baseline survey. We used convenience sampling to obtain our cohort. I identified these patients by examining the answer to the question, "How would you describe your cigarette smoking?" This question can be found in Appendix D Section 11 \#1.

\section{Timing and Setting}

RQ1 utilized quantitative surveys conducted before the LDCT but after the decision-making discussion with the clinician for patients who accepted the LDCT. For those who declined the LDCT, we conducted surveys after the decision-making discussion. Trained research assistants (RAs) conducted the quantitative surveys with patients primarily over the phone, or in person. The RA at each institution conducted their own patients' surveys.

Study termination occurred for the following reasons: 1) patient declined further participation, 2) lung cancer was diagnosed, or 3) follow-up was completed. If patients were lost to follow-up, attempted contacts were made via telephone, letter, and contact of the patient's primary care provider. If the patient was diagnosed with lung cancer, she/he was asked to complete a follow-up survey after diagnosis which focused on concerns about the lung cancer evaluation process. At the end of the study, 497 patients were 
consented total; 414 enrolled for RQ1 and RQ2, and 51 patients and 24 clinicians for RQ3. Five of the 414 enrolled were diagnosed with lung cancer.

\section{Data}

At the initial study visit, we collected data on the primary outcome, smoking behaviors, as well as secondary outcomes not utilized in this dissertation. We also collected demographic, health history, and other electronic health record data. The RA at each site collected all survey and electronic health record data on paper forms. These forms were then shipped to the lead study RA from Portland, the coordinating site, who compiled all the surveys and inputted that, along with the survey data from Portland patients, into a VA REDCap database. REDCap is "a secure web application for building and managing online surveys and databases," that we were able to modify to fit the study needs (Harris et al. 2009).

\section{Descriptive Variables}

For RQ1, the primary descriptive variables were educational attainment, employment status, income, race/ethnicity, marital status, age, gender, and study site location. All variables were from the baseline survey. The exact questions asked for the descriptive variables can be found in Appendix D Section 1 Questions \#1-6 and 8. I grouped demographic variables accordingly based on frequency during the initial data analysis phase.

Smoking status is defined by a self-report answer to the question, "How would you describe your cigarette smoking?" Response options include: Never smoked (less than 100 cigarettes in your lifetime); Past smoker (quit over 7 days ago); and Current 
smoker (any smoking, even a puff, within the past 7 days) (Appendix D Section 11 \#1). This defines the 7-day point prevalence abstinence, a commonly used and well-validated measure of successful tobacco cessation (Velicer and Prochaska 2004). We did not measure biochemical evidence of smoking. This variable was dichotomized into former vs current smoking. Each descriptive variable was used to describe and compare those who formerly smoked and those who currently smoked.

\section{Table 1. Research Question 1 Variables}

\begin{tabular}{|l|l|}
\hline Descriptive Variables & Dependent Variable \\
\hline Income & Smoking status (dichotomized) \\
\hline Educational attainment & \\
\hline Employment status & \\
\hline Race/ethnicity & \\
\hline Marital status & \\
\hline Age & \\
\hline Gender & \\
\hline Study site location & \\
\hline
\end{tabular}

RQ1 Analysis

After describing the cohort, I performed a bivariate analysis to explore the relationship between the variables (Sayad 2018) in the two smoking groups.

\section{$\underline{\text { Research Question } 2 \text { Overview }}$}

$\mathrm{RQ} 2$ is a longitudinal quantitative study of patients designed to examine if communication influences smoking status. We used convenience sampling to obtain the 
cohort, as was used in RQ1. For this research question I only included patients who currently smoked at baseline. I identified these patients by examining the answer to the question, "How would you describe your cigarette smoking?" This question can be found in Appendix D Section $11 \# 1$.

Data

I measured presence of communication based on the answer to one question from a survey instrument based on work by Borrelli (Borrelli et al. 2001; Borrelli, Lee, and Novak 2008). The question asks, "Did the person who talked with you most about screening discuss quitting smoking with you?" The response options include: No, Yes, and Could Not Recall (Appendix D Section 12 \#1). Two previous studies by Borrelli used this instrument to determine that attitudes and beliefs about smoking are significantly associated with counseling behaviors for nurses providing information about smoking cessation (Borrelli et al. 2001), and to compare communication quality of nurses providing cessation (Borrelli, Lee, and Novak 2008). The entire instrument is 16 questions, however there is not a summary index available, only individual questions are used.

For RQ2, smoking status at one-year follow-up is the dependent variable, defined identically as in Aim 1. Table 2 below lists the covariates. Study site location is either VAPORHCS, VA Minneapolis, or Duke University. Nicotine dependence was measured using one question from the Fagerström Test for Cigarette/Nicotine Dependence (Heatherton 1991): "How soon after you wake up do you smoke your first cigarette?" This question was found to be most predictive of nicotine dependence (Heatherton 1991). 


\section{Table 2. Research Question 2 Variables}

\begin{tabular}{|l|l|l|}
\hline Independent & Dependent Variable & Covariates \\
\hline Variable & $\begin{array}{l}\text { Smoking status at 1-year follow-up } \\
\text { (dichotomized) }\end{array}$ & $\begin{array}{l}\text { Study Site } \\
\text { Location }\end{array}$ \\
\hline $\begin{array}{l}\text { Presence of } \\
\text { Communication }\end{array}$ & $\begin{array}{l}\text { Nicotine } \\
\text { Dependence }\end{array}$ \\
\hline
\end{tabular}

Analysis

For RQ2, I first summarized the descriptive data for demographic variables and the scores on self-report measures for all participants. Next, I performed bivariate statistics to determine differences between the two groups. I then utilized a logistic regression analysis to determine the association of presence of patient-clinician communication with smoking status at one-year follow-up. I selected logistic regression because the dependent variable is binary. The primary models were constructed parsimoniously, excluding variables that were not confounders if the marginal effect was not more than $10 \%$. I also performed a sensitivity analysis separating the Could Not Recall and No discussion responses into two variables. I used STATA v.16 for analysis, employing $\mathrm{p}<0.05$ criterion for statistical significance.

\section{$\underline{\text { Research Question } 3 \text { Overview }}$}

RQ3 is a qualitative study that explores how patients and clinicians communicate about smoking within the LCS decision-making discussion. This study provides nuance 
and explanation for the findings in Research Questions 1 and 2, as well as provides evidence about the use of the 5A's and their use in LCS programs.

\section{Sampling}

For RQ3, we used purposive sampling to strive for maximum variation in patient characteristics and response to the evaluative process. We aimed to select approximately 16 patients from each site until we reached 48: 36 patients who opted for screening and 12 who did not. We conservatively anticipated the rate of positive results after the initial CT would be $25 \%$ so we expected 5 patients in this group. Given our hypothesis that this group may be at particular risk of distress, we also over-sampled 12 extra patients known to have positive results. These 12 patients were recruited in year 2 , after the initial subjects were enrolled. For RQ3, we consented 65 patients total and enrolled 51.

Twenty-four clinicians were consented and enrolled for qualitative interviews only. We recruited clinicians based on identification by the local site PIs as being involved in the LCS process. We initially recruited clinicians via an email invitation letter.

\section{Timing and Setting}

The qualitative patient interviews utilized herein were conducted before the LDCT but after the decision-making discussion for those who accepted the LDCT. For those who declined the LDCT, the interviews were conducted within 4 weeks of the decision-making discussion. I conducted the qualitative interviews (occasionally with the PI) over the phone, or in person if possible. If the patient was seen in person, the interview was conducted in a private room at the subject's preferred institution. There 
was one interview for clinicians that was not time dependent. We conducted clinician interviews over the phone, and all were conducted by me in a private office space.

Data

Each patient baseline interview lasted approximately 45 minutes. Provider interviews lasted 45-60 minutes. We utilized semi-structured, in-depth qualitative interviews using an interview guide that allowed for other themes and questions to emerge. We digitally recorded and transcribed interviews, taking care to remove any identifiers during transcription. Further, we coded transcripts to protect anonymity. Patients described their experiences with LCS, focusing on communication processes, as well as discussed thoughts about smoking in relation to screening and barriers to smoking cessation. Clinician interviews focused on communication regarding smoking, the perceived importance of discussing smoking and screening together, and perceived patient challenges to cessation (Appendix E). I aimed to identify facilitators and barriers to smoking cessation (including use of communication and patient factors, like the 5A's and self-efficacy).

Analysis

We used a conventional content analysis approach to determine nuances about communication regarding smoking during LCS decision-making discussions. I first read each completed transcript closely to become familiar with the content. Next, I reviewed two transcripts to develop a preliminary codebook, although some preliminary codes were identified previously as key concepts based on the interview guide. A second reviewer reviewed the same two transcripts and reviewed the coding and codebook with 
me. I then independently coded an additional three transcripts and discussed with the second reviewer. As a group with the PI, we met to discuss and refine the codebook, review, and re-code transcripts as needed until all were coded. If other themes arose from the data, I added them to the coding scheme and re-coded any transcripts coded previously. Lastly, I reviewed the data again to identify further codes, create new memos, and reconcile discrepancies. Throughout this process I evaluated any overlapping coding or uncoded text to verify appropriateness.

I first created main, or 'parent,' codes; some parent codes included several, more specific, 'child' codes. We developed initial and integrative memos throughout in order to capture thoughts or analytic ideas, which aided in the final interpretation of the data through identifying patterns and variations in the transcripts. We used Atlas.ti v.7.1.7 for organizing and coding transcripts.

$\underline{\text { Hypotheses and Future Studies }}$

For RQ1, I expected to find that individuals of lower income, less education, unemployment, of minority racial/ethnic status, not married, female gender, and those at the VAPORHCS or Minneapolis VA would be less likely to report successful smoking cessation compared to those who had higher income, more education, employment, were non-minorities, were married, were male, and were at Duke University (Gorini et al. 2018; Jha et al. 2006; Royal College of Physicians 2016). For RQ2, I expected that individuals reporting presence of communication about smoking with their clinician would be more likely to report successful smoking cessation at the end of the study 
period. For RQ3, I expected to find out more details about how patients and clinicians communicate about smoking.

Future studies can be guided by these data. For instance, health promotion literature indicates that targeting specific subgroups of people with health-related messages may work better than large-scale canvassing (Latimer, Salovey, and Rothman 2007). Therefore, talking to specific groups of patients who smoke may influence them more than other types of cessation advertising or recommendations. The knowledge of the addition of the LCS decision-making discussion being a potential motivator to influence patients to improve their smoking behaviors would be clinically important. By targeting those offered LCS and using cessation-related messages that are tailored to their specific subgroup, we may be able to help certain populations successfully quit smoking in future studies designed to develop interventions. 


\section{References}

2008 PHS Guideline Update Panel, Liaisons, and Staff. 2008. "Treating Tobacco use and Dependence: 2008 Update U.S. Public Health Service Clinical Practice Guideline Executive Summary." Respiratory Care 53(9):1217-1222.

Adler, N. E. and K. Newman. 2002. "Socioeconomic Disparities in Health: Pathways and Policies." Health Affairs (Project Hope) 21(2):60-76.

Agency for Healthcare Research and Quality. December 2012. "Five major steps to intervention (The "5 A's").", Retrieved June 14, 2018. (https://www.ahrq.gov/professionals/clinicians-providers/guidelinesrecommendations/tobacco/5steps.html).

American Cancer Society. 2020. "Key Statistics for Lung Cancer." Atlanta, GA: American Cancer Society, Retrieved 09/18, 2020. (https://www.cancer.org/cancer/lung-cancer/about/keystatistics.html\#: :text=The\%20American\%20Cancer\%20Society's\%20estimates,men \%20and\%2063\%2C220\%20in\%20women)).

Andersen, Ronald M. 1995. "Revisiting the Behavioral Model and Access to Medical Care: Does it Matter?" Journal of Health and Social Behavior 36(March):1-10. 
Atkins, Graham T., Taeha Kim and Jeffrey Munson. 2017. "Residence in Rural Areas of the United States and Lung Cancer Mortality: Disease Incidence, Treatment Disparities and Stage Specific Survival." Annals of the American Thoracic Society.

Bach, Peter B., Joshua N. Mirkin, Thomas K. Oliver, Christopher G. Azzoli, Donald A. Berry, Otis W. Brawley, Tim Byers, Graham A. Colditz, Michael K. Gould, James R. Jett, Anita L. Sabichi, Rebecca Smith-Bindman, Douglas E. Wood, Amir Qaseem and Frank C. Detterbeck. 2012. "Benefits and Harms of CT Screening for Lung Cancer: A Systematic Review." Jama 307(22):2418-2429.

Bailey, Steffani R., Victor J. Stevens, Stephen P. Fortmann, Stephen E. Kurtz, Mary A. McBurnie, Elisa Priest, Jon Puro, Leif I. Solberg, Rebecca Schweitzer, Andrew L. Masica and Brian Hazlehurst. 2018. "Long-Term Outcomes from Repeated Smoking Cessation Assistance in Routine Primary Care." Am J Health Promot:0890117118761886.

Bandura, Albert. 1997. Self-Efficacy: The Exercise of Control.USA: W.H. Freeman and Co.

Banik, Anna, Aleksandra Luszczynska, Izabela Pawlowska, Roman Cieslak, Nina Knoll and Urte Scholz. 2016. "Enabling, Not Cultivating: Received Social Support and Self-Efficacy Explain Quality of Life After Lung Cancer Surgery." Annals of Behavioral Medicine. 
Bao, Y., N. Duan and S. A. Fox. 2006. "Is some Provider Advice on Smoking Cessation Better than no Advice? an Instrumental Variable Analysis of the 2001 National Health Interview Survey." Health Services Research 41(6):2114-2135.

Bartley, Mel, David Blane and George D. Smith. 1998. "Introduction: Beyond the Black Report." Sociology of Health and Illness 20:563-577.

Borrelli, B., J. P. Hecht, G. D. Papandonatos, K. M. Emmons, L. R. Tatewosian and D. B. Abrams. 2001. "Smoking-Cessation Counseling in the Home. Attitudes, Beliefs, and Behaviors of Home Healthcare Nurses." American Journal of Preventive Medicine 21(4):272-277.

Borrelli, B., C. Lee and S. Novak. 2008. "Is Provider Training Effective? Changes in Attitudes Towards Smoking Cessation Counseling and Counseling Behaviors of Home Health Care Nurses." Preventive Medicine 46(4):358-363.

Bottorff, J. L., R. Haines-Saah, M. T. Kelly, J. L. Oliffe, I. Torchalla, N. Poole, L. Greaves, C. A. Robinson, M. H. Ensom, C. T. Okoli and J. C. Phillips. 2014. "Gender, Smoking and Tobacco Reduction and Cessation: A Scoping Review." International Journal for Equity in Health 13:114-014-0114-2.

Braveman, P. A., C. Cubbin, S. Egerter, D. R. Williams and E. Pamuk. 2010. "Socioeconomic Disparities in Health in the United States: What the Patterns Tell Us." American Journal of Public Health 100 Suppl 1:S186-96. 
Bray, Robert M., Laurel L. Hourani, Kristine L. R. Olmsted, Michael Witt, Janice M. Brown, Michael R. Pemberton, Mary E. Marsden, Bernadette Marriott, Scott Scheffler, Russ Vandermaas-Peeler, BeLinda Weimer, Sara Calvin, Michael Bradshaw, Kelly Close and Douglas Hayden. 2006. 2005 Department of defense survey of health related behaviors among active duty military personnel: A component of the Defense Lifestyle Assessment Program (DLAP). Research Triangle Park, NC: RTI International.

Broms, Ulla, Karri Silventoinen, Eero Lahelma, Markku Koskenvuo and Jaakko Kaprio. 2004. "Smoking Cessation by Socioeconomic Status and Marital Status: The Contribution of Smoking Behavior and Family Background." Nicotine \& Tobacco Research 6(3):447-455.

Campling, Barbara G., Wei-Ting Hwang, Jiameng Zhang, Stephanie Thompson, Leslie A. Litzky, Anil Vachani, Ilene M. Rosen and Kenneth M. Algazy. 2005. "A Population-Based Study of Lung Carcinoma in Pennsylvania: Comparison of Veterans Administration and Civilian Populations." Cancer 104(4):833-840.

Carpenter, Kristen M., Jeffrey M. Fowler, G. L. Maxwell and Barbara L. Andersen. 2010. "Direct and Buffering Effects of Social Support among Gynecologic Cancer Survivors." Annals of Behavioral Medicine : A Publication of the Society of Behavioral Medicine 39(1):79-90. 
Centers for Disease Control and Prevention. a. "Smoking \& Tobacco Use.", Retrieved 03/08, 2018.

(https://www.cdc.gov/tobacco/data_statistics/fact_sheets/fast_facts/index.htm).

b. "What Are the Risk Factors for Lung Cancer?", Retrieved 03/08, 2018.

(https://www.cdc.gov/cancer/lung/basic_info/risk_factors.htm).

c. "Tobacco-Related Disparities.", Retrieved 01/06, 2017.

(https://www.cdc.gov/tobacco/disparities/).

2020. "Smoking and Tobacco Use. Tobacco-Related Disparities.", Retrieved

March 15, 2020. (https://www.cdc.gov/tobacco/disparities/index.htm).

Cesar Neto, J. B., E. F. Rosa, C. M. Pannuti and G. A. Romito. 2012. "Smoking and Periodontal Tissues: A Review." Brazilian Oral Research 26 Suppl 1:25-31.

Coambs, Robert B., Selina Li and Lynn T. Kozlowski. 1992. "Age Interacts with Heaviness of Smoking in Predicting Success in Cessation of Smoking." American Journal of Epidemiology 135(3):240-246.

de Walque, Damien. 2007. "Does Education Affect Smoking Behaviors?: Evidence using the Vietnam Draft as an Instrument for College Education." Journal of Health Economics 26(5):877-895. doi: https://doi.org/10.1016/j.jhealeco.2006.12.005. 
Department of Defense. 2013.

2011 Health Related Behaviors Survey of Active Duty Military Personnel .

Department of Veterans Affairs, Veterans Health Administration. 2015. 2015 Survey of Veteran Enrollees' Health and Use of Health Care.Veterans Health Administration.

DiClemente, Carlo C., James O. Prochaska and Michael Gibertini. 1985. "Self-Efficacy and the Stages of Self-Change of Smoking." Cognitive Therapy and Research 9(2):181-200.

Docherty, G. and A. McNeill. 2012. "The Hardening Hypothesis: Does it Matter?" Tobacco Control 21(2):267-268.

Drope, J., A. C. Liber, Z. Cahn, M. Stoklosa, R. Kennedy, C. E. Douglas, R. Henson and J. Drope. 2018. "Who's Still Smoking? Disparities in Adult Cigarette Smoking Prevalence in the United States." CA: A Cancer Journal for Clinicians 68(2):106115.

Dunga, J. A., Y. Adamu, I. M. Kida, D. Alasiya, Y. Jibrin, U. Sabo, C. Ukoli, C. H. Chuhwak and J. J. Musa. 2015. "Tobacco Abuse and its Health Effect." Nigerian Journal of Medicine : Journal of the National Association of Resident Doctors of Nigeria 24(4):354-362. 
Elo, Irma T. 2009. "Social Class Differentials in Health and Mortality: Patterns and Explanations in Comparative Perspective." Annual Review of Sociology 35(1):553572.

Feirman, S. P., A. M. Glasser, L. Teplitskaya, D. R. Holtgrave, D. B. Abrams, R. S. Niaura and A. C. Villanti. 2016. "Medical Costs and Quality-Adjusted Life Years Associated with Smoking: A Systematic Review." BMC Public Health 16:646-0163319-z.

Frohlich, K. L., L. Potvin, P. Chabot and E. Corin. 2002. "A Theoretical and Empirical Analysis of Context: Neighbourhoods, Smoking and Youth." Social Science \& Medicine (1982) 54(9):1401-1417.

GBD 2015 Tobacco Collaborators. 2017. "Smoking Prevalence and Attributable Disease Burden in 195 Countries and Territories, 1990-2015: A Systematic Analysis from the Global Burden of Disease Study 2015." Lancet (London, England) 389(10082):1885-1906.

Golden, S. E., S. S. Ono, A. Melzer, J. Davis, S. B. Zeliadt, J. L. Heffner, H. Kathuria, G. Garcia-Alexander and C. G. Slatore. 2020. "'I Already Know that Smoking Ain'T Good for Me": Patient and Clinician Perspectives on Lung Cancer Screening Decision-Making Discussions as a Teachable Moment." Chest 158(3):1250-1259. 
Golden, Sara E., Sujata Thakurta, Hyeyoung Woo, Christopher G. Slatore and Donald R. Sullivan. 2018. "Military Factors Associated with Smoking in Veterans." Mil Med 183(11-12):e402-e408.

Gorini, Giuseppe, Giulia Carreras, Barbara Cortini, Simona Verdi, Maria G. Petronio, Piersante Sestini and Elisabetta Chellini. 2018. "Socioeconomic Disparities in Quitting Smoking and in Steps on the Smoking Cessation Pathway among Smokers in Italy: Findings from the SIDRIAT Cohort Study." Addiction Research \& Theory 26(1):63-70.

Gwaltney, C. J., J. Metrik, C. W. Kahler and S. Shiffman. 2009. "Self-Efficacy and Smoking Cessation: A Meta-Analysis." Psychology of Addictive Behaviors : Journal of the Society of Psychologists in Addictive Behaviors 23(1):56-66.

Harris, Paul A., Robert Taylor, Robert Thielke, Jonathon Payne, Nathaniel Gonzalez and Jose G. Conde. 2009. "Research Electronic Data Capture (REDCap) - A MetadataDriven Methodology and Workflow Process for Providing Translational Research Informatics Support." Journal of Biomedical Informatics 42(2):377-381.

Harris, R. E., J. R. Hebert and E. L. Wynder. 1989. "Cancer Risk in Male Veterans Utilizing the Veterans Administration Medical System." Cancer 64(5):1160-1168.

Harris, R. P., S. L. Sheridan, C. L. Lewis, C. Barclay, M. B. Vu, C. E. Kistler, C. E. Golin, J. T. DeFrank and N. T. Brewer. 2014. "The Harms of Screening: A Proposed 
Taxonomy and Application to Lung Cancer Screening." JAMA Internal Medicine 174(3):484.

Heaney, Catherine A. and Barbara A. Israel. 2008. "Social Support." Pp. 189-192 in Health Behavior and Health Education., edited by K. Glanz, B.K. Rimer and K. Viswanath. San Francisco, CA: Jossey-Bass.

Heatherton, T. F., L. T. Kozlowski, R. C. Frecker and K. O. Fagerström. 1991. "The Fagerström Test for Nicotine Dependence: A Revision of the Fagerström Tolerance Questionnaire." British Journal of Addiction 86(9):1119-1127.

Higgins, S. T., A. N. Kurti, R. Redner, T. J. White, D. R. Keith, D. E. Gaalema, B. L. Sprague, C. A. Stanton, M. E. Roberts, N. J. Doogan and J. S. Priest. 2016. "CoOccurring Risk Factors for Current Cigarette Smoking in a U.S. Nationally Representative Sample." Preventive Medicine 92:110-117.

Hoffman, Catherine and Julia Paradise. 2008. "Health Insurance and Access to Health Care in the United States." Annals of the New York Academy of Sciences 1136:149160.

House, J. S. 2002. "Understanding Social Factors and Inequalities in Health: 20th Century Progress and 21st Century Prospects." Journal of Health and Social Behavior 43(2):125-142. 
Humphrey, Linda L., Mark Deffebach, Miranda Pappas, Christina Baumann, Kathryn Artis, Jennifer P. Mitchell, Bernadette Zakher, Rongwei Fu and Christopher G. Slatore. 2013. "Screening for Lung Cancer with Low-Dose Computed Tomography: A Systematic Review to Update the US Preventive Services Task Force Recommendation." Annals of Internal Medicine 159(6):411-420.

Ikeda, Ai, Ichiro Kawachi, Hiroyasu Iso, Motoki Iwasaki, Manami Inoue and Shoichiro Tsugane. 2013. "Social Support and Cancer Incidence and Mortality: The JPHC Study Cohort II." Cancer Causes \& Control : CCC 24(5):847-860.

IOM (Institute of Medicine). 2013. "Delivering High-Quality Cancer Care: Charting a New Course for a System in Crisis.".

Jaklitsch, Michael T., Francine L. Jacobson, John H. M. Austin, John K. Field, James R. Jett, Shaf Keshavjee, Heber MacMahon, James L. Mulshine, Reginald F. Munden, Ravi Salgia, Gary M. Strauss, Scott J. Swanson, William D. Travis and David J. Sugarbaker. 2012. "The American Association for Thoracic Surgery Guidelines for Lung Cancer Screening using Low-Dose Computed Tomography Scans for Lung Cancer Survivors and Other High-Risk Groups." The Journal of Thoracic and Cardiovascular Surgery 144(1):33-38.

Jensen, Tamara S., Joseph Chin, Lori Ashby, Jamie Hermansen and Joseph D. Hutter. 2015. Decision Memo for Screening for Lung Cancer with Low Dose Computed Tomography (LDCT). 
Jha, P., R. Peto, W. Zatonski, J. Boreham, M. J. Jarvis and A. D. Lopez. 2006. "Social Inequalities in Male Mortality, and in Male Mortality from Smoking: Indirect Estimation from National Death Rates in England and Wales, Poland, and North America." Lancet (London, England) 368(9533):367-370.

Jürges, Hendrik, Steffen Reinhold and Martin Salm. 2011. "Does Schooling Affect Health Behavior? Evidence from the Educational Expansion in Western Germany." Economics of Education Review 30(5):862-872. doi: https://doi.org/10.1016/j.econedurev.2011.04.002.

Kabat, G. C., A. Morabia and E. L. Wynder. 1991. "Comparison of Smoking Habits of Blacks and Whites in a Case-Control Study." Am J Public Health 81(11):1483-1486.

Kandel, D. B., G. E. Kiros, C. Schaffran and M. C. Hu. 2004. "Racial/Ethnic Differences in Cigarette Smoking Initiation and Progression to Daily Smoking: A Multilevel Analysis." American Journal of Public Health 94(1):128-135.

Kawachi, I., B. P. Kennedy, K. Lochner and D. Prothrow-Stith. 1997. "Social Capital, Income Inequality, and Mortality." American Journal of Public Health 87(9):14911498.

Kroenke, Candyce H., Charles Quesenberry, Marilyn L. Kwan, Carol Sweeney, Adrienne Castillo and Bette J. Caan. 2013. "Social Networks, Social Support, and Burden in Relationships, and Mortality After Breast Cancer Diagnosis in the Life After Breast 
Cancer Epidemiology (LACE) Study." Breast Cancer Research and Treatment 137(1):261-271.

Lancaster, T. and L. Stead. 2004. "Physician Advice for Smoking Cessation." The Cochrane Database of Systematic Reviews (4):CD000165. doi(4):CD000165.

Latimer, A. E., P. Salovey and A. J. Rothman. 2007. "ThThe Effectiveness of GainFramed Messages for Encouraging Disease Prevention Behavior: Is all Hope Lost?" Journal of Health Communication 12(7):645.

Lindson-Hawley, N., T. P. Thompson and R. Begh. 2015. "Motivational Interviewing for Smoking Cessation." The Cochrane Database of Systematic Reviews (3):CD006936. doi(3):CD006936.

Link, Bruce G. and Jo C. Phelan. 1995. "Social Conditions as Fundamental Causes of Disease." Journal of Health and Social Behavior extra:80.

Lorenz, Frederick O., K. A. S. Wickrama, Rand D. Conger and Glen H. Elder Jr. 2006. "The Short-Term and Decade-Long Effects of Divorce on Women's Midlife Health." Journal of Health and Social Behavior 47(2):111-125.

Lund, M., K. E. Lund and E. Kvaavik. 2011. "Hardcore Smokers in Norway 1996-2009." Nicotine \& Tobacco Research : Official Journal of the Society for Research on Nicotine and Tobacco 13(11):1132-1139. 
Luszczynska, Aleksandra, Izabela Pawlowska, Roman Cieslak, Nina Knoll and Urte Scholz. 2013. "Social Support and Quality of Life among Lung Cancer Patients: A Systematic Review: Social Support and Quality of Life in Lung Cancer Patients: A Review." Psycho-Oncology:n/a-n/a.

Mariolis, P., VJ Rock, K. Asman, R. Merritt, A. Malarcher, C. Husten and T. Pechacek. 2006. Tobacco Use Among Adults --- United States, 2005.Office on Smoking and Health, National Center for Chronic Disease Prevention and Health Promotion, CDC.

Marmot, Michael and Richard G. Wilkinson. 2006. Social Determinants of Health.Oxford, UK: Oxford University Press.

Marmot, M. G., G. D. Smith, S. Stansfeld, C. Patel, F. North, J. Head, I. White, E. Brunner and A. Feeney. 1991. "Health Inequalities among British Civil Servants: The Whitehall II Study." Lancet (London, England) 337(8754):1387-1393.

Mazzoni, D. and E. Cicognani. 2011. "Social Support and Health in Patients with Systemic Lupus Erythematosus: A Literature Review." Lupus 20(11):1117-1125.

McClure, E. A., N. L. Baker, K. M. Gray, C. O. Hood, R. L. Tomko, M. J. Carpenter, V. R. Ramakrishnan, C. J. Buchanan and M. E. Saladin. 2020. "The Influence of Gender and Oxytocin on Stress Reactivity, Cigarette Craving, and Smoking in a 
Randomized, Placebo-Controlled Laboratory Relapse Paradigm."

Psychopharmacology 237(2):543-555.

McKinney, W. P., D. D. McIntire, T. J. Carmody and A. Joseph. 1997. "Comparing the Smoking Behavior of Veterans and Nonveterans." Public Health Reports (Washington, D.C.: 1974) 112(3):212-7; discussion 218.

Mead, Nicola and Peter Bower. 2000. "Patient-Centredness: A Conceptual Framework and Review of the Empirical Literature." Social Science \& Medicine 51(7):10871110.

Miranda, L. S., S. Datta, A. C. Melzer, R. S. Wiener, J. M. Davis, B. C. Tong, S. E. Golden and C. G. Slatore. 2017. "Rationale and Design of the Lung Cancer Screening Implementation. Evaluation of Patient-Centered Care Study." Annals of the American Thoracic Society 14(10):1581-1590.

Mirowsky, J. and C. E. Ross. 2015. "Education, Health, and the Default American Lifestyle." Journal of Health and Social Behavior 56(3):297-306.

Mirowsky, John and Catherine E. Ross. 2003. Education, Social Status, and Health.New Brunswick, NJ: Aldine Transaction. 
Morgan, R. O., C. R. Teal, S. G. Reddy, M. E. Ford and C. M. Ashton. 2005.

"Measurement in Veterans Affairs Health Services Research: Veterans as a Special Population." Health Services Research 40(5 Pt 2):1573-1583.

Moyer, Virginia A. 2014. "Screening for Lung Cancer: U.S. Preventive Services Task Force Recommendation Statement." Annals of Internal Medicine 160(5):330-338.

National Institute on Drug Abuse. 2020. Are there gender differences in tobacco smoking?NIDA.

National Lung Screening Trial Research Team, D. R. Aberle, A. M. Adams, C. D. Berg, W. C. Black, J. D. Clapp, R. M. Fagerstrom, I. F. Gareen, C. Gatsonis, P. M. Marcus and J. D. Sicks. 2011. "Reduced Lung-Cancer Mortality with Low-Dose Computed Tomographic Screening." The New England Journal of Medicine 365(5):395-409.

Nausheen, Bina, Yori Gidron, Robert Peveler and Rona Moss-Morris. 2009. "Social Support and Cancer Progression: A Systematic Review." Journal of Psychosomatic Research 67(5):403-415.

Ney, T., A. Gale, RB Coambs, L. T. Kozlowski and R. G. Ferrence. 1989. "The Future of Tobacco Use and Smoking Research." Pp. 337-348 in Smoking and Human Behavior., edited by T. Ney and A. Gale. New York, NY: Wiley \& Sons Ltd. 
Nollen, N. L., M. S. Mayo and Sanderson Cox, L. et al. 2019. "Factors that Explain Differences in Abstinence between Black and White Smokers: A Prospective Intervention Study." Jnci 111(20):1078-1087.

Osler, Merete, Matt McGue, Rikke Lund and Kaare Christensen. 2008. "Marital Status and Twinsâ€ TM Health and Behavior: An Analysis of Middle-Aged Danish Twins:" Psychosomatic Medicine 70(4):482-487.

Peto, Richard, Sarah Darby, Harz Deo, Paul Silcocks, Elise Whitley and Richard Doll. 2000. "Smoking, Smoking Cessation, and Lung Cancer in the UK since 1950: Combination of National Statistics with Two Case-Control Studies." Bmj 321(7257):323-329.

Phelan, Jo C., Bruce G. Link, Ana Diez-Roux, Ichiro Kawachi and Bruce Levin. 2004. ""Fundamental Causes" of Social Inequalities in Mortality: A Test of the Theory." Journal of Health and Social Behavior 45:265-285.

Phelan, J. C., B. G. Link and P. Tehranifar. 2010. "Social Conditions as Fundamental Causes of Health Inequalities: Theory, Evidence, and Policy Implications." Journal of Health and Social Behavior 51 Suppl:S28-40.

Pierce, John P., Millie Naquin, Elizabeth Gilpin, Gary Giovino, Sherry Mills and Steven Marcus. 1991. "Smoking Initiation in the United States: A Role for Worksite and 
College Smoking Bans." JNCI: Journal of the National Cancer Institute 83(14):1009-1013.

Pinquart, Martin and Paul R. Duberstein. 2010. "Associations of Social Networks with Cancer Mortality: A Meta-Analysis." Critical Reviews in Oncology/Hematology 75(2):122-137.

Robert Wood Johnson Foundation. 2014. Education: It Matters More to Health than Ever Before. Richmond, VA: VCU Center on Society and Health.

Roberts, M. E., N. J. Doogan and A. N. e. a. Kurti. 2016. "Rural Tobacco use Across the United States: How Rural and Urban Areas Differ, Broken Down by Census Regions and Divisions." Health Place 39:153-159.

Ross, Catherine E. and John Mirowsky. 1999. "Refining the Association between Education and Health: The Effects of Quantity, Credential, and Selectivity." Demography 36(4):445.

Royal College of Physicians. 2016. Nicotine without Smoke: Tobacco Harm Reduction. London: RCP.

Royeen, Charlotte B. 2002. "Occupation Reconsidered." Occupational Therapy International 9(2):111-120. 
Samet, Jonathan M., Richard Crowell, Jose E. San, Cynthia Rand, Albert A. Rizzo and Rex Yung. 2012. American lung association: Providing guidance on lung cancer screening to patients and physicians.

Sanner, T. and T. K. Grimsrud. 2015. "Nicotine: Carcinogenicity and Effects on Response to Cancer Treatment - A Review." Frontiers in Oncology 5:196.

Sayad, Saed. 2018. "Data Mining Map.", Retrieved June 26, 2018. (http://www.saedsayad.com/bivariate_analysis.htm).

Schnittker, J. 2004. "Education and the Changing Shape of the Income Gradient in Health." Journal of Health and Social Behavior 45(3):286-305.

Shishehbor, M. H., D. Litaker, C. E. Pothier and M. S. Lauer. 2006. "Association of Socioeconomic Status with Functional Capacity, Heart Rate Recovery, and all-Cause Mortality." Jama 295(7):784-792.

Siegel, Rebecca L., Kimberly D. Miller and Ahmedin Jemal. 2016. "Cancer Statistics, 2016." CA: A Cancer Journal for Clinicians 66(1):7-30.

Simpson, Michael, Robert Buckman, Moira Stewart, Peter Maguire, Mack Lipkin, Dennis Novack and James Till. 1991. "Doctor-Patient Communication: The Toronto Consensus Statement." BMJ: British Medical Journal 303(6814):1385. 
Smith, Elizabeth A., Sara A. Jahnke, Walker S. C. Poston, Larry N. Williams, Christopher K. Haddock, Steven A. Schroeder and Ruth E. Malone. 2014. "Is it Time for a Tobacco-Free Military?" New England Journal of Medicine 371(7):589591.

Sprey, Erica. 2020. "VA works to raise awareness for lung cancr screening Veterans." Department of Veterans Affairs, Retrieved 09/16, 2020. (https://www.research.va.gov/currents/0720-VA-works-to-raise-awareness-for-lungcancer-screening-in-Veterans.cfm).

Steinberg, M. B. and C. D. Delnevo. 2013. "Increasing the "smoking Age": The Right Thing to Do." Annals of Internal Medicine 159(8):558-559.

Sterling, T. and J. Weinkam. 1990. "The Confounding of Occupation and Smoking and its Consequences." Social Science \& Medicine 30(4):457-467. doi: https://doi.org/10.1016/0277-9536(90)90348-V.

Street, Richard L., Gregory Makoul, Neeraj K. Arora and Ronald M. Epstein. 2009. "How does Communication Heal? Pathways Linking Clinicianâ€"patient Communication to Health Outcomes." Patient Education and Counseling 74(3):295301. 
Strom, Joni L. and Leonard E. Egede. 2012. "The Impact of Social Support on Outcomes in Adult Patients with Type 2 Diabetes: A Systematic Review." Current Diabetes Reports 12(6):769-781.

Subramanian, S. V. and I. Kawachi. 2004. "Income Inequality and Health: What have we Learned so Far?" Epidemiologic Reviews 26:78-91.

Syme, S. L. and Irene H. Yen. 2000. "Social Epidemiology and Medical Sociology: Different Approaches to the Same Problem." Pp. 365-376 in Handbook of Medical Sociology., edited by C.E. Bird, P. Conrad and A.M. Fremont. New Jersey: Prentice Hall Publishing.

Tajvar, Maryam, Astrid Fletcher, Emily Grundy and Mohammad Arab. 2013. "Social Support and Health of Older People in Middle Eastern Countries: A Systematic Review." Australasian Journal on Ageing 32(2):71-78.

Taylor, F. R. 2015. "Tobacco, Nicotine, and Headache." Headache 55(7):1028-1044.

The Clinical Practice Guideline Treating Tobacco Use and Dependence 2008 Update Panel, Liaisons, and Staff. 2008. "A Clinical Practice Guideline for Treating Tobacco use and Dependence: 2008 Update: A U.S. Public Health Service Report." American Journal of Preventive Medicine 35(2):158-176. 
Thoits, Peggy A. 2010. "Stress and Health: Major Findings and Policy Implications." J Health Soc Behav 51(1):S41-S53.

U.S. Department of Health and Human Services. 1964. The 1964 Report on Smoking and Health. Bethesda, MD: U.S. National Library of Medicine.

U.S. Department of Health and Human Services. 1998. Tobacco Use Among U.S. Racial/Ethnic Minority Groups- African Americans, American Indians and Alaska Natives, Asian Americans and Pacific Islanders, Hispanics: A Report of the Surgeon General. Atlanta, GA: U.S. Department of Health and Human Services, Centers for Disease Control and Prevention, National Center for Chronic Disease Prevention and Health Promotion, Office on Smoking and Health.

U.S. Department of Health and Human Services. 2014. The Health Concequences of Smoking- 50 Years of Progress: a report of the Surgeon General. Atlanta, GA: .

U.S. Food and Drug Administration. 2020. "Tobacco use in the military: A danger for those who keep us safe." FDA, Retrieved 09/16, 2020. (https://www.fda.gov/tobacco-products/health-information/tobacco-use-militarydanger-those-who-keep-us-safe).

Umberson, Debra, Robert Crosnoe and Corrine Reczek. 2010. "Social Relationships and Health Behavior Across Life Course." Annu Rev Sociol 36:139-157. 
Umberson, D. and J. K. Montez. 2010. "Social Relationships and Health: A Flashpoint for Health Policy." Journal of Health and Social Behavior 51 Suppl:S54-66.

US Preventive Services, Task F. 2004. "Lung Cancer Screening: Recommendation Statement." Annals of Internal Medicine 140(9):738-739.

van der Heide, I., J. Wang, M. Droomers, P. Spreeuwenberg, J. Rademakers and E. Uiters. 2013. "The Relationship between Health, Education, and Health Literacy: Results from the Dutch Adult Literacy and Life Skills Survey." Journal of Health Communication 18 Suppl 1(Suppl 1):172-184.

Vannimenus, C., H. Bricout, O. Le Rouzic, F. Mouawad, D. Chevalier, E. Dansin, L. Rotsaert, G. Lefebvre, O. Cottencin, H. Porte, A. Scherpereel, A. El Fahsi, F. Richard, B. Rolland and ALTAK Study Group. 2018. "Compared Characteristics of Current Vs. Past Smokers at the Time of Diagnosis of a First-Time Lung Or Head and Neck Cancer: A Cross-Sectional Study." BMC Cancer 18(1):372-018-4253-5.

Velicer, W. F. and J. O. Prochaska. 2004. "A Comparison of Four Self-Report Smoking Cessation Outcome Measures." Addictive Behaviors 29(1):51-60.

Warnakulasuriya, S., T. Dietrich, M. M. Bornstein, E. Casals Peidro, P. M. Preshaw, C. Walter, J. L. Wennstrom and J. Bergstrom. 2010. "Oral Health Risks of Tobacco use and Effects of Cessation." International Dental Journal 60(1):7-30. 
Warren, G. W. and K. M. Cummings. 2013. "Tobacco and Lung Cancer: Risks, Trends, and Outcomes in Patients with Cancer." American Society of Clinical Oncology Educational Book.American Society of Clinical Oncology.Meeting:359-364.

Weiland, Anne, de K. Van, Annette H. Blankenstein, Van Saase, Jan L. C. M., der M. Van, Wichor M. Bramer, Alexandra M. Van Dulmen and Lidia R. Arends. 2012. "Encounters between Medical Specialists and Patients with Medically Unexplained Physical Symptoms; Influences of Communication on Patient Outcomes and use of Health Care: A Literature Overview." Perspectives on Medical Education 1(4):192206.

Wender, Richard, Elizabeth T. H. Fontham, Ermilo Barrera, Graham A. Colditz, Timothy R. Church, David S. Ettinger, Ruth Etzioni, Christopher R. Flowers, G. Scott Gazelle, Douglas K. Kelsey, Samuel J. LaMonte, James S. Michaelson, Kevin C. Oeffinger, Ya-Chen T. Shih, Daniel C. Sullivan, William Travis, Louise Walter, Andrew M. D. Wolf, Otis W. Brawley and Robert A. Smith. 2013. "American Cancer Society Lung Cancer Screening Guidelines: American Cancer Society Lung Cancer Screening Guidelines." CA: A Cancer Journal for Clinicians 63(2):106-117.

Williams, David R. 1997. "Race and Health: Basic Questions, Emerging Directions." Annals of Epidemiology 7(5):322-333. doi: https://doi.org/10.1016/S1047$\underline{2797(97) 00051-3 .}$ 
Williams, G. H. 2003. "The Determinants of Health: Structure, Context and Agency." Sociology of Health \& Illness 25(3):131.

Wood, D. E. 2015. "National Comprehensive Cancer Network (NCCN) Clinical Practice Guidelines for Lung Cancer Screening." Thoracic Surgery Clinics 25(2):185-197. 


\section{Chapter 2. Description and Comparison of Former and Current Hardened Smokers Offered Lung Cancer Screening Using Traditionally Well-Correlated Socioeconomic and Sociodemographic Factors}

Sara E. Golden, $\mathrm{MPH}^{1,2}$; Hyeyoung Woo, $\mathrm{PhD}^{2}$; Ginny Garcia-Alexander, $\mathrm{PhD}^{3}$; Jeffrey Robinson, $\mathrm{PhD}^{4}$; Christopher G. Slatore, $\mathrm{MD}, \mathrm{MS}^{1,5,6}$

1. Center to Improve Veteran Involvement in Care, VA Portland Health Care System; Portland, OR

2. Department of Sociology, Portland State University; Portland, OR

3. Department of Sociology, University of Texas- San Antonio; San Antonio, TX

4. Department of Communication, Portland State University; Portland, OR

5. Division of Pulmonary \& Critical Care Medicine, Department of Medicine, Oregon Health \& Science University; Portland, OR

6. Section of Pulmonary \& Critical Care Medicine, VA Portland Health Care System; Portland, OR 


\begin{abstract}
Objective: Lung cancer screening (LCS) using low-dose computed tomography (LDCT) is now covered by private insurers as well as the Centers for Medicare and Medicaid Services. LCS-eligible patients can generally be considered as "hardened" smokers who have no intention to quit or find it extremely difficult to quit. Hardened smokers have not been described. This study aims to describe the characteristics of hardened smokers and to determine which important socioeconomic and sociodemographic factors are associated with former or active smoking in this population.
\end{abstract}

Methods: We surveyed patients eligible for LCS from three medical centers in the US with established LCS programs. We enrolled patients before the LDCT for those who accepted the LDCT, and within three weeks for those who did not accept the LDCT. We summarized the descriptive socioeconomic and sociodemographic data for all participants and conducted bivariate analyses using Pearson chi-squared tests to compare the current and former smokers.

Results: Our analytic sample consisted of 404 participants: 229 (57\%) participants who currently smoked cigarettes and 175 (43\%) participants who reported formerly smoking cigarettes at baseline. The majority of the subjects were male (87\%), had some college or vocational work (46\%), were not employed (76\%), with $25 \%$ making less than $\$ 20,000$ per year. Our sample was largely non-Hispanic white (85\%) and married (47\%). Current and former smokers were similar on several measures. We observed significant differences in income: current smokers reported incomes of less than $\$ 20,000$ per year with much greater frequency $(31 \%)$ compared to former smokers $(16 \%)$. We also 
observed significant race differences as a larger percentage of former smokers were nonHispanic white (89\%) compared to current smokers (81\%). In addition, we found that former smokers were more likely to report male gender (93\% vs $83 \%)$.

Conclusion: Patients offered LCS may be different compared to patients in other settings where socioeconomic and sociodemographic factors seem to play more of a role in smoking behaviors. Smoking cessation programs could tailor their approach to patients offered LCS who may have other individual- or system- level characteristics that influence the association between socioeconomic and sociodemographic factors, smoking status, and smoking cessation. 


\section{Introduction}

The United States Preventive Services Task Force recommends lung cancer screening (LCS) using low-dose computed tomography (LDCT) and has mandated its coverage by private insurers; the Centers for Medicare and Medicaid Services (CMS) has also agreed to pay for LCS (Jensen 2015). Patients offered LCS using LDCT are by definition at high-risk of developing lung cancer and can be considered "hardened" smokers. For our purposes, hardened smokers are identified based on LCS eligibility criteria, i.e. age (55-77 years), smoking history (either currently smoking or a $\geq 30$ packyear history), and comorbidities. Importantly, those who have successfully quit smoking, but were hardened smokers in the recent past, meet eligibility criteria for LCS.

Hardened smokers are those who are "less likely to be influenced by cessation measures" (Ney 1989) and have no intention to quit and/or find it very difficult to quit (Docherty and McNeill 2012). Hardened smokers are more likely to be from disadvantaged socioeconomic backgrounds (Lund et al. 2011), which further increases likelihood of smoking as well as smoking-related illness (Drope et al. 2018; Marmot and Wilkinson 2006; U.S. Department of Health and Human Services 2014). These smokers are difficult to reach but are still important to target for smoking cessation. Notably, characteristics of hardened smokers have not been well-described in prior literature.

Accordingly, this study aims to describe the characteristics of hardened smokers and to determine which socioeconomic and sociodemographic factors are associated with former or active smoking in this population. Indeed, it remains important to identify people for smoking cessation as quitting at any stage, including later in life, has 
significant health benefits (Peto 2000). By describing factors associated with a hardened smokers' ability to quit smoking, we add to the scant knowledge about hardened smokers and more closely define this population.

We focus on hardened smokers offered LCS recruited from Veterans Affairs (VA) and non-VA (Duke University) facilities to answer the following questions: 1) What are the socioeconomic and sociodemographic factors of hardened smokers? 2) Are there differences in traditionally well-correlated socioeconomic and sociodemographic factors between active and former hardened smokers?

Socioeconomic status (SES) is "a key underlying factor" that influences numerous health outcomes (Link and Phelan 1995). Accordingly, a large body of literature has established the importance of SES in predicting smoking initiation, smoking cessation (Nagelhout 2012; Federico et al 2007; Pierce et al 1989), and smoking-related illness (Campaign for Tobacco-Free Kids 2015; Singh 2011; Clegg 2009). For example, individuals of lower SES are more likely to smoke, and among smokers, those with lower SES are less likely to quit. As a result, the prevalence of smoking-related illness is almost three times higher among socially disadvantaged individuals, compared to their counterparts (Drope 2018). Thus, we incorporate factors of SES: income, educational attainment, and employment status. Each factor, separately and combined, is a traditionally well-known correlate to smoking. Formally, those with lower incomes, educational attainment, and who are not employed are more likely to smoke.

Smoking cessation has also been linked to several sociodemographic factors including race/ethnicity, marital status, age, gender, and location. Analyses have shown 
that non-Hispanic white individuals generally smoke at a higher rate than some minority populations, e.g. non-Hispanic blacks, Hispanics, and Asians, but they smoke less than American Indian/Alaska Natives (CDC 2020). However, non-Hispanic whites are more likely to use cessation treatments and successfully quit smoking compared with Hispanics (Babb 2020). Interestingly, non-Hispanic blacks are actually more likely to attempt to quit smoking but are less likely to successfully quit (CDC 2020).

Married individuals are also more likely to successfully quit smoking (CDC 2020; Vannimenus 2018) in many populations, with indicators that this may be a consistent trend across groups. Between the ages of 25 and 64, current smoking rates are about the same, around $16 \%$. Over the age of 64 , however, it drops to $8.4 \%$ (CDC 2020). This finding may relate to an increase in desire to quit as tobacco-related and other health or financial effects produce a heavier burden during aging (Steinberg and Delnevo 2013; Golden et al. 2020). Males have a higher smoking rate than females (15.6\% vs $12.0 \%$, respectively) (CDC 2020) in the general population and generally have a higher smoking intensity (McClure et al. 2020). People from rural areas not only have higher smoking rates (Roberts 2016), but also higher disease incidence per capita and lower survival, despite access to diagnostic services (Atkins 2017). They also have less treatments available for cessation, making it harder for them to quit successfully (Butler 2012). It is important to determine if these previously correlated factors are similarly reflected among hardened smokers.

SES, race, marital status, age, gender, and location, among others, have all been documented as important correlates to health under the umbrella of fundamental causes. 
A fundamental cause is a social factor interconnected with disease, and social and economic resources (Link and Phelan 1995). Further, theory around fundamental causes requires an enduring, persistent relationship between the cause and health even after conditions associated with the cause are eliminated by control. The mechanisms are likely multifactorial. For preventable diseases though, like lung cancer, there are higher SES-mortality gradients compared to non-preventable diseases, and this link is based on mechanisms like increased control, knowledge, demand, lifestyle, or psychosocial resources (Ross and Wu 1995; Phelan et al. 2004; Dahl, Hofoss, and Elstad. 2007; Song and Byeon 2000).

This evidence supports the fundamental cause theory because it shows that there must be qualities inherent in the social concept of SES that signifies some advantage in avoiding preventable disease. There is something about SES and the effect on mortality that is not explained by behavioral, environmental, psychological, or other physiologic mechanisms. If the fundamental cause theory were incorrect and public health epidemiology was on the right track in focusing on proximal mechanisms for health and disease, then preventable and non-preventable diseases would all equate to similar outcomes for people of all SES levels since it would not matter if some had greater resources to prevent disease. This is not the case and has been shown in several diseases such as breast cancer (Krieger et al. 2003) and lung cancer (Glied and Llleras-Muney 2008). It is important to study and document the associations of fundamental causes like those listed here with health in order to add evidence to theory and the knowledgebase about unknown populations, like hardened smokers. 
This study provides a unique opportunity to better understand hardened smokers as it offers an assessment of the socioeconomic and sociodemographic factors of those who were able to quit compared to those who were currently smoking. It is important to determine if traditionally well-correlated socioeconomic and sociodemographic factors remain significant across this potentially different population. Further, this is generally considered a hard to reach population, and they have historically been left out of cessation trials (Zbikowski 2012; Docherty 2012). Thus, little is known about their characteristics, and this analysis contributes to foundational knowledge about hardened smokers.

\section{Methods}

Setting

We surveyed patients eligible for LCS from three medical centers in the US with established LCS programs; VA Portland Health Care System (VAPORHCS), Portland, OR; Minneapolis VA Medical Center, Minneapolis, MN; and Duke University Medical Center, Durham, NC.

Sample

We enrolled 414 patients who were eligible for LCS based on research referrals from clinicians, who verified clinical criteria, including smoking history, age, etc., (Miranda et al. 2017) not further confirmed by the research team. The research-specific criteria were that patients must have been offered LCS by a clinician. Also, we excluded those with severe dementia, severe, uncontrolled schizophrenia or other mental illness, and severe hearing impairment. No exclusions were made based on race/ethnicity, but we 
limited enrollees to English speakers, either as a primary or secondary language. We included patients regardless of whether they agreed or declined to undergo the LDCT. We enrolled patients before the LDCT for those who accepted the LDCT, and within three weeks for those who did not accept the LDCT. The study was IRB-approved at each participating site (VAPORHCS \#3482; Minneapolis VA \#4645-B; Duke \#Pro00073394).

\section{Data and variable definition}

We conducted quantitative surveys to establish baseline characteristics of patients before the LDCT but after the decision-making discussion with the provider. For those who declined screening, we conducted surveys within 4 weeks of the decision-making discussion.

We defined smoking status by a self-report answer to the question, "How would you describe your cigarette smoking?". Response options include: Never smoked (less than 100 cigarettes in your lifetime); Past smoker (quit over 7 days ago); and Current smoker (any smoking, even a puff, within the past 7 days) (Appendix D). This defines the 7-day point prevalence abstinence, a commonly used and well-validated measure of successful tobacco cessation (Velicer and Prochaska 2004). We did not measure biochemical evidence of smoking.

The primary descriptive variables are educational attainment, employment status, and income. We collected these data by asking participants, "What is the highest level or grade of school you have completed?"; "Are you currently employed?"; and "What is the average total yearly income for your household?" We categorized educational attainment 
into high school or less, some college/vocational work, and college graduate or more. These categories were based frequencies. Employment was dichotomized into employed vs not employed, based on previous literature showing the importance of employment. Income was measured by total household income and then split into 5 categories for analysis: less than $\$ 20,000 ; \$ 20-39,999 ; \$ 40-59,999 ; \$ 60-79,999$; and greater than or equal to $\$ 80,000$. These categories were chosen based on current poverty levels (U.S. Department of Health and Human Services. Office of the Assistant Secretary for Planning and Evaluation. 2017). Additional variables included in the study are: race/ethnicity, based on US Census questions (United States Census Bureau 2018) and categorized into non-Hispanic white, all others, and refused, based on frequencies; marital status categorized into married, divorced/separated/widowed, never married, and refused, based on past literature showing health differences between categories (CDC 2020); age; self-reported gender, with responses being male or female; and site location. All questions with the possible responses are shown in Appendix A. Analysis

Prior to conducting analyses, we checked the data for completeness and accuracy (STATA v.16). For this analysis we excluded those with missing values for income $(\mathrm{n}=1)$, educational attainment $(\mathrm{n}=8)$, employment status $(\mathrm{n}=4)$, or smoking status $(\mathrm{n}=2)$ for a final analytic sample of 404 participants. We summarize the descriptive data for demographic variables and self-report measures for all participants in Table 1. We conducted bivariate analyses using Pearson chi-squared tests to compare socioeconomic 
and sociodemographic factors of participants who reported formerly smoking cigarettes or currently smoked cigarettes at baseline (Table 2).

\section{Results}

\section{Descriptive findings}

Our sample consisted of 404 total participants: 229 (57\%) participants who currently smoked cigarettes and 175 (43\%) participants who reported formerly smoking cigarettes at baseline. Slightly more than half (51\%) were treated at the VAPORHCS, $32 \%$ at the VA Minneapolis, and $17 \%$ at Duke University, with an average age of 65 . The majority of the subjects were male (87\%), had some college or vocational work (46\%), and were not employed (76\%). Income categories were relatively even, with $25 \%$ making less than $\$ 20,000$ per year. Our sample was largely non-Hispanic white (85\%) and married (47\%) (Table 1).

Table 2 shows descriptive statistics of our sample stratified by smoking status. Current and former smokers were similar on several measures. For example, both current and former smokers most commonly reported some college or vocational work (45\% vs $47 \%$, respectively) and the majority were not employed (75\% and $78 \%$, respectively). Former smokers were slightly older (66 years) versus current smokers who were an average age of 64 years old, but this difference was not statistically significant. However, differences were observed across several measures. We did observe significant differences $(p<0.05)$ in income as current smokers reported incomes of less than $\$ 20,000$ per year with much greater frequency $(31 \%)$ compared to former smokers $(16 \%)$. We also observed significant race differences as a larger percentage of former smokers were 
non-Hispanic white $(89 \%)$ compared to current smokers $(81 \%)(\mathrm{p}<0.05)$. In addition, we found that former smokers were more likely to report male gender (93\% vs $83 \%$ ) $(\mathrm{p}<0.005)$. Other differences, though non-significant were also observed: a greater percentage of former smokers were married (51\%) compared to current smokers (44\%).

\section{Discussion}

We had the opportunity to describe a sample of generally hard to reach smokers. Our results provide a description of hardened smokers' characteristics focusing on important socioeconomic and sociodemographic factors to add to the knowledge base about this population. We determined which factors were associated with former or active smoking. Consistent with previous findings, we found that income was significantly lower for participants who currently smoked at baseline, males were less likely to currently smoke, and non-Hispanic whites were less likely to currently smoke (Drope 2018).

Our finding that income was significantly lower for participants who currently smoked supports prior research documenting the importance of income on health. Other studies have shown that those who are in poverty when measured by income are more likely to continue to smoke (i.e., not successfully quit). Our findings suggest that the link with poverty and continuation of smoking holds for Veterans and civilians (Golden 2018; Marmot and Wilkinson 2006). A number of mechanisms may account for the association between income and current smoking. For example, income affects health through both direct and indirect pathways. Income can impact the ability toaccess health care and health information more easily and higher income can allow for utilization of preventive 
medicine more appropriately (Frolich et al 2002). Those with higher incomes generally have higher-paying jobs and people in these positions generally have a greater sense of autonomy and self-efficacy, thereby leading to better health. The groups with the largest decreases in ability to quit smoking have been those in the highest income brackets (Drope 2018).

Educational attainment and employment status differences were not observed for current versus former smokers. This is somewhat unexpected as a number of studies have established the importance of these factors in predicting successful smoking cessation (Nagelhout 2012; Pierce 1989). However, given the relatively older age of this sample (recruitment targeted those 55 and older) and retirement status of this group, it is likely that these factors are less relevant with respect to smoking behavior. It is also possible that since our sample had been smoking for many years prior to being offered LCS and our survey, the effects of these characteristics had already run their course. Other characteristics may have become more prominent for influencing smoking status, such as more graphic warning labels as deterrents (Azagba and Sharaf 2013; Shang et al 2017), fear of withdrawal symptoms, or continued desire of stress reduction (Baker et al 2004). The role of educational attainment and employment in predicting smoking behaviors in hardened smokers should be investigated more closely.

As expected, we found that non-Hispanic whites were less likely to currently smoke at baseline. Some racial/ethnic groups are more likely to currently smoke compared to non-Hispanic whites, for example, American Indians or Alaska Natives. Individuals who report as Asian or Hispanic or Latino, however, have lower rates of 
current smoking. Due to our large majority of non-Hispanic whites we were unable to account for other racial/ethnic differences beyond two groups. Many differences in smoking based on race can be explained by differences in socioeconomic factors (Nollen 2019). One study showed that cessation counseling by a primary care provider was less likely to occur in non-Hispanic other race individuals, similar to females when compared to their male counterparts (Bailey 2018). Certainly, males have a higher smoking prevalence in the general population. But males are also more positively impacted by cessation interventions, possibly accounting for our finding. Cessation interventions are often thought to work the same across genders (Bottorff et al. 2014), or may only differ based on biological factors, ignoring social gender-specific issues. This assumption is in contrast to the evidence that quit rates differ significantly between genders. Thus, it is important to be aware of the differences between genders in the reasons and theory behind their smoking behaviors in order to be able to develop and implement effective interventions. The mechanisms behind the differences based on race/ethnicity and gender are not well-understood (Department of Health \& Human Services 2014).

Social stress may be one mechanism for increased smoking between disparate groups based on factors like fundamental causes. Social stress can be caused by social isolation or by inclusion in society that "fails to provide the expected returns" (Aneshensel 1992). Increased levels of chronic social stress based on race/ethnicity and gender may occur due to barriers in achievement, resource deprivation, and social and economic hardship (Eckenrode 1984). But there are also baseline differences in stress between racial groups, for instance, that do not seem to be caused by typical areas of 
chronic stress (Bratter and Eschbach 2005). It would be interesting to examine in future research the reported levels of social stress experienced by hardened smokers to determine social stress as a possible mechanism behind smoking behaviors. There may also be a need to capture more racial/ethnic (or gender) variation to capture socially caused mechanisms for differences in smoking behaviors.

Hardened smokers have not been well-described in previous research. This is the first study to illustrate socioeconomic and sociodemographic factors i this population. By documenting differences between current and former hardened smokers based on income, race, and gender, we can start to explore possible mechanisms for these differences, and importantly, determine mechanisms that might help with cessation. For example, it is possible that screening for income, race, and gender, prior to LCS decision-making discussions could be possible in order to provide extra, or different, cessation strategies. Indeed, one strategy does not fit everyone. It may be necessary to encourage cessation with financial incentives, for instance, or to include counseling that involves discussions of racial- or gender- based stressors and how to minimize those stressors. It is also important to document differences within hardened smokers since the differences may equate to relevant costs in other areas of sociological interest such as crime, educational achievements, or social mobility or cohesion (Aneshensel 1992).

This study is ongoing and more data on smoking patterns are being collected. We will be studying whether or not these findings are predictive of cessation for current smokers at baseline. Our follow-up surveys also query patients about their decisionmaking discussion. It is possible that those with fewer socioeconomic factors are less 
likely to be influenced by provider communication within the discussion. We will also able to evaluate this hypothesis and possible mechanisms for our findings, such as communication quality, self-efficacy, and decisional conflict.

There are limitations to this research. We did not examine mechanisms for these findings, but further analyses and our qualitative work can provide nuance and insight into pathways. Since information was self-reported, participants might say what they think the researchers want to hear, also called moderator acceptance bias. The goal of this study was to establish a baseline of the existing resources among hardened smokers and thus focused on cross-sectional data. However, the longitudinal design offers an opportunity to assess responses over time and will be used to compensate for the limitation of capturing just one snapshot in time. Smoking can be a sensitive topic, so it is possible patients did not recall or report their smoking status accurately. We can address consistency with our ongoing data collection.

\section{Conclusion}

Our findings suggest that patients offered LCS may be different compared to patients in other settings where socioeconomic factors seem to play more of a role in smoking behaviors. Smoking cessation programs could tailor their approach to patients offered LCS who may have other individual- or system- level characteristics that influence the association between socioeconomic and sociodemographic factors, smoking status, and smoking cessation. Support for new interventions are crucial to address disparities. To address some possible mediating characteristics, we plan further analyses 
to examine changes in smoking behaviors over time and associations with patientclinician communication and patient self-efficacy scores. 
Table 1. Self-reported Descriptive Statistics of All Subjects, $n=404$

\begin{tabular}{|c|c|c|c|c|}
\hline 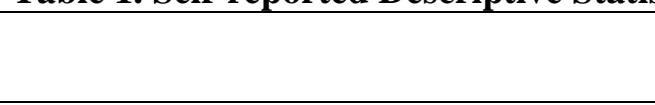 & $\mathrm{N}$ & Percentage* & Mean & $\begin{array}{l}\text { Std. } \\
\text { Deviation }\end{array}$ \\
\hline $\begin{array}{l}\text { Smoking Status at Baseline } \\
\text { Current smoker } \\
\text { Former smoker } \\
\end{array}$ & $\begin{array}{l}229 \\
175 \\
\end{array}$ & $\begin{array}{l}57 \\
43 \\
\end{array}$ & $\mathrm{n} / \mathrm{a}$ & $\mathrm{n} / \mathrm{a}$ \\
\hline Accepted Lung Cancer Screening LDCT & 395 & 98 & $\mathrm{n} / \mathrm{a}$ & $\mathrm{n} / \mathrm{a}$ \\
\hline $\begin{array}{l}\text { Education } \\
\text { High school or less } \\
\text { Some college/vocational work } \\
\text { College graduate or more }\end{array}$ & $\begin{array}{l}135 \\
187 \\
82\end{array}$ & $\begin{array}{l}33 \\
46 \\
20\end{array}$ & $\mathrm{n} / \mathrm{a}$ & $\mathrm{n} / \mathrm{a}$ \\
\hline $\begin{array}{l}\text { Employment status } \\
\text { Not employed (retired, unemployed, } \\
\text { disabled) } \\
\text { Employed (full time, part time, and/or } \\
\text { irregular work) }\end{array}$ & $\begin{array}{l}309 \\
95\end{array}$ & $\begin{array}{l}76 \\
24\end{array}$ & $\mathrm{n} / \mathrm{a}$ & $\mathrm{n} / \mathrm{a}$ \\
\hline $\begin{array}{l}\text { Income } \\
\quad \leq \$ 19,999 \\
\$ 20,000-39,999 \\
\$ 40,000-59,999 \\
\$ 60,000-79,999 \\
\geq \$ 80,000 \\
\text { Refused/Don't Know }\end{array}$ & $\begin{array}{l}100 \\
102 \\
97 \\
50 \\
43 \\
12 \\
\end{array}$ & $\begin{array}{l}25 \\
25 \\
24 \\
12 \\
11 \\
3\end{array}$ & $\mathrm{n} / \mathrm{a}$ & $\mathrm{n} / \mathrm{a}$ \\
\hline $\begin{array}{l}\text { Race/ethnicity } \\
\text { Non-Hispanic White } \\
\text { All Others } \\
\text { Refused }\end{array}$ & $\begin{array}{l}342 \\
61 \\
1\end{array}$ & $\begin{array}{l}85 \\
15 \\
<1\end{array}$ & $\mathrm{n} / \mathrm{a}$ & $\mathrm{n} / \mathrm{a}$ \\
\hline $\begin{array}{l}\text { Marital Status } \\
\text { Married } \\
\text { Divorced/Separated/Widowed } \\
\text { Never Married } \\
\end{array}$ & $\begin{array}{l}191 \\
183 \\
30 \\
\end{array}$ & $\begin{array}{l}47 \\
45 \\
7 \\
\end{array}$ & $\mathrm{n} / \mathrm{a}$ & $\mathrm{n} / \mathrm{a}$ \\
\hline $\begin{array}{l}\text { Treatment location } \\
\text { VA Portland Health Care System } \\
\text { VA Minneapolis } \\
\text { Duke University }\end{array}$ & $\begin{array}{l}204 \\
130 \\
70\end{array}$ & $\begin{array}{l}51 \\
32 \\
17\end{array}$ & $\mathrm{n} / \mathrm{a}$ & $\mathrm{n} / \mathrm{a}$ \\
\hline Age (yr.) & $\mathrm{n} / \mathrm{a}$ & $\mathrm{n} / \mathrm{a}$ & 65 & 5.6 \\
\hline $\begin{array}{r}\text { Gender } \\
\text { Male }\end{array}$ & 351 & 87 & $\mathrm{n} / \mathrm{a}$ & $\mathrm{n} / \mathrm{a}$ \\
\hline
\end{tabular}




\begin{tabular}{|c|c|c|c|}
\hline & $\begin{array}{l}\text { Current } \\
\mathrm{N}=229 \\
\end{array}$ & $\begin{array}{l}\text { Former } \\
\mathrm{N}=175\end{array}$ & P-value \\
\hline Characteristic & $\begin{array}{c}\mathbf{N}(\%) * \\
\text { Or } \\
\text { Mean (SD) }\end{array}$ & $\begin{array}{c}\mathbf{N}(\%) * \\
\text { Or } \\
\text { Mean (SD) }\end{array}$ & \\
\hline Accepted Lung Cancer Screening LDCT & $224(98)$ & $171(98)$ & 0.42 \\
\hline $\begin{array}{l}\text { Education } \\
\text { High school or less } \\
\text { Some college/vocational work } \\
\text { College graduate or more }\end{array}$ & $\begin{array}{l}85(37) \\
104(45) \\
40(17)\end{array}$ & $\begin{array}{l}50(29) \\
83(47) \\
42(24)\end{array}$ & 0.11 \\
\hline $\begin{array}{l}\text { Employment status } \\
\text { Not employed (retired, unemployed, disabled) } \\
\text { Employed (full time, part time, and/or irregular } \\
\text { work) }\end{array}$ & $\begin{array}{c}172(75) \\
57(25)\end{array}$ & $\begin{array}{c}137(78) \\
38(22)\end{array}$ & 0.46 \\
\hline $\begin{array}{l}\text { Income } \\
\leq \$ 19,999 \\
\$ 20,000-39,999 \\
\$ 40,000-59,999 \\
\$ 60,000-79,999 \\
\geq \$ 80,000 \\
\text { Refused/Don't Know }\end{array}$ & $\begin{array}{c}72(31) \\
57(25) \\
46(20) \\
29(13) \\
19(8) \\
6(3) \\
\end{array}$ & $\begin{array}{c}28(16) \\
45(26) \\
51(29) \\
21(12) \\
24(14) \\
6(3) \\
\end{array}$ & 0.007 \\
\hline $\begin{array}{l}\text { Race/ethnicity } \\
\text { Non-Hispanic White } \\
\text { All Others } \\
\end{array}$ & $\begin{array}{c}186(81) \\
43(19)\end{array}$ & $\begin{array}{c}156(89) \\
19(11)\end{array}$ & $\mathbf{0 . 0 3}$ \\
\hline $\begin{array}{l}\text { Marital Status } \\
\text { Married } \\
\text { Divorced/Separated/Widowed } \\
\text { Never Married } \\
\end{array}$ & $\begin{array}{r}101(44) \\
107(47) \\
21(9) \\
\end{array}$ & $\begin{array}{c}90(51) \\
76(43) \\
9(5) \\
\end{array}$ & 0.17 \\
\hline $\begin{array}{l}\text { Treatment location } \\
\text { VA Portland Health Care System } \\
\text { VA Minneapolis } \\
\text { Duke University }\end{array}$ & $\begin{array}{l}101(44) \\
73(32) \\
55(24)\end{array}$ & $\begin{array}{l}103(59) \\
57(33) \\
15(9)\end{array}$ & 0.48 \\
\hline Age (yr.) & $64(5.5)$ & $66(5.5)$ & 0.35 \\
\hline $\begin{array}{r}\text { Gender } \\
\text { Male }\end{array}$ & $189(83)$ & $162(93)$ & 0.003 \\
\hline
\end{tabular}




\section{References}

Aneshensel, C. 1992. "Social Stress: Theory and Research." Annual Review of Sociology $18: 15$.

Atkins, Graham T., Taeha Kim and Jeffrey Munson. 2017. "Residence in Rural Areas of the United States and Lung Cancer Mortality: Disease Incidence, Treatment Disparities and Stage Specific Survival." Annals of the American Thoracic Society 14(3):403-411.

Azagba, Sunday and Mesbah F. Sharaf. 2013. "The Effect of Graphic Cigarette Warning Labels on Smoking Behavior: Evidence from the Canadian Experience." Nicotine \& Tobacco Research: Official Journal of the Society for Research on Nicotine and Tobacco 15(3):708-717.

Babb, Stephen, Ann Malarcher, Kat Asman, Michelle Johns, Ralph Caraballo, Brenna VanFrank and Bridgette Garrett. 2020. "Disparities in Cessation Behaviors between Hispanic and Non-Hispanic White Adult Cigarette Smokers in the United States, 2000-2015." Prev.Chronic Dis. 17:190279.

Bailey, Steffani R., Victor J. Stevens, Stephen P. Fortmann, Stephen E. Kurtz, Mary A. McBurnie, Elisa Priest, Jon Puro, Leif I. Solberg, Rebecca Schweitzer, Andrew L. Masica and Brian Hazlehurst. 2018. "Long-Term Outcomes from Repeated Smoking 
Cessation Assistance in Routine Primary Care." Am J Health Promot: 0890117118761886.

Baker, Timothy B., Thomas H. Brandon and Laurie Chassin. 2004. "Motivational Influences on Cigarette Smoking." Annual Review of Psychology 55(1):463-491.

Bottorff, Joan L., Rebecca Haines-Saah, Mary T. Kelly, John L. Oliffe, Iris Torchalla, Nancy Poole, Lorraine Greaves, Carole A. Robinson, Mary H. Ensom, Chizimuzo T. Okoli and J. Craig Phillips. 2014. "Gender, Smoking and Tobacco Reduction and Cessation: A Scoping Review." International Journal for Equity in Health 13:114014-0114-2.

Bratter, Jenifer L. and Karl Eschbach. 2005. "Race/Ethnic Differences in Nonspecific Psychological Distress: Evidence from the National Health Interview Survey*." Social Science Quarterly 86(3):620-644.

Butler, Karen M., Amanda Fallin and S. Lee Ridner. 2012. "Evidence-Based Smoking Cessation for College Students." Nursing Clinics of North America 47(1):21-30.

Campaign for Tobacco-Free Kids. 2015. "Tobacco and Socioeconomic Status". Washington D.C. Accessed June 13, 2020. 
Centers for Disease Control and Prevention. 2020. "Smoking and Tobacco Use. TobaccoRelated Disparities.", Accessed May 15, 2020. (https://www.cdc.gov/tobacco/disparities/index.htm).

Clegg, Limin X., Marsha E. Reichman, Barry A. Miller, Benjamin F. Hankey, Gopal K. Singh and Yi D. Lin, et al. 2009. "Impact of Socioeconomic Status on Cancer Incidence and Stage at Diagnosis: Selected Findings from the Surveillance, Epidemiology, and End Results: National Longitudinal Mortality Study external Icon." Cancer Causes Control 20(4):417-435.

Dahl, Espen, Dag Hofoss and Jon I. Elstad. 2007. "Educational Inequalities in Avoidable Deaths in Norway: A Population Based Study." Health Sociology Review 16(2):146159.

Docherty, Graeme and Ann McNeill. 2012. "The Hardening Hypothesis: Does it Matter?" Tobacco Control 21(2):267-268.

Drope, Jeffrey, Alex C. Liber, Zachary Cahn, Michal Stoklosa, Rosemary Kennedy, Clifford E. Douglas, Rosemarie Henson and Jacqui Drope. 2018. "Who's Still Smoking? Disparities in Adult Cigarette Smoking Prevalence in the United States." CA: A Cancer Journal for Clinicians 68(2):106-115.

Eckenrode, John. 1984. "Impact of Chronic and Acute Stressors on Daily Reports of Mood." Journal of Personality and Social Psychology 46(4):907-918. 
Federico, Bruno, Giuseppe Costa and Anton E. Kunst. 2007. "Educational Inequalities in Initiation, Cessation, and Prevalence of Smoking among 3 Italian Birth Cohorts." Am J Public Health 97:838-845.

Frohlich, Katherine L., Louise Potvin, Patrick Chabot, and Ellen Corin. 2002. "A Theoretical and Empirical Analysis of Context: Neighbourhoods, Smoking and Youth." Social Science \& Medicine (1982) 54(9):1401-1417.

Glied, S. and A. Lleras-Muney. 2008. "Technological Innovation and Inequality in Health." Demography 45(3):741-761.

Golden, Sara E., Sujata Thakurta, Hyeyoung Woo, Christopher G. Slatore and Donald R. Sullivan. 2018. "Military Factors Associated with Smoking in Veterans." Mil Med 183(11-12):e402-e408.

Jensen, Tamara S., Joseph Chin, Lori Ashby, Jamie Hermansen and Joseph D. Hutter. 2015. “Decision Memo for Screening for Lung Cancer with Low Dose Computed Tomography (LDCT)”. Centers for Medicare \& Medicaid Services.

Krieger, N., J.T. Chen, P.D. Waterman, D.H. Rehkopf and S.V. Subramanian. 2003. "Race/ethnicity, gender, and monitoring socioeconomic gradients in health: a comparison of area-based socioeconomic measures--the public health disparities geocoding project.” Am J Public Health 93(10):1655-1671. 
Link, Bruce G. and Jo C. Phelan. 1995. "Social Conditions as Fundamental Causes of Disease." Journal of Health and Social Behavior extra:80.

Lund, Marianne, Karl Erik Lund and Elisabeth Kvaavik. 2011. "Hardcore Smokers in Norway 1996-2009." Nicotine \& Tobacco Research: Official Journal of the Society for Research on Nicotine and Tobacco 13(11):1132-1139.

Marmot, Michael and Richard G. Wilkinson. 2006. "Social Determinants of Health". Oxford, UK: Oxford University Press.

McClure, E. A., N. L. Baker, K. M. Gray, C. O. Hood, R. L. Tomko, M. J. Carpenter, V. R. Ramakrishnan, C. J. Buchanan and M. E. Saladin. 2020. "The Influence of Gender and Oxytocin on Stress Reactivity, Cigarette Craving, and Smoking in a Randomized, Placebo-Controlled Laboratory Relapse Paradigm." Psychopharmacology 237(2):543-555.

Miranda, Leah S., Santanu Datta, Anne C. Melzer, Renda S. Wiener, James M. Davis, Betty C. Tong, Sara E. Golden and Christopher G. Slatore. 2017. "Rationale and Design of the Lung Cancer Screening Implementation. Evaluation of PatientCentered Care Study." Annals of the American Thoracic Society 14(10):1581-1590.

Nagelhout, Gera E., Dianne de Korte-de Boer, Anton E. Kunst, Regina M. van der Meer, Hein de Vries, Boukje M. van Gelder and Marc C. Willemsen. 2012. "Trends in Socioeconomic Inequalities in Smoking Prevalence, Consumption, Initiation, and 
Cessation between 2001 and 2008 in the Netherlands. Findings from a National Population Survey." BMC Public Health 12:303-2458-12-303.

Ney, T., A. Gale, RB Coambs, L. T. Kozlowski and R. G. Ferrence. 1989. "The Future of Tobacco Use and Smoking Research." Pp. 337-348 in Smoking and Human Behavior., edited by T. Ney and A. Gale. New York, NY: Wiley \& Sons Ltd.

Nollen, Nicolle L., Matthew S. Mayo and Lisa Sanderson Cox et al. 2019. "Factors that Explain Differences in Abstinence between Black and White Smokers: A Prospective Intervention Study." Jnci 111(20):1078-1087.

Peto, Richard, Sarah Darby, Harz Deo, Paul Silcocks, Elise Whitley and Richard Doll. 2000. "Smoking, Smoking Cessation, and Lung Cancer in the UK since 1950: Combination of National Statistics with Two Case-Control Studies." Bmj 321(7257):323-329.

Phelan, Jo C., Bruce G. Link, Ana Diez-Roux, Ichiro Kawachi and Bruce Levin. 2004. "'Fundamental Causes" of Social Inequalities in Mortality: A Test of the Theory." Journal of Health and Social Behavior 45:265-285.

Pierce, John P., Michael C. Fiore, Thomas E. Novotny, Evridiki J. Hatziandreu and Ronald M. Davis. 1989. "Trends in Cigarette Smoking in the United States. Educational Differences are Increasing." Jama 261(1):56-60. 
Roberts, Megan E., Nathan J. Doogan, Allison N. Kurti et al. 2016. "Rural Tobacco use Across the United States: How Rural and Urban Areas Differ, Broken Down by Census Regions and Divisions". Health Place 39:153-159.

Ross, Catherine E. and Chia-ling Wu. 1995. "The Links between Education and Health." American Sociological Review 60(5):719-745.

Shang, Ce, Jidong Huang, Kai-Wen Cheng, Yanhun He and Frank J. Chaloupka. 2017. "The Association between Warning Label Requirements and Cigarette Smoking Prevalence by Education-Findings from the Global Adult Tobacco Survey (GATS)." International Journal of Environmental Research and Public Health 14(1):10.3390/ijerph14010098.

Singh, Gopal K., Shanita D. Williams, Mohammad Siahpush and Aaron Mulhollen. 2011. "Socioeconomic, Rural-Urban, and Racial Inequalities in US Cancer Mortality: Part I-All Cancers and Lung Cancer and Part II-Colorectal, Prostate, Breast, and Cervical Cancers External Icon." Journal of Cancer Epidemiology 2011:107497.

Song, Y. M. and J. J. Byeon. 2000. "Excess Mortality from Avoidable and NonAvoidable Causes in Men of Low Socioeconomic Status: A Prospective Study in Korea." Journal of Epidemiology and Community Health 54(3):166-172.

Steinberg, M. B. and C. D. Delnevo. 2013. "Increasing the "smoking Age": The Right Thing to Do." Annals of Internal Medicine 159(8):558-559. 
U.S. Department of Health and Human Services. 2014. "The Health Consequences of Smoking-50 Years of Progress: A Report of the Surgeon General”. Accessed June 2, 2020.

U.S. Department of Health and Human Services. Office of the Assistant Secretary for Planning and Evaluation. 2017. "Poverty estimates, trends and analysis.". Accessed March, 2020. (https://aspe.hhs.gov/poverty-estimates-trends-and-analysis).

United States Census Bureau. 2018. "Census Bureau Statement on 2020 Census Race and Ethnicity Questions.", Accessed June 10, 2020. (https://www.census.gov/newsroom/press-releases/2018/2020-race-questions.html).

Vannimenus, Corinne, Hélène Bricout, Olivier Le Rouzic, François Mouawad et al. 2018. "Compared Characteristics of Current vs. Past Smokers at the Time of Diagnosis of a First-Time Lung or Head and Neck Cancer: A Cross-Sectional Study”. BMC Cancer 18(1):372

Velicer, Wayne F. and James O. Prochaska. 2004. "A Comparison of Four Self-Report Smoking Cessation Outcome Measures." Addictive Behaviors 29(1):51-60. 
Zbikowski, Susan M., Brooke Magnusson, Jessica R. Pockey, Hilary A. Tindle and Kathryn E. Weaver. 2012. "A Review of Smoking Cessation Interventions for Smokers Aged 50 and Older." Maturitas 71(2):131-141 


\section{Chapter 3. The Association between Patient-Clinician Communication and Smoking Cessation among Patients Offered Lung Cancer Screening}

Sara E. Golden, $\mathrm{MPH}^{1,2}$; Hyeyoung $\mathrm{Woo}, \mathrm{PhD}^{2}$; Ginny Garcia-Alexander, $\mathrm{PhD}^{3}$; Jeffrey Robinson, $\mathrm{PhD}^{4}$; Christopher G. Slatore, MD, MS ${ }^{1,5,6}$

1. Center to Improve Veteran Involvement in Care, VA Portland Health Care System; Portland, OR

2. Department of Sociology, Portland State University; Portland, OR

3. Department of Sociology, University of Texas- San Antonio; San Antonio, TX

4. Department of Communication, Portland State University; Portland, OR

5. Division of Pulmonary \& Critical Care Medicine, Department of Medicine, Oregon Health \& Science University; Portland, OR

6. Section of Pulmonary \& Critical Care Medicine, VA Portland Health Care System; Portland, OR 


\begin{abstract}
Objective: Insurers have now agreed to extend coverage for lung cancer screening (LCS) using low-dose computed tomography (LDCT), but one stipulation for reimbursement is to deliver a shared decision-making discussion for the patient and clinician to include communication about smoking. It is unknown if the presence of communication about smoking positively influences smoking cessation within the LCS decision-making discussion.
\end{abstract}

Methods: We surveyed patients eligible for LCS and who underwent a decision-making discussion from three medical centers in the US with established LCS programs (two VA and one non-VA). We enrolled patients before the LDCT for those who accepted the LDCT, and within three weeks of the decision-making discussion for those who did not accept the LDCT. Each were also surveyed after one year. We summarized the descriptive data for demographic variables and the scores on self-report measures for all participants. We performed a logistic regression analysis to determine the association between patient-clinician communication and smoking status at one-year follow-up.

Results: Our sample consisted of 135 total participants who were currently smoking at baseline: the majority (81\%) were still smoking at one-year follow-up and $94 \%$ accepted the LDCT. Almost half reported attending some college or vocation work (45\%), and $76 \%$ were not employed at the time of the survey. The plurality had an income of less than $\$ 20,000$ per year (35\%). Recalling having discussed smoking cessation during the LCS decision-making discussion was not significantly associated with successfully quitting smoking (OR 1.18; 95\% CI, 0.43-3.19; $\mathrm{P}=0.74)$. We found that participants at 
our non-VA site had a significantly higher odds of quitting than those at our VA sites

(OR 4.94; 95\% CI, 1.29-23.34; $\mathrm{P}=0.02)$.

Conclusion: Our results indicate that the LCS decision-making discussion may not be the most influential moment to talk about smoking cessation. Indeed, future policies may not need to mandate communication about smoking during the LCS decision-making discussion. 


\section{Introduction}

\section{The LCS Decision-Making Discussion}

Lung cancer screening (LCS) using low-dose computed tomography (LDCT) has been recommended by several institutions (Bach et al. 2012; Jacklitsch et al. 2012; Moyer 2014; National Comprehensive Cancer Network 2012).The Centers for Medicare and Medicaid Services (CMS) has agreed to extend coverage for LCS. These recommendations, however, were not without stipulations (Jensen et al. 2015). For instance, insurers require a shared decision-making discussion, which includes a full dialogue about smoking behaviors prior to receipt of the LDCT. Because a decision requiring a shared decision-making discussion is unprecedented among insurers, much is still unknown about how communication within the discussion can positively influence smoking cessation.

A systematic review (Joosten et al. 2008) showed that shared decision-making is "particularly suitable for long-term decisions," and can improve patient satisfaction and treatment adherence (Golden et al. 2016; Legare et al. 2018). However, LCS decisionmaking discussions vary in the amount and type of information provided to a patient. For example, clinicians cite time restraints and lack of in-depth information about LCS and the decision-making process as reasons why they may or may not discuss smoking cessation and other elements with patients (Melzer et al. 2019). Shared decision-making, at least as described in the most literature (Joosten et al. 2008; Legare et al. 2018), may not be occurring as intended. To date it is unknown if clinicians are actually discussing smoking within the decision-making discussion as mandated. Certainly, impacts of 
shared decision-making on smoking behaviors, especially within LCS, have limited evidence (Slatore et al. 2014; Golden et al. 2020). As a result, it is unknown what factors may or may not be associated with positive changes in smoking behaviors (Kathuria et al. 2018; Slatore et al. 2014) within the LCS decision-making discussion.

\section{Communication}

Communication encompasses more than shared decision-making (Figure 1). Given the importance of smoking cessation, this study focuses on whether or not patientreported presence of communication about smoking within an LCS decision-making discussion affects cessation. Indeed, high-quality patient-clinician communication can improve patient-centered outcomes like smoking cessation and abstinence, as well as increased exercise and other positive health behaviors (Institute of Medicine [IOM] 2013; Mead and Bower 2000; Simpson et al. 1991; Weiland et al. 2012). For these reasons, effective communication between patient and clinician is often considered a part of highquality care (IOM 2013). A 2008 report published by the Agency for Healthcare Research and Quality recommends that "every individual entering a health care setting" should have their smoking status assessed and clinicians should advise their patients who smoke to quit (2008 PHS Guideline Update Panel, Liaisons, and Staff 2008). Research based on a meta-analysis shows that even brief advice given by a physician (Lancaster and Stead 2004), or by other clinicians (Bao, Duan, and Fox 2006), can significantly increase cessation rates. Additionally, another meta-analysis has shown that any type of communication within a cessation intervention is more effective than self-help or no communication (Hollis et al. 2000). Just the presence of talking to patients about smoking 
during a clinical encounter is associated with increased cessation rates anywhere from 3$50 \%$ depending on the nicotine dependence of the smoker (Hartmann 2000). These findings underscore that when clinicians ask patients about their smoking at any encounter, it has been shown to lead to reduced smoking (Bailey et al. 2018; U.S. Preventive Services Task Force 2017). Despite these empirical studies, it is not known if communication about smoking occurs within the LCS decision-making discussion and how that presence of communication influences smoking cessation. Findings of this study may point to mechanisms for improved smoking behaviors.

\section{Methods}

Setting

We surveyed patients eligible for LCS and who underwent a decision-making discussion from three medical centers in the US with established LCS programs: VA Portland Health Care System (VAPORHCS), Portland, OR; Minneapolis VA Medical Center, Minneapolis, MN; and Duke University Medical Center, Durham, NC. We recruited patients based on research referrals from clinicians who verified clinical criteria (Miranda et al. 2017) not further confirmed by the research team. Notably, all patients in this sample received a decision-making discussion.

Sample

We included patients regardless of whether they agreed or declined to undergo the LDCT. The study was IRB-approved at each participating site (VAPORHCS \#3482; Minneapolis VA \#4645-B; Duke \#Pro00073394). The Portland State University Office of Research Integrity and IRB waived oversight of this study (see Appendix F). We enrolled 
patients after their decision-making discussion with their clinician, and data were collected at baseline and one year. We collected baseline data at time points depending on if the patient accepted or declined the LDCT: before the LDCT for those who accepted the scan, and within three weeks of the decision-making discussion for those who did not accept the LDCT. We collected one-year follow-up data for all patients, again timing depended on if they accepted or declined the LDCT. That is, one year after the scan for those who accepted the LDCT, and one year after the decision-making discussion for those who declined the LDCT. For this analysis we included current smokers at baseline, identified by their response to the question, "How would you describe your cigarette smoking?" There were no patients who started smoking after baseline and we did not include former smokers at baseline since we were most interested in smoking cessation at one-year follow-up.

\section{Data}

We enrolled 414 patients in the study who completed quantitative surveys, of whom 135 who were currently smoking at baseline and had a response for smoking status at one-year follow-up, and thus included in this analysis. At the initial and follow-up study visits, we collected data on the independent and dependent variables. At the initial visit only we collected sociodemographic data, pack years, and e-cigarette use .

\section{Primary Outcome}

We defined smoking status at one-year follow-up based on the question, "Have your smoking habits changed since the last survey?" We classified patients as having successfully quit if they responded that they had quit smoking at least 7 days ago, based 
on a commonly used measure of successful tobacco cessation by the 7-day point prevalence abstinence (Velicer and Prochaska 2004).

\section{Primary Exposure}

We measured communication using one question from a survey instrument based on work by Borrelli (Borrelli et al. 2001; Borrelli, Lee, and Novak 2008). The question asks, "Did the person who talked with you most about screening discuss quitting smoking with you?" The response options include: No, Yes, and Could Not Recall. Two previous studies by Borrelli used this instrument to determine that attitudes and beliefs about smoking are significantly associated with counseling behaviors for nurses providing information about smoking cessation (Borrelli et al. 2001), and to compare communication quality of nurses providing cessation (Borrelli, Lee, and Novak 2008). The entire instrument is 16 questions, however there is not a summary index available, only individual questions are used. We also found that $72(53 \%)$ of participants either Could Not Recall or reported No, they did not have a decision-making discussion, therefore they skipped the rest of the instrument and greatly reduced our sample size. Additionally, as discussed above, even brief communication regarding smoking cessation can have an impact on patient health behaviors. We combined the No and Could Not Recall responses for our analysis.

\section{Covariates}

We adjusted for study site location: VAPORHCS, VA Minneapolis, and Duke University. We also adjusted for nicotine dependence. We measured nicotine dependence using one question from the Fagerström Test for Cigarette/Nicotine Dependence: "How 
soon after you wake up do you smoke your first cigarette?" This question was found to be most predictive of nicotine dependence (Heatherton et al. 1991).

Analysis

We first summarized the descriptive data for sociodemographic variables and the scores on self-report measures for all participants. Next, we conducted t-tests or ChiSquared tests to see potential compositional differences between people who were able to quit and those who were not able to quit smoking. We then estimated a logistic regression analysis to determine the association of presence of patient-clinician communication with smoking status at one-year follow-up. The primary models were constructed parsimoniously, excluding variables that did not appear to be confounders if the marginal effect was not more than $10 \%$. We also performed a sensitivity analysis separating the Could Not Recall and No discussion responses into two variables. We used STATA v.16 for analysis, employing $\mathrm{p}<0.05$ criterion for statistical significance.

\section{Results}

Table 1 displays the characteristics of the 135 participants included in this analysis. All included participants completed the baseline and one-year follow-up survey, including responding to the independent and dependent variables questions. The majority (81\%) were still smoking at one-year follow-up and 94\% accepted the LDCT. Almost half reported attending some college or vocational work (45\%), and 76\% were not employed at the time of the survey. Additionally, the plurality reported an income of less than $\$ 20,000$ per year (35\%). Eighty-four percent of participants were non-Hispanic white and $85 \%$ reported male gender. Half of participants were 
divorced/separated/widowed (50\%) and 7\% used e-cigarettes at baseline. Given the eligibility criteria to be offered LCS, it follows that our average age was 64, with 49 average pack years of smoking. Almost half of participants reported discussing smoking cessation during their LCS decision-making discussion (47\%), while 39\% reported not discussing smoking cessation, and 15\% could not recall discussing smoking cessation. The only significant comparison was for study site location $(\mathrm{P}=0.04)$.

We provide the odds ratios for the association of presence of patient-clinician communication about smoking cessation and cessation outcomes in Table 2. Recalling having discussed smoking cessation during the LCS decision-making discussion was not significantly associated with lower odds of successfully quitting smoking (OR 1.18; $95 \%$ $\mathrm{CI}, 0.43-3.19 ; \mathrm{P}=0.74)$. We also found that a significantly higher odds of quitting among the participants at Duke University than those at VAPORHCS (OR 4.94; 95\% CI, 1.2923.34; $\mathrm{P}=0.02$ ). Our sensitivity analysis separating the Could Not Recall from the No discussion options did not lead to a reliable result since after doing a crosstabulation of the original groups, we found only 7 patients in the Could Not Recall /quit smoking group.

\section{Discussion}

We found that our respondents who did report discussing smoking cessation during their LCS decision-making discussion had lower odds of successfully quit smoking at one year compared to those who could not recall or said no, although this was not statistically significant. Despite past literature finding otherwise, communication was not found to be associated with smoking cessation in people who currently smoke. We 
offer three plausible explanations for the unexpected finding. First, given that discussions of smoking cessation are required and encouraged by several organizations, it is likely that most (if not all) patients, even those who could not recall, did have a decisionmaking discussion to include talk of smoking cessation. In addition, most patients qualitatively report having smoking behaviors discussed by their clinicians within routine and LCS-related encounters (Golden et al. 2020). Thus, it is possible that the participants who could not recall or did not report having a discussion of smoking had differing cognitive abilities or baseline anxiety regarding lung cancer or LCS. Anxiety and distress, age, and perceived importance of medical information can all create recollection issues, but even without these factors, "memory for medical information is often poor and inaccurate" (Kessels 2003). Therefore, all patients who participated in our study may have subconsciously picked up on the importance of smoking cessation. Or more likely, patients may have focused more on the fact they were at high risk of lung cancer and realized that smoking cessation was the best way to reduce their chance of being diagnosed with lung cancer. Indeed, most patients in our study already realize that smoking causes lung cancer and want to make the decision to quit themselves (Golden et al. 2020), perhaps above and beyond communication during the LCS decision-making discussion. An interesting addition to the model would be self-efficacy scores. We did collect self-efficacy scores, however there were so many missing responses, it would have greatly diminished our sample size.

Second, study site location, which was significant in our analysis, can be seen as a proxy for socioeconomic status (SES). Our sites were chosen purposively to collect data 
from diverse socioeconomic and sociodemographic populations, as different sites may reflect different levels of SES of patients in general. Those with a lower SES are more often current smokers when compared to those with a higher SES (Marmot and Wilkinson 2006), and those with a higher SES tend to have more resources for trying to quit smoking. Since Duke University, for instance, may have more private-pay patients, their patients may be more likely to have more resources that are not captured by our SES variables (i.e. education, employment, and income). They may have access to other resources that may be helpful to quit smoking compared to patients at other sites, like possibly greater family support or other factors not captured here that may influence smoking status more than presence of communication. Additionally, those from lower a SES may have lower health literacy and may not be able to interpret the discussion about smoking behaviors as easily as those from a higher SES. Low health literacy, indeed, effects an estimated 36\% (80 million adults) of the US population (Kutner, Greenberg, and Baer 2006) and it disproportionately impacts people from socioeconomically disadvantaged groups (Mantwill, Monestel-Umana, and Schulz 2015; Hayward et al. 2000). Not only could SES differences in site lead to different levels of self-efficacy, but so could their proactive choice to join a cessation clinic. Indeed, SES can impact psychological and social factors like self-efficacy and willingness to quit and senses of control over their health behaviors.

Finally, study site location is also a proxy for willingness to quit smoking. Certainly, Duke University participants were recruited from a dedicated smoking cessation clinic and possibly felt more self-efficacy to be able to quit smoking. They 
proactively enrolled into smoking cessation counseling clinic where LCS was discussed within their smoking cessation clinician encounter. Participants at Duke, therefore, were likely more motivated to quit smoking and felt more selfefficacy compared to the other sites and these characteristics may explain the significance of the study site location variable in our analysis. Self-efficacy and sense of control can be influenced by many factors, so it is possible that future interventions may need to identify how underlying factors like SES or willingness to quit, impact them.

Moving forward, our finding should be interpreted with caution. Because active participation in health care, including effective communication between patients and clinicians, has many benefits, we should note that some patients may lack the necessary skills to ask relevant questions and to advocate for themselves and their health. It is possible our measurement of communication did not capture the importance of a dialogue between patients and clinicians. The measurement of communication did not ask about quality, patient-reported satisfaction, or rank the effect of the impact of the communication on their smoking behaviors. Clinicians also may lack necessary communication skills (D'Agostino et al. 2017). So even though clinicians may have discussed smoking with our patients, the discussions may not have incorporated all domains of patient-centered communication. All of the patient-centered communication domains are amenable to training though, (D'Agostino et al. 2017) and improvements in all domains lead to better health outcomes, like smoking cessation. For example, Lindson-Hawley and colleagues found that motivational interviewing is one form of communication that can lead to improved smoking cessation (2015). 
Communication strategies are critical factors in improving patient-centered outcomes for those with and at-risk of cancer (Epstein and Street 2007; IOM 2013). Indeed, "medical care is fundamentally a communicative enterprise in which clinicians [and] patients discuss a patient's health, decide on the best therapeutic action, and make plans [on] those decisions" (Street et al. 2009). While the LCS decision-making discussion itself may not influence smoking cessation, subsequent abnormal findings or diagnoses may prove to be a more beneficial time to talk about the importance of smoking cessation (Slatore et al. 2014). Communication in all encounters, however, remains imperative, especially since repeated encounter to include talk of smoking have been shown to have more impact on smoking behaviors (Bailey et al. 2018). More research should be done on how communication impacts health behaviors within the unique LCS decision-making discussion.

\section{Limitations}

The study does have limitations. First, while the inclusion of multiple sites increases the generalizability of the study, there remains a limitation due to the majority of the cohort being Veterans. Veterans are more likely to be male and Caucasian. However, our previous qualitative work among Veterans and non-Veterans has uncovered similar themes about deficits in patient-centered care (Golden et al. 2016). Second, this study suffers from reporting bias, in that those who participate may be more likely to report higher incidence or quality of communication. This may have impacted our findings to show a bias towards presence of communication. Future research in this area could benefit from audio or visual confirmation of communication about smoking 
occurring during the LCS decision-making discussion. The third limitation is selection bias. We found that patients unwilling to undergo the LDCT were also unwilling to participate in our research study, limiting our ability to document those who decline the LDCT. Participants agreeing to undergo the LDCT will likely have significant differences compared to participants who decline to undergo the LDCT and should be investigated further. Fourth, this study suffers from recall bias; it is possible that participants may not recall, or want to recall, certain items. Participants might say what they think the researchers want to hear, also called moderator acceptance bias. Timing may not capture overall feelings since each survey captures just one snapshot in time. Finally, I did not investigate specific mechanisms.

\section{Conclusion}

Our results indicate that the LCS decision-making discussion may not be the most influential moment to talk about smoking cessation. Although we did not find a significant association, even a null finding can be informative for future work. Indeed, future policies may not need to mandate communication about smoking during the LCS decision-making discussion. Also, future research can be informed about what should be included or not in subsequent analyses. While we did not investigate specific mechanisms, it remains imperative to first determine the association of perceived quality communication with a health outcome, which can serve as a foundation for future studies about proximal and intermediate outcomes. 
Figure 1. Patient-Centered Communication Model

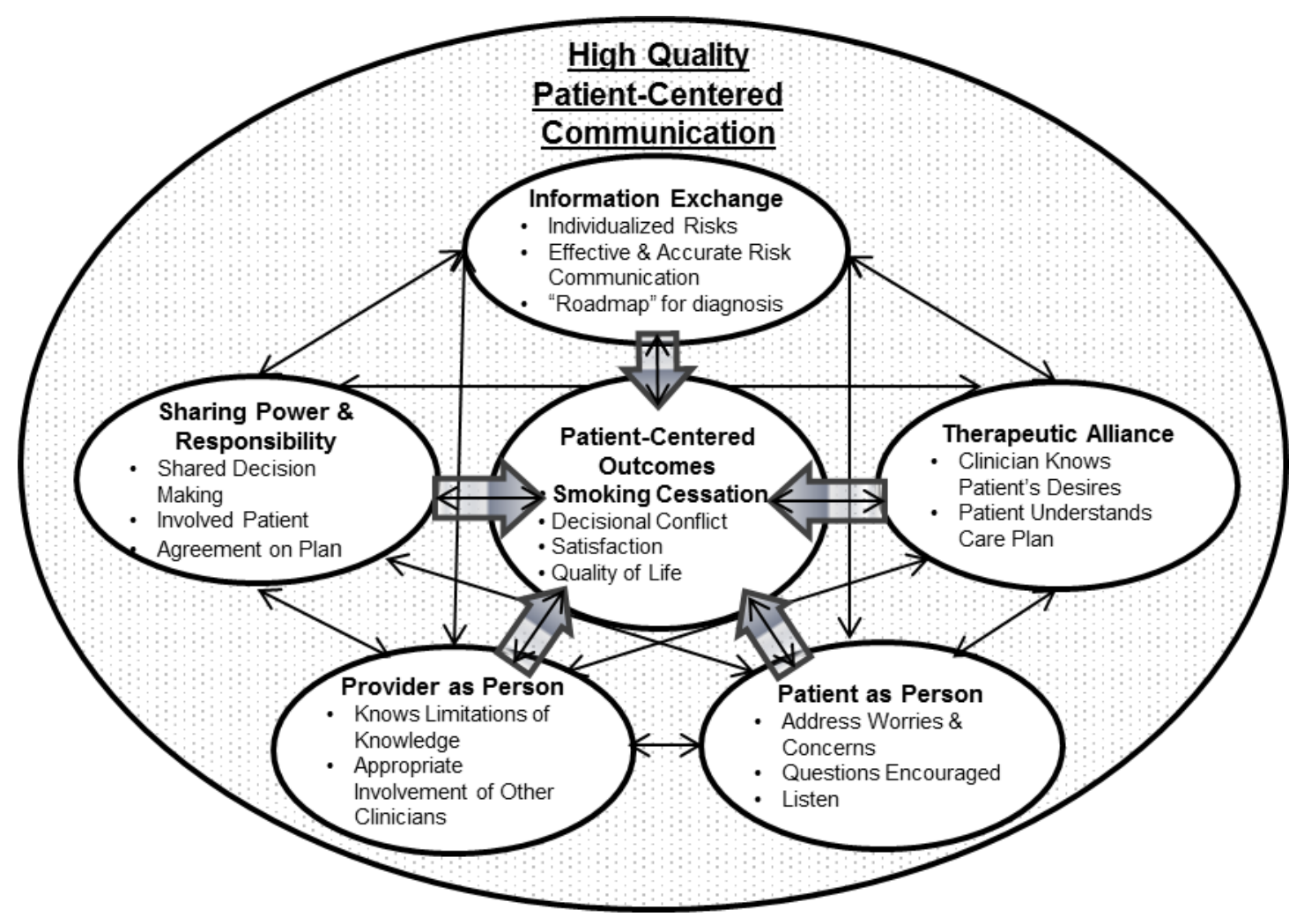




\begin{tabular}{|c|c|c|c|c|c|}
\hline & & $\begin{array}{l}\text { Quit } \\
\text { smoking }\end{array}$ & smoking & & \\
\hline Characteristic & $\begin{array}{l}\mathbf{N}(\%)^{*} \\
\text { Or Mean } \\
\text { (SD) }\end{array}$ & $\begin{array}{l}\mathbf{N}(\%) * \text { Or } \\
\text { Mean (SD) }\end{array}$ & $\begin{array}{l}\mathbf{N}(\%) * \text { Or } \\
\text { Mean (SD) }\end{array}$ & $\begin{array}{l}\text { p-value } \\
\text { from } \\
\text { chi-2 }\end{array}$ & $\begin{array}{l}\text { p-value } \\
\text { from t-test }\end{array}$ \\
\hline $\begin{array}{l}\text { Accepted lung cancer } \\
\text { screening LDCT }\end{array}$ & $127(94)$ & $25(100)$ & $102(93)$ & 0.38 & $\mathrm{n} / \mathrm{a}$ \\
\hline \multicolumn{6}{|l|}{ Education } \\
\hline High school or less & $50(37)$ & $12(48)$ & $38(35)$ & 0.42 & $\mathrm{n} / \mathrm{a}$ \\
\hline $\begin{array}{l}\text { Some college/vocational } \\
\text { work }\end{array}$ & $61(45)$ & $10(40)$ & $51(46)$ & & \\
\hline College graduate or more & $24(18)$ & $3(12)$ & $21(19)$ & & \\
\hline \multicolumn{6}{|l|}{ Employment status } \\
\hline $\begin{array}{l}\text { Not employed (retired, } \\
\text { unemployed, disabled) }\end{array}$ & $103(76)$ & $20(80)$ & $83(75)$ & 0.75 & $\mathrm{n} / \mathrm{a}$ \\
\hline $\begin{array}{l}\text { Employed (full time, part } \\
\text { time, and/or irregular work) }\end{array}$ & $30(22)$ & $5(20)$ & $25(23)$ & & \\
\hline Refused & $2(1)$ & $0(0)$ & $2(2)$ & & \\
\hline \multicolumn{6}{|l|}{ Income } \\
\hline$<\$ 19,999$ & $47(35)$ & $7(28)$ & $40(36)$ & 0.31 & $\mathrm{n} / \mathrm{a}$ \\
\hline$\$ 20,000-39,999$ & $29(21)$ & $3(12)$ & $26(24)$ & & \\
\hline$\$ 40,000-59,999$ & $34(25)$ & $10(40)$ & $24(22)$ & & \\
\hline$\$ 60,000-79,999$ & $14(10)$ & $2(8)$ & $12(11)$ & & \\
\hline$>\$ 80,000$ & $9(7)$ & $2(8)$ & $7(6)$ & & \\
\hline Refused/Don't Know & $2(1)$ & $1(4)$ & $1(1)$ & & \\
\hline \multicolumn{6}{|l|}{ Race/ethnicity } \\
\hline Non-Hispanic White & $114(84)$ & $24(96)$ & $90(82)$ & 0.08 & $\mathrm{n} / \mathrm{a}$ \\
\hline All Others & $21(16)$ & $1(4)$ & $20(18)$ & & \\
\hline \multicolumn{6}{|l|}{ Marital Status } \\
\hline Married & $56(41)$ & $15(60)$ & $41(37)$ & 0.11 & $\mathrm{n} / \mathrm{a}$ \\
\hline Divorced/Separated/Widowed & $67(50)$ & $9(36)$ & $58(53)$ & & \\
\hline Never Married & $12(9)$ & $1(4)$ & $11(10)$ & & \\
\hline \multicolumn{6}{|l|}{ Treatment location } \\
\hline $\begin{array}{l}\text { VA Portland Health Care } \\
\text { System }\end{array}$ & $57(42)$ & $5(20)$ & $52(47)$ & 0.04 & $\mathrm{n} / \mathrm{a}$ \\
\hline VA Minneapolis & $55(41)$ & $13(52)$ & $42(38)$ & & \\
\hline Duke University & $23(17)$ & $7(28)$ & $16(15)$ & & \\
\hline Age, in years (SD) & $64(5.7)$ & $66(5.3)$ & $64(5.8)$ & $\mathrm{n} / \mathrm{a}$ & 0.17 \\
\hline Male gender & $115(85)$ & $20(80)$ & $95(86)$ & 0.42 & $\mathrm{n} / \mathrm{a}$ \\
\hline Currently use e-cigarettes & $9(7)$ & $3(12)$ & $6(5)$ & 0.25 & $\mathrm{n} / \mathrm{a}$ \\
\hline Missing & $8(6)$ & $1(4)$ & $7(6)$ & & \\
\hline
\end{tabular}




\begin{tabular}{|l|c|c|c|c|c|}
\hline Average pack years (SD) & $49(23)$ & $57(25)$ & $47(23)$ & n/a & 0.09 \\
\hline Missing & 4 & 2 & 2 & & \\
\hline Cessation Discussed & & & & & \\
\hline Yes & $63(47)$ & $13(52)$ & $50(45)$ & 0.55 & $\mathrm{n} / \mathrm{a}$ \\
\hline No & $52(39)$ & $6(24)$ & $46(42)$ & & \\
\hline Could not Recall & $20(15)$ & $6(24)$ & $14(13)$ & & \\
\hline $\begin{array}{l}\text { Smoking at one-year follow- } \\
\text { up }\end{array}$ & $110(81)$ & $110(100)$ & n/a & n/a \\
\hline *Percents may not add up to 100\% due to rounding \\
\hline
\end{tabular}




\begin{tabular}{|l|l|l|}
\hline $\begin{array}{l}\text { Table 2. Odds Ratios for the Association of Patient-Clinician Communication about } \\
\text { Smoking Cessation and Cessation Outcomes }\end{array}$ & P Value \\
\hline Characteristic & $\begin{array}{l}\text { OR (95\% Confidence } \\
\text { Interval) }\end{array}$ & \\
\hline Cessation discussed & Reference \\
Yes & $1.18(0.43-3.19)$ & 0.74 \\
No/Could not Recall & Reference & \\
\hline Time to First Cigarette & $0.55(0.22-1.38)$ & 0.20 \\
Over 30 minutes & Reference & \\
Under 30 minutes & $3.08(1.00-9.46)$ & 0.05 \\
\hline Site & $4.94(1.21-20.12)$ & $\mathbf{0 . 0 3}$ \\
VA Portland & & \\
VA Minneapolis &
\end{tabular}




\section{References}

2008 PHS Guideline Update Panel, Liaisons, and Staff. 2008. "Treating Tobacco use and Dependence: 2008 Update U.S. Public Health Service Clinical Practice Guideline Executive Summary." Respiratory Care 53(9):1217-1222.

Bach, Peter B., Joshua N. Mirkin, Thomas K. Oliver, Christopher G. Azzoli, Donald A. Berry, Otis W. Brawley, Tim Byers, Graham A. Colditz, Michael K. Gould, James R. Jett, Anita L. Sabichi, Rebecca Smith-Bindman, Douglas E. Wood, Amir Qaseem and Frank C. Detterbeck. 2012. "Benefits and Harms of CT Screening for Lung Cancer: A Systematic Review." Jama 307(22):2418-2429.

Bailey, Steffani R., Victor J. Stevens, Stephen P. Fortmann, Stephen E. Kurtz, Mary A. McBurnie, Elisa Priest, Jon Puro, Leif I. Solberg, Rebecca Schweitzer, Andrew L. Masica and Brian Hazlehurst. 2018. "Long-Term Outcomes from Repeated Smoking Cessation Assistance in Routine Primary Care." Am J Health Promot:0890117118761886.

Bao, Y., N. Duan and S. A. Fox. 2006. "Is some Provider Advice on Smoking Cessation Better than no Advice? an Instrumental Variable Analysis of the 2001 National Health Interview Survey." Health Services Research 41(6):2114-2135.

Borrelli, B., J. P. Hecht, G. D. Papandonatos, K. M. Emmons, L. R. Tatewosian and D. B. Abrams. 2001. "Smoking-Cessation Counseling in the Home. Attitudes, Beliefs, and 
Behaviors of Home Healthcare Nurses." American Journal of Preventive Medicine 21(4):272-277.

Borrelli, B., C. Lee and S. Novak. 2008. "Is Provider Training Effective? Changes in Attitudes Towards Smoking Cessation Counseling and Counseling Behaviors of Home Health Care Nurses." Preventive Medicine 46(4):358-363.

D'Agostino, T. A., T. M. Atkinson, L. E. Latella, M. Rogers, D. Morrissey, A. P. DeRosa and P. A. Parker. 2017. "Promoting Patient Participation in Healthcare Interactions through Communication Skills Training: A Systematic Review." Patient Education and Counseling 100(7):1247-1257.

Epstein, RM and R. L. Street Jr. 2007. "Patient-Centered Communication in Cancer Care: Promoting Healing and Reducing Suffering." NIH Publication No. 07-6225.

Golden, S. E., S. S. Ono, A. Melzer, J. Davis, S. B. Zeliadt, J. L. Heffner, H. Kathuria, G. Garcia-Alexander and C. G. Slatore. 2020. "'I Already Know that Smoking Ain'T Good for Me": Patient and Clinician Perspectives on Lung Cancer Screening Decision-Making Discussions as a Teachable Moment." Chest 158(3):1250-1259.

Golden, S. E., C. R. Thomas Jr, M. E. Deffebach, M. S. Sukumar, P. H. Schipper, B. H. Tieu, A. Y. Kee, A. C. Tsen, C. G. Slatore and Early Stage Lung Cancer Comparative Effectiveness Research Consortium. 2016. "'Even if I Don'T Remember, I Feel Better". A Qualitative Study of Patients with Early-Stage Non- 
Small Cell Lung Cancer Undergoing Stereotactic Body Radiotherapy Or Surgery." Annals of the American Thoracic Society 13(8):1361-1369.

Hartmann, Katherine E. 2000. "Clear and Concise Interventions for Smoking Cessation." Hospital Physician (August):19-27.

Hayward, Mark D., Toni P. Miles, Eileen M. Crimmins and Yu Yang. 2000. "The Significance of Socioeconomic Status in Explaining the Racial Gap in Chronic Health Conditions." American Sociological Review 65(6):910-930.

Heatherton, T. F., L. T. Kozlowski, R. C. Frecker and K. O. Fagerström. 1991. "The Fagerström Test for Nicotine Dependence: A Revision of the Fagerström Tolerance Questionnaire." British Journal of Addiction 86(9):1119-1127.

Hollis, J. F., R. Bills, E. Whitlock, V. J. Stevens, J. Mullooly and E. Lichtenstein. 2000. "Implementing Tobacco Interventions in the Real World of Managed Care." Tobacco Control 9 Suppl 1:I18-24.

IOM (Institute of Medicine). 2013. "Delivering High-Quality Cancer Care: Charting a New Course for a System in Crisis.".

Jaklitsch, Michael T., Francine L. Jacobson, John H. M. Austin, John K. Field, James R. Jett, Shaf Keshavjee, Heber MacMahon, James L. Mulshine, Reginald F. Munden, Ravi Salgia, Gary M. Strauss, Scott J. Swanson, William D. Travis and David J. 
Sugarbaker. 2012. "The American Association for Thoracic Surgery Guidelines for Lung Cancer Screening using Low-Dose Computed Tomography Scans for Lung Cancer Survivors and Other High-Risk Groups." The Journal of Thoracic and Cardiovascular Surgery 144(1):33-38.

Jensen, Tamara S., Joseph Chin, Lori Ashby, Jamie Hermansen and Joseph D. Hutter. 2015. Decision Memo for Screening for Lung Cancer with Low Dose Computed Tomography (LDCT).

Joosten, E. A. G., L. DeFuentes-Merillas, G. H. de Weert, T. Sensky, der S. van and C. A. J. de Jong. 2008. "Systematic Review of the Effects of Shared Decision-Making on Patient Satisfaction, Treatment Adherence and Health Status." Psychotherapy and Psychosomatics 77(4):219-226.

Kathuria, H., E. Koppelman, B. Borrelli, C. G. Slatore, J. A. Clark, K. E. Lasser and R. S. Wiener. 2018. "Patient-Physician Discussions on Lung Cancer Screening: A Missed Teachable Moment to Promote Smoking Cessation." Nicotine \& Tobacco Research : Official Journal of the Society for Research on Nicotine and Tobacco.

Kessels, Roy P. C. 2003. "Patients' Memory for Medical Information." Journal of the Royal Society of Medicine 96(5):219-222. 
Kutner, Mark, Elizabeth Greenberg and Justin Baer. 2006. National assessment of adult literacy (NAAL): A first look at the literacy of America's adults in the 21st century.NCES.

Lancaster, T. and L. Stead. 2004. "Physician Advice for Smoking Cessation." The Cochrane Database of Systematic Reviews (4):CD000165. doi(4):CD000165.

Legare, F., R. Adekpedjou, D. Stacey, S. Turcotte, J. Kryworuchko, I. D. Graham, A. Lyddiatt, M. C. Politi, R. Thomson, G. Elwyn and N. Donner-Banzhoff. 2018. "Interventions for Increasing the use of Shared Decision Making by Healthcare Professionals." The Cochrane Database of Systematic Reviews 7:CD006732.

Lindson-Hawley, N., T. P. Thompson and R. Begh. 2015. "Motivational Interviewing for Smoking Cessation." The Cochrane Database of Systematic Reviews (3):CD006936. doi(3):CD006936.

Mantwill, S., S. Monestel-Umaña and P. J. Schulz. 2015. "The Relationship between Health Literacy and Health Disparities: A Systematic Review." PloS One 10(12):e0145455.

Marmot, Michael and Richard G. Wilkinson. 2006. Social Determinants of Health.Oxford, UK: Oxford University Press. 
Mead, Nicola and Peter Bower. 2000. "Patient-Centredness: A Conceptual Framework and Review of the Empirical Literature." Social Science \& Medicine 51(7):10871110.

Melzer, A. C., S. E. Golden, S. S. Ono, S. Datta, K. Crothers and C. G. Slatore. 2019. "What Exactly is Shared Decision-Making? A Qualitative Study of Shared DecisionMaking in Lung Cancer Screening." Journal of General Internal Medicine.

Miranda, L. S., S. Datta, A. C. Melzer, R. S. Wiener, J. M. Davis, B. C. Tong, S. E. Golden and C. G. Slatore. 2017. "Rationale and Design of the Lung Cancer Screening Implementation. Evaluation of Patient-Centered Care Study." Annals of the American Thoracic Society 14(10):1581-1590.

Moyer, Virginia A. 2014. "Screening for Lung Cancer: U.S. Preventive Services Task Force Recommendation Statement." Annals of Internal Medicine 160(5):330-338.

National Comprehensive, Cancer N. 2012. National comprehensive cancer network: Nccn guidelines on lung cancer screening.

Simpson, Michael, Robert Buckman, Moira Stewart, Peter Maguire, Mack Lipkin, Dennis Novack and James Till. 1991. "Doctor-Patient Communication: The Toronto Consensus Statement." BMJ: British Medical Journal 303(6814):1385. 
Slatore, Christopher,G., Christina Baumann, Miranda Pappas and Linda L. Humphrey. 2014. "Smoking Behaviors among Patients Receiving Computed Tomography for Lung Cancer Screening. Systematic Review in Support of the U.S. Preventive Services Task Force." Annals of the American Thoracic Society 11(4):619-627.

Street, Richard L., Gregory Makoul, Neeraj K. Arora and Ronald M. Epstein. 2009. "How does Communication Heal? Pathways Linking Clinicianâ€"patient Communication to Health Outcomes." Patient Education and Counseling 74(3):295301.

U.S. Preventive Services Task Force. 2017. Final Recommendation Statement: Tobacco Smoking Cessation in Adults, Including Pregnant Women: Behavioral and Pharmacotherapy Interventions. Rockville, MD: USPSTF Program Office.

Velicer, W. F. and J. O. Prochaska. 2004. "A Comparison of Four Self-Report Smoking Cessation Outcome Measures." Addictive Behaviors 29(1):51-60.

Weiland, Anne, de K. Van, Annette H. Blankenstein, Van Saase, Jan L. C. M., der M. Van, Wichor M. Bramer, Alexandra M. Van Dulmen and Lidia R. Arends. 2012. "Encounters between Medical Specialists and Patients with Medically Unexplained Physical Symptoms; Influences of Communication on Patient Outcomes and use of Health Care: A Literature Overview." Perspectives on Medical Education 1(4):192206. 


\section{Chapter 4. Patient and Clinician Perspectives on Lung Cancer Screening Decision- Making Discussions and Smoking Cessation}

A version of this paper has been published: Golden, S.E., S.S. Ono, A. Melzer, J. Davis,

S.B. Zeliadt, J.L. Heffner, H. Kathuria, G. Garcia-Alexander and C.G. Slatore. 2020.

""I Already Know that Smoking Ain't Good for Me": Patient and Clinician

Perspectives on Lung Cancer Screening Decision-Making Discussions as a Teachable Moment." Chest 158(3):1250-1259. 


\section{Abstract}

The importance of communication using a specific strategy recommended by the U.S. Preventive Services Task Force, the 5A's (Ask, Advise, Assess, Assist, Arrange), in addition to the psychosocial resource of self-efficacy, are widely discussed in smoking cessation literature. However, the use of the 5A's and the importance of self-efficacy is less well-understood in the context of lung cancer screening (LCS). We use the LCS decision-making discussion to examine these concepts and their relation to smoking cessation. We used in-depth interviews focused on how patients and clinicians communicate about smoking and performed a qualitative evaluation of the experiences of 51 former or current smokers and 24 clinicians.

Patients and clinicians agreed that communicating about smoking cessation is an important aspect of care, especially through use of the 5A's. Clinicians viewed the LCS decision-making discussion as an opportunity to offer support and enhance the likelihood of cessation and commonly indicated efforts to minimize patient distress. Further, all reported regular use of the first three A's (Ask, Advise, Assist) and considered the LCS decision-making discussion a unique opportunity to do so. Comparatively, patients appreciated these discussions in the LCS context but felt the decision to pursue cessation was unrelated to the decision-making discussion. Both groups agreed that the decisionmaking discussion was less important than a patient's sense of readiness and selfefficacy. Nonetheless, our findings suggest the use of the $5 \mathrm{~A}$ 's is concordant with the patient's perceptions of quality patient-clinician communication, which has the potential 
to improve trust and self-efficacy. While the LCS decision-making discussion is perceived as less impactful than other motivations with respect to cessation, it represents a key avenue through which to aid a major behavior change like smoking cessation. The potential of the decision-making discussion to improve smoking outcomes should receive continued investigation. 


\section{Introduction}

\section{Lung Cancer Screening}

Smoking is the number one preventable cause of death and disease in the United States (US) (Centers for Disease Control and Prevention 2018) and is linked to 80-90\% of all lung cancers. Lung cancer has the highest cancer mortality rate in America (Siegel, Miller, and Jemal 2016). Lung cancer screening (LCS) using annual low-dose computed tomography (LDCT) reduces the relative risk of lung cancer mortality by $20 \%$. LCSis now recommended for high-risk smokers by several organizations such as the US Preventive Services Task Force (USPSTF) (Moyer 2014), the American Cancer Society (Wender et al. 2013), and others (National Comprehensive Cancer Network 2012; Bach et al. 2012; Jaklitsch et al. 2012; Samet et al. 2012).

The Centers for Medicare and Medicaid Services (CMS) agreed to include LCS as a reimbursable service in 2015 (Jensen et al. 2015), though this came with several stipulations and suggestions (Jensen et al. 2015; Mazzone 2018; Wiener 2015). CMS mandated a shared decision-making discussion using a decision aid to help patients decide whether to receive the LDCT or not. A qualified practitioner must also communicate about smoking abstinence and offer cessation services to active smoker within the decision-making discussion. To date, no guidelines have been developed as to what qualifies as shared decision-making for LCS or how to provide this discussion appropriately to patients, especially regarding smoking cessation counseling. Formally, our research question herein is: How do patients and clinicians communicate about smoking within an LCS decision-making discussion? We aim to provide clarity about the 
use of a communication technique to provide smoking cessation counseling, the 5A's, in addition to the role of self-efficacy, and motivations for cessation, within the LCS decision-making discussion.

\section{Routine Discussion of Smoking Cessation using the 5A's}

Patient-clinician communication is a key component of high quality health care that can improve outcomes such as smoking cessation (IOM (Institute of Medicine) 2013; Mead and Bower 2000; Simpson et al. 1991; Weiland et al. 2012). The USPSTF specifically recommends use of the 5A's (Ask, Advise, Assess, Assist, and Arrange) during every clinical visit with a patient as part of quality communication for smoking cessation that has been shown to improve outcomes (USPSTF; Fiore 2008). "Ask" refers to identifying a patient's smoking status; "Advise" refers to encouraging cessation in a “clear, strong, and personalized manner"; "Assess" refers to determining the patient's willingness to quit; "Assist" refers to offering tailored smoking cessation strategies, such as referrals to counseling or pharmacotherapy, or other resources; and "Arrange" refers to scheduling follow-up to assess treatment outcomes and provide ongoing care (Agency for Health Research and Quality 2012). The US Department of Veterans Affairs (VA) and other medical systems have adopted use of the 5A's via guidelines put forth by the US Public Health Service (VA/DoD EBP 2013). It is recommended that clinicians use the 5A's at every clinical encounter. A clinical encounter in which LCS is discussed is a natural opportunity to perform the 5A's. Few studies have evaluated use and effectiveness of the 5A's in routine care settings or across both federal and community 
sites. It is unknown if or how this strategy is used within the context of LCS decisionmaking discussions, despite the mandate for discussions of smoking cessation. Self-efficacy

In addition to communication using the 5A's, one's personal feeling of selfefficacy has the potential to improve rates of cessation. Self-efficacyis conceptualized as the internal sense of personal control someone has to produce desired effects by their actions. Further, self-efficacy has been shown to contribute to health and well-being (Bandura 1997; Link and Phelan 2000), and sociologists have established that this concept has a direct link to smoking cessation (Brod and Hall 1984; DiClemente 1981; Nicki, Remington, and MacDonald 1984; Prochaska and DiClemente 1984; Strecher et al. 1985). For example, Gorini and colleagues found that workers with lower reported levels of self-efficacy in smoking cessation were less likely to report 6 months of continued smoking abstinence (Gorini et al. 2018). A meta-analysis showed that selfefficacy has a well-correlated relationship with smoking cessation as well as future abstinence; in other words, rates of cessation and continued abstinence are improved among those reporting higher levels of self-efficacy (Gwaltney et al. 2009).

Similarly, high quality patient-clinician communication, as in use of the 5A's, has been shown to lead to higher patient self-efficacy. When people receive positive communication they may prioritize health behaviors (Dornbusch, Herman, and Morley 1996) to try and make positive behavioral changes (like quitting smoking), largely through impacts on self-esteem and self-efficacy. Thoits (2011) and others (Cohen and McKay 1984; Weiss 1974) have noted that positive feedback can aid in coping behaviors 
and subsequently increase self-efficacy and motivation for health behavioral change. It may be that discussions of LCS provide positive feedback and encouragement about smoking cessation framed as being able to change the behavior "before it's too late." Importantly, patient-clinician LCS decision-making discussions can be shaped by the patient and the clinician (Lawson 2009). Patients may interpret positive communication as encouragement, which boosts feelings of self-efficacy, possibly leading to a greater chance at successful smoking cessation. But the clinician perspective is also essential. Clinicians can gauge a patient's personal feelings of self-efficacy to use as a motivator for cessation, or to add in positive behavioral change. However, previous qualitative studies showed that patients' misunderstanding about LCS and smoking cessation are associated with continued smoking behaviors (Zeliadt 2015; Kathuria 2018); or that discussions of LCS may cause patients to have lower motivations to quit smoking (Zeliadt 2015). Accordingly, it is necessary to investigate both the perceived importance of LCS decision-making discussions to improve rates of smoking cessation.

\section{Individual Characteristics for the LCS-Eligible Population}

According to CMS reimbursement schedules, patients who are eligible for LCS are those with a significant smoking history (e.g. >30 pack-years) and are middle-aged or elderly adults. Active smokers in this cohort are often classified as "hardened" smokers ${ }^{1}$ who are "less likely to be influenced by cessation measures" (Ney et al. 1989). Hardened smokers often have no intention to quit or find it very difficult to quit (Docherty and

\footnotetext{
${ }^{1}$ The authors acknowledge the pejorative nature of the term "hardened" smokers. However previous and current literature utilizes this term and we found no more appropriate term to use.
} 
McNeill 2012). Hardened smokers are also more likely to come from disadvantaged backgrounds (Lund, Lund, and Kvaavik 2011), which is an independent risk factor for inability to abstain from smoking (Jarvis 2006 in Marmot; Tsai 2011; Smith 2015; USDHHS 1990). Despite the difficulties with smoking cessation, hardened smokers are an important population to target because it is never too late to quit smoking (Maryland Resource Center for Quitting Use \& Initiation of Tobacco) and they need the most assistance. Despite knowing the importance of cessation, hardened smokers are often unable or unwilling to quit (Warner 2003). We know less about effective cessation strategies because they do not frequently enroll in trials (Zbikowski 2012) or because they are excluded from trials due to comorbidities (Docherty 2012). These omissions make knowledge about how to help them quit important to understand. To this end, we wanted to examine how hardened smokers and clinicians communicate about smoking in the context of an LCS decision-making discussion.

\section{Methods}

We evaluated qualitative data on the experiences of former or current hardened smokers who underwent LCS decision-making discussions and clinicians (primary care clinicians, pulmonologists, or LCS nurse, physician assistant, or advanced practice nurse coordinators) from three medical centers in the US with established LCS programs: VA Portland Health Care System (VAPORHCS), Portland, OR; Minneapolis VA Medical Center, Minneapolis, MN; and Duke University Medical Center, Durham, NC. We strategically chose these sites to include participants with demographic diversity across racial, ethnic, and urban/rural domains. We conducted interviews between April 2016 and 
November 2017. All participants completed the informed consent process either by phone or in-person before the first interview using IRB-approved documents. The study was IRB-approved at each participating site (VAPORHCS \#3482; Minneapolis VA \#4645-B; Duke \#Pro00073394).

Patient Sample

We enrolled 51 patients who were eligible for LCS based on research referrals from clinicians, who verified clinical criteria not further confirmed by the research team. We used purposive recruitment for qualitative interviews to oversample minorities. We limited enrollment to patients who were eligible for LCS based on their local institution's criteria, which were similar to USPSTF eligibility criteria (Miranda 2017). We limited enrollees to English speakers, either as a primary or secondary language. We included patients regardless of whether they agreed or declined to undergo the LDCT scan (herein, 'LCS' refers to the process of screening while 'LDCT' refers to the scan itself).

\section{Clinician Sample}

We recruited 24 clinicians based on identification by the local site PIs as being involved in the LCS decision-making process. We initially recruited clinicians via an emailed invitation letter. We conducted one-time, semi-structured, in-depth qualitative interviews.

\section{Data Collection}

We conducted in-person and telephone interviews using a semi-structured interview guide that included many questions about communication in general, as well as questions focused on communication about smoking (Appendix E). The interview guides 
allowed for other themes, additional information, and follow-up questions to emerge. The qualitative analyst (SEG) conducted all interviews in a private space. The principle investigator was a pulmonologist involved in offering and directing LCS at one of the sites as well as in assisting with smoking cessation, so we had two impartial investigators (SEG and SSO) lead the interview and analytic process to mitigate bias. We digitally recorded and transcribed the interviews, removing identifiers during transcription. Participants are identified by a letter "P" followed by randomly assigned letters or "C" followed by randomly assigned numbers not related to name or treating hospital system for patients and clinicians respectively. Individual participants are referred to as "she/her" to protect anonymity. Per our original research question aimed at focusing on communication practices, we achieved saturation of two main themes (Patton 2002; Pope et al. 2006): Role of the 5A's in Quality of Communication; Role of Self-efficacy and Motivators in Smoking Cessation. Participants self-reported demographic (patients and clinicians) and smoking characteristics (patients only) prior to the first interview. Analysis

We used ATLAS.ti 7.1.7 (ATLAS.ti GmbH, Berlin, Germany) to organize and support conventional content analysis of the qualitative data. We identified codes previously as key concepts based on the interview guide and developed other codes as we identified themes in the data. Throughout the analytic process, we evaluated any overlapping coding or un-coded text to verify appropriateness. We developed initial and integrative memos throughout to capture thoughts or analytic ideas, which aided in the final interpretation of the data through identifying patterns and variations in the 
transcripts. We also utilized an audit trail for tracking of modifications and decisions related to the codebook and qualitative analysis.

\section{Results}

\section{Participant Characteristics}

We interviewed 51 patients and 24 clinicians. At baseline, 33 patients were currently smoking, 18 were former smokers (one had quit within the last month). Fortythree patients accepted the LDCT, 6 declined, and 2 were undecided at the baseline interview. Over half of patients were from VA sites, however, we did not find substantially different responses from subjects across the three study site locations apart from patients at Duke enrolled in a specialized smoking cessation clinic, as discussed above. Clinician distribution was equal between study site locations and we did not find substantially different responses between sites for clinicians. We did not note any discernible patterns based on demographics. The average age of our patient sample was 63 years, with mostly white (83\%), and male-identified (76\%) participants (Table 1). Clinician participants were an average age of 42 years, $75 \%$ white, and $33 \%$ identified as male. Most were primary care providers (PCPs) (42\%) (Table 2).

Below we organize our results under the following themes 1) Role of the 5A's in Quality of Communication; 2) Role of Self-efficacy in Smoking Cessation and Motivation in Cessation. We first introduce the theme, then report findings for patients and, subsequently, clinicians.

\section{Theme 1: Role of the 5A's in Quality of Communication}


We first report how patients and clinicians communicate about smoking, specifically using the recommended $5 \mathrm{~A}$ framework.

\section{Patients}

Patients reported that at all clinical visits, even those prior to the LCS decisionmaking discussion, they were Asked about smoking "gently" and respectfully Advised to quit, but only sometimes Assessed for their readiness (the first three of the 5A's). Patients reported they understand it is the clinician's job to discuss smoking abstinence at each visit, no matter the indication for the visit, saying: It's just part of the deal. (P-XX). Patients indicated this was an expected conversation as part of a quality clinical encounter. The majority of patients reported that the clinician Asking, Advising, and Assessing did not influence their desire to quit or abstain from smoking, either positively or negatively.

Despite reporting that the LCS decision-making discussion did not necessarily influence their desire to quit smoking compared to discussions at other clinical visits, most did agree that it was a convenient and understandable time for the clinician to address smoking since the discussion included mention of lung cancer. All patients reported the LDCT was not an appropriate substitute for cessation, even without clear Advising, Assessing, or Assisting. Importantly, all patients reported that they viewed LCS and smoking as two separate decisions (i.e., to undergo screening vs. to quit smoking). Patients emphasized that patients needed to feel ready to quit smoking before pursuing cessation. 
...these CT scans are just going to give a baseline... If you want to keep smoking, keep smoking. $(P-B)$

I am always concerned about [my smoking] so [the LCS discussion] has not affected [my smoking] anymore. $(\mathrm{P}-\mathrm{HH})$

Me deciding that I needed to quit smoking had nothing to do with [the discussion or LDCT]. (P-J)

\section{Clinicians}

Clinicians varied in their use of the 5A's during these clinical encounters. For example, some capitalized on the LCS decision-making discussion not only as an additional means through which to broach the conversation but also to mitigate potentially negative feelings associated with being Asked about smoking: I know you're not ready to talk about [cessation] now, but I'm just warning you I'm gonna bring it up every single time you come in. So you know, just don't get upset with me, it's part of being a doctor and I need to bring this up and point it out (C-15). In this way, the 5A's may offer a usable framework through which uncomfortable topics may be approached with patients.

Others were more focused on the LCS decision-making discussion as an opportunity to Assess readiness to quit: [LCS] provides an opportunity to discuss the cessation. And figure out where people are on their journey toward smoking cessation. $(C-3)$ 
I strongly think that [LCS] should be used as a jumping off board for smoking

interventions. Not, again, necessarily because it's a magical time to talk to people about smoking, but just because you've corralled a bunch of smokers. (C-22)

Eighteen clinicians described using at least parts of the 5A framework all the time. About half of clinicians interviewed reported explicitly Assessing patients for their readiness to quit. The other half did not mention whether they Assessed or not. All clinicians related that including the 5A's in discussions with current smokers was important and most felt the LCS decision-making discussion could be used as an opportunity to discuss smoking. Barriers to this discussion, however, were time for the encounter and issues related to perceived patient self-efficacy and readiness to quit. If clinicians did not feel a patient was ready to quit, they did not want to "push" them or make them feel ashamed for the inability to quit. No patients were provided information or Advised about their actual risk. For patients who reported a desire to quit, clinicians offered to Assist and Arrange resources, and ensured those patients not ready to quit were aware that there were future opportunities for cessation resources. Clinicians reported more variable use of Assisting and Arranging since these components related heavily to the patient's sense of self-efficacy.

Almost all clinicians agreed with the belief that the process of discussing or undergoing the LDCT would not positively or negatively influence patients' motivation for abstinence. For example: I wish I could say that paired with offering CT scans, that motivates people [to quit smoking], but I can't say that's a motivating factor. (C-16) Clinicians did not report reframing the LDCT as a positive motivator for change. They 
did discuss potential LDCT findings as motivators for quitting, with most agreeing that a pulmonary nodule finding would likely positively influence abstinence, however, there were several who disagreed: [Patients] don't perceive [a nodule finding] as a very sentinel event in their lives and a wake-up call to quit smoking... because we kind of minimize the impact. $(C-12)$ There was often discussion of the balance between alarming a patient with results to motivate them to quit or abstain from smoking and providing accurate information about the risk of lung cancer based on the results. Some clinicians said motivation to quit seemed to depend on if the results were presented as suspicious or likely benign. Some acknowledged they were surprised the discussion of lung cancer risk during prior visits with other patients did not affect smoking change in patients as much as they would have thought: Risk doesn't mean a lot... it's a concept, it's not an actual disease that hits home for a lot of people. (C-17

\section{Theme 2: Role of Self-efficacy and Motivators for Smoking Cessation}

We next report on the role of self-efficacy in smoking cessation and on how patients and clinicians describe which individual circumstances actually influence their smoking behaviors.

\section{Patients}

No patients indicated their clinician connected LCS and smoking in a way that influenced their desire to quit. The majority of patients felt it was likely helpful for some patients to have smoking mentioned (at least Asked about) at each visit—just not for them. If patients were not ready to quit, they felt confident they could obtain resources when necessary - that is, they did not desire additional help with Assist at that time. 
Patient responses commonly indicated that readiness and desire to quit were of paramount importance with respect to smoking cessation:

[LCS] don't give me no green light to continue to smoke. Some people would think of it as a green light to continue to smoke, but I'm wanting to quit because I'd like to live a little bit longer. $(P-I I)$

So [bariatric surgery] was the initial motivator, but quite frankly the motivation was the reason for the surgery. ... I need a better quality of life. And I can only get that through better health. I'm a late learner. (P-CC)

Similar to clinicians, most patients indicated that lung cancer risk was not a primary motivator for smoking cessation and that hearing they were eligible for LCS, because of their smoking status and age, did not cause distress. Only two of the 32 current smokers indicated that talking about their lung cancer risk positively influenced the desire to quit smoking since everyone had been aware for years that they are at a higher risk of lung cancer due to smoking:

So, it's like, well, somebody could tell me, "Smoking is not good for you. Blah. Blah. Blah." Well you already know that, so it's like, “OK." It goes in one ear and out the other because I already know that smoking ain't good for me. (P-PP)

It's not gonna sway me. They're told to [bring up smoking]. I mean, yeah, everybody knows smoking is bad for you. (P-L) 
Notably, when asked, most patients largely overestimated their actual risk of lung cancer but indicated that even this high risk did not cause much distress or prompt behavior change.

Patients reported other motivations for quitting that largely did not seem to be discussed in clinician encounters. Examples of motivations were family encouragement: ... [my] 11-year old grandson. He rides me pretty hard. $(P-D)$ They also mentioned the financial cost of smoking: I think about the thousands of dollars I spent on cigarettes and

I've been buying my girlfriend cigarettes now too for 5 years. So, yeah, it's all pretty sick. $(P-Y)$ And many mentioned the impact on their overall health and quality of life: Just the physical of it. Getting away from being in the middle of something and stopping this to go have a cigarette. Get rid of all that. $(P-J J)$ As you get older, you've got to put things in perspective! Like you know, 10 more good years of having a good mind, not having a stroke, being able to walk, being able to go on vacations. 10 years and I might not be able to do that if I don't stop smoking! (P-P)

Patient-identified barriers mainly included: a difficult habit/addiction to break, smoking relieves anxiety or stress, lack of desire to commit to cessation, and the act of smoking is enjoyable. Despite these barriers, patients appreciated that their clinicians cared enough to discuss smoking since they knew it put them at a higher risk of developing lung cancer.

\section{Clinicians}

Clinicians did not report communicating about the LDCT as a positive motivator for change, but most said the encounter was a good opportunity for discussion since you 
have the patient in the office. Six of the 24 clinicians reported the LCS decision-making discussion was a unique time to talk about smoking because it elicited a different reaction from the patient regarding increasing their desire to quit smoking compared to other patient visits: I think it is a unique time. I think it does make them hyper-aware that maybe [smoking cessation] is something they should start thinking about. (C-5)

Some acknowledged they were surprised the discussion of lung cancer risk during prior visits with other patients did not affect smoking change in patients as much as they would have thought. To that end, they did not use lung cancer risk as a motivator or discussion point. Most clinicians did not link the risk of lung cancer to smoking cessation for fear of making patients feel ashamed or pressured, or because they realized patients already knew they were at some risk of lung cancer. These clinicians also reported they often did not feel comfortable Advising specific risk values for the patient's likelihood of developing lung cancer: I just usually say increased risk... I don't use numbers with my patients. (C-25)

Clinicians discussed potential barriers to quitting with the most common being: stress, habit, and it's just "too hard to quit": Most of the time it's a habit that they've had for years... we can give them medication to help with the withdrawal and the urges, and I try to work with them with behavioral therapy and replacing those behaviors, but [the habit] is the biggest barrier. (C-8) Several described the difficulty in quitting and how many patients give up after trying to quit multiple times, which may make patients less likely to be motivated by an LCS decision-making discussion: I think a lot of them have sort of given up. (C-20) 
[Smoking] rapidly becomes not a choice. Obviously... the powerful addiction of components are worse than cocaine. (C-24)

\section{Discussion}

Similar to previous research (Slatore 2014, Zeliadt 2015, Kathuria 2018), we found that LCS decision-making discussions are unlikely to influence smoking behavior. Patients and clinicians reported that clinicians mostly adhered to the 5A framework for cessation counseling, and that self-efficacy was important through evidence of always Assessing before Assisting. The groups diverged on their evaluation of the relative importance of using the 5A's at every encounter with a patient, with clinicians feeling it to be more imperative as a form of quality communication. Importantly, while we observed some gap in views on the importance of the clinical encounter in the cessation process, we learned that patients felt there are more meaningful factors related to smoking cessation. Patients mentioned personal reasons like finances or family as reasons to quit smoking rather than the risks of lung cancer or other health problems. These factors seem to not be currently leveraged by current clinician communication practices to motivate positive behavioral change.

Based on two previous qualitative studies (Zeliadt 2015; Kathuria 2018), we were interested in whether patients' misconceptions about LCS and smoking cessation would be associated with static or negative smoking behaviors. We directly asked participants about their thoughts on this. In particular, one study reported that discussions of LCS may cause patients to have lower motivations to quit smoking (Zeliadt 2015). This finding is opposite from the expected and desired outcome. Fortunately, and despite the belief their 
actual risk of lung cancer is higher than in reality, the patients in our study emphatically, and sometimes even derisively, reported they would not negatively change their smoking behaviors. Patients did not consider the LDCT to be a "green light" to continue to smoke. Overall, we found that patients were not positively or negatively motivated to change their smoking behavior based on the LCS decision-making discussion that included more direct mention of lung cancer risk (usually in general terms) compared to other clinical visits, suggesting that the LCS decision-making discussion is not harmful.

Based on clinicians' descriptions and patients' reports of their conversations, clinicians did appear to use most of the 5A framework, although patients reported the Assist and Arrange steps should only be utilized when the patient indicated a desire to quit. Clinicians seemed to believe the use of the 5A's were more important than patients. This could be due to clinicians being more aware of the evidence behind use of the 5A's. In contrast to patient beliefs, clinicians placed more emphasis on discussing smoking cessation during the LCS decision-making discussion. They felt it was a beneficial time to communicate about the importance of cessation, whereas patients did not see a difference compared to other encounters.

Despite the patient view of the discussion as comparatively less important than clinicians, communication about cessation may still serve to improve self-efficacy and trust, which has the potential to improve health behaviors. Indeed, self-efficacy is influenced by communication and self-efficacy influences all aspects of behavior, not only ceasing negative behaviors (Strecher 1986). If improved communication can lead to improved self-efficacy it may be that patients will undergo other positive health behavior 
changes besides smoking, like maybe improved diet changes or decreased risky sexual activity. Clinicians can also act upon self-efficacy through other ways beyond communication, such as increasing self-esteem, anxiety, or depression. Therefore, addressing these types of psychosocial factors may help to increase self-efficacy within a clinical visit, possibly while communicating effectively about smoking. Importance of self-efficacy is illustrated through patient responses that often implied their feelings of readiness were most likely to produce behavioral change. Clinicians acknowledged this importance as well, but still thought the 5A's were an appropriate technique for communicating about smoking cessation.

There may be other ways to frame the discussion with patients. For instance, Assessing patients for their readiness to quit is essential to gauge their levels of selfefficacy. Importantly, when patients felt they were not ready to quit, they all reported enough self-efficacy that they could obtain assistance when needed, but clinicians still must ensure that patients realize they will be Assisted when they desire. Additionally, instead of concentrating on lung cancer risk as a motivator for cessation, Advising might incorporate discussion of risk for other smoking-related diseases, improvements to quality and duration of life, financial or family related concerns, or subsequent increases in negative emotional responses. Patients already knew that they were at high risk of lung cancer - it was not new information.

Clinicians were surprised that discussion of lung cancer risk did not affect patients smoking as much as expected, perhaps due to optimistic bias. For instance, if the risk of lung cancer is less than expected, patients may feel a lesser risk compared to others, 
which might decrease distress and increase reassurance. Patients did not recall specific lung cancer risk estimates, but the elevated risk of lung cancer was already acknowledged by these patients. Typically, patients dramatically overestimated their risk. So, increasing awareness of the personalized risks of other smoking-related diseases may be helpful, and this type of information has been shown to lead to improved smoking behaviors in other settings (Weinstein 1998; Baranowski et al. 1997; Kaminsky 2011). However, it may also result in the opposite effect. Emphasizing smoking cessation may also decrease the patient's recollection of LCS-related information, as shown in the patients from Duke, leading to no effect on smoking behaviors. Our findings also suggest clinicians do not consider a discussion of the patient's risk of cancer or other negative outcomes to be a required component of Advise. Accordingly, this presents an opportunity for continued investigation into how the 5A's may be used to maximize communication and whether a discussion of risk is needed.

\section{Limitations}

There are several limitations of this study. While the inclusion of multiple sites increases the generalizability of the study, most of the cohort were Veterans. We oversampled for minorities and women to address this limitation. This limitation may also be mitigated because non-Veteran smokers who are eligible for LCS likely have similar disadvantaged socioeconomic characteristics as Veterans (Kinsinger 2017; Aberle 2011). We found that many patients who declined to receive an LDCT were also unwilling to participate in our research study, limiting our ability to evaluate those who decline screening. However, we still reached saturation of the main themes. This study 
may suffer from selection bias. Duke University patient participants self-selected to enroll in a cessation program and therefore were likely more motivated to quit even prior to discussing LCS. This study also suffers from moderator acceptance and recall biases. Timing of data collection may not capture all feelings and attitudes since each survey and interview captures just one snapshot in time; however, the longitudinal design of this study is intended to help compensate for this limitation. Follow-up interviews are ongoing, and findings will be subsequently published.

\section{Conclusion}

Our findings indicate that clinicians and patients differ on their view of lung cancer screening discussions as an opportunity to communicate about smoking cessation. The patient's internal readiness to change and self-efficacy were agreed upon as more important for a large behavior change like quitting smoking rather than emphasizing lung cancer screening. Through continued utilization of the 5A's, clinicians can improve communication and thereby potentially increase trust and patient self-efficacy, which may be especially important in hardened smokers. 


\begin{tabular}{|c|c|}
\hline Characteristic & $\mathbf{N}(\%)^{*}$ Or Mean (SD) \\
\hline Accepted LDCT & $43(84 \%)$ \\
\hline $\begin{array}{l}\text { Treatment location } \\
\text { VA Portland Health Care System } \\
\text { VA Minneapolis } \\
\text { Duke University }\end{array}$ & $\begin{array}{l}19(39 \%) \\
18(35 \%) \\
14(26 \%)\end{array}$ \\
\hline $\begin{array}{l}\text { Days after SDM (interview) } \\
\text { VA Portland Health Care System } \\
\text { VA Minneapolis } \\
\text { Duke University }\end{array}$ & $\begin{array}{c}20.4(16.6) \\
75.7(60.6) \\
10.3(4.9)\end{array}$ \\
\hline Age (yr.) & $63(5.83)$ \\
\hline $\begin{array}{r}\text { Gender } \\
\text { Male }\end{array}$ & $39(76 \%)$ \\
\hline $\begin{array}{l}\text { Race/ethnicity, n (\%) } \\
\text { White } \\
\text { Black/African American } \\
\text { Hispanic } \\
\text { Refused } \\
\end{array}$ & $\begin{array}{l}41(80 \%) \\
6(12 \%) \\
2(4 \%) \\
2(4 \%)\end{array}$ \\
\hline $\begin{array}{l}\text { Marital Status } \\
\text { Married } \\
\text { Not Married } \\
\end{array}$ & $\begin{array}{l}18(35 \%) \\
33(65 \%)\end{array}$ \\
\hline $\begin{array}{l}\text { Smoking Status } \\
\text { Current Smoker } \\
\text { Former Smoker } \\
\end{array}$ & $\begin{array}{l}33(65 \%) \\
18(35 \%)\end{array}$ \\
\hline $\begin{array}{l}\text { Average Cigarettes per day } \\
\qquad \begin{array}{l}11-20 \\
21-30 \\
31 \text { or more }\end{array}\end{array}$ & $\begin{array}{c}28(55 \%) \\
14(27 \%) \\
9(18 \%)\end{array}$ \\
\hline $\begin{array}{l}\text { Education, } \mathrm{n}(\%) \\
\text { High school or less } \\
\text { Some college or vocational work } \\
\text { College graduate or more }\end{array}$ & $\begin{array}{l}20(39 \%) \\
26(51 \%) \\
5(10 \%)\end{array}$ \\
\hline $\begin{array}{l}\text { Employment status, } \mathrm{n}(\%) \\
\text { Retired, disabled, and/or currently not working } \\
\text { Employed (full time, part time, and/or irregular work) }\end{array}$ & $\begin{array}{l}30(59 \%) \\
21(41 \%)\end{array}$ \\
\hline $\begin{array}{l}\text { Income, } \mathrm{n}(\%) \\
\$ 60,000 \text { or more }\end{array}$ & $12(23 \%)$ \\
\hline $\begin{array}{l}\text { Comorbidities (self-reported, could chose more than one) } \\
\text { Chronic Obstructive Pulmonary Disease (COPD) } \\
\text { Depression } \\
\text { Posttraumatic Stress Disorder (PTSD) } \\
\text { Asthma }\end{array}$ & $\begin{array}{l}14(31 \%) \\
19(40 \%) \\
10(22 \%) \\
3(7 \%)\end{array}$ \\
\hline
\end{tabular}




\begin{tabular}{|c|c|}
\hline Characteristic & $\mathbf{N}(\%)^{*}$ or Mean (SD) \\
\hline Age (yr.) & $42(12.5)$ \\
\hline \multicolumn{2}{|l|}{ Gender } \\
\hline Male & $8(33 \%)$ \\
\hline Female & $16(67 \%)$ \\
\hline \multicolumn{2}{|l|}{ Race } \\
\hline Caucasian & $18(75 \%)$ \\
\hline Asian & $3(13 \%)$ \\
\hline Black/African American & $3(13 \%)$ \\
\hline \multicolumn{2}{|l|}{ Specialty } \\
\hline Primary Care Provider/General Internist & $10(42 \%)$ \\
\hline Pulmonologist & $3(12 \%)$ \\
\hline Thoracic Surgeon & $1(4 \%)$ \\
\hline Radiologist & $1(4 \%)$ \\
\hline Physician Assistant & $4(17 \%)$ \\
\hline Nurse Practitioner/Registered Nurse & $5(21 \%)$ \\
\hline \multicolumn{2}{|l|}{ Years in Practice (since end of training) } \\
\hline $0-10$ & $14(58 \%)$ \\
\hline $11-20$ & $5(21 \%)$ \\
\hline$>21$ & $5(21 \%)$ \\
\hline \multicolumn{2}{|l|}{ Site } \\
\hline Portland & $8(33 \%)$ \\
\hline Minneapolis & $8(33 \%)$ \\
\hline Durham & $8(33 \%)$ \\
\hline \multicolumn{2}{|l|}{ Years spent in current site } \\
\hline $0-5$ & $14(58 \%)$ \\
\hline $6-10$ & $4(17 \%)$ \\
\hline$>11$ & $6(25)$ \\
\hline \multicolumn{2}{|l|}{ Practice Setting } \\
\hline Government & $16(67 \%)$ \\
\hline University-Based & $8(33 \%)$ \\
\hline \multicolumn{2}{|l|}{ Type of Clinic } \\
\hline Internal Medicine/Primary Care & $16(67 \%)$ \\
\hline Pulmonary & $4(17 \%)$ \\
\hline Other & $4(17 \%)$ \\
\hline
\end{tabular}




\section{References}

Aberle DR, Adams AM, National Lung Screening Trial Research Team. 2011. "Reduced lung-cancer mortality with low-dose computed tomographic screening." New England Journal of Medicine 365(5):395-409.

Bach, Peter B., Joshua N. Mirkin, Thomas K. Oliver, Christopher G. Azzoli, Donald A. Berry, Otis W. Brawley, Tim Byers, Graham A. Colditz, Michael K. Gould, James R. Jett, Anita L. Sabichi, Rebecca Smith-Bindman, Douglas E. Wood, Amir Qaseem and Frank C. Detterbeck. 2012. "Benefits and Harms of CT Screening for Lung Cancer: A Systematic Review." JAMA 307(22):2418-2429.

Bandura, Albert. 1997. Self-Efficacy: The Exercise of Control. USA: W.H. Freeman and Co.

Brod, M. I. and S. M. Hall. 1984. "Joiners and Non-Joiners in Smoking Treatment: A Comparison of Psychosocial Variables." Addictive Behaviors 9(2):217-221.

Centers for Disease Control and Prevention. 2018 "Tobacco-Related Disparities." Retrieved January 6, 2018. (https://www.cdc.gov/tobacco/disparities/).

Cohen, Sheldon and Garth McKay. 1984. "Social Support, Stress and the Buffering Hypothesis." Pp. 253-267 in Handbook of Psychology and Health., edited by A. Baum, S.E. Taylor and J.E. Singer. Hillsdale, NJ: Lawrence Erlbaum. 
DiClemente, Carlo C. 1981. "Self-Efficacy and Smoking Cessation Maintenance: A Preliminary Report." Cognitive Therapy and Research 5(2):175-187.

Docherty, G. and A. McNeill. 2012. "The Hardening Hypothesis: Does it Matter?" Tobacco Control 21(2):267-268.

Dornbusch, Sanford M., Melissa R. Herman and Jeanne A. Morley. 1996. "Domains of Adolescent Achievement." Pp. 181-231 in Psychosocial Development During Adolescence: Advances in Adolescent Development. Vol. 8, edited by G. Adams and R. Montemayor. Thousand Oaks, CA: Sage.

Gorini, Giuseppe, Giulia Carreras, Barbara Cortini, Simona Verdi, Maria G. Petronio, Piersante Sestini and Elisabetta Chellini. 2018. "Socioeconomic Disparities in Quitting Smoking and in Steps on the Smoking Cessation Pathway among Smokers in Italy: Findings from the SIDRIAT Cohort Study." Addiction Research \& Theory 26(1):63-70.

Gwaltney, C. J., J. Metrik, C. W. Kahler and S. Shiffman. 2009. "Self-Efficacy and Smoking Cessation: A Meta-Analysis." Psychology of Addictive Behaviors : Journal of the Society of Psychologists in Addictive Behaviors 23(1):56-66.

IOM (Institute of Medicine). 2013. "Delivering High-Quality Cancer Care: Charting a New Course for a System in Crisis.". 
Jaklitsch, Michael T., Francine L. Jacobson, John H. M. Austin, John K. Field, James R. Jett, Shaf Keshavjee, Heber MacMahon, James L. Mulshine, Reginald F. Munden, Ravi Salgia, Gary M. Strauss, Scott J. Swanson, William D. Travis and David J. Sugarbaker. 2012. "The American Association for Thoracic Surgery Guidelines for Lung Cancer Screening using Low-Dose Computed Tomography Scans for Lung Cancer Survivors and Other High-Risk Groups." The Journal of Thoracic and Cardiovascular Surgery 144(1):33-38.

Link, Bruce G. and Jo C. Phelan. 2000. "Social Context of Health and Illness." Pp. 33 in Handbook of Medical Sociology., edited by C.E. Bird, P. Conrad and A.M. Fremont. New Jersey: Prentice Hall Publishing.

Lund, M., K. E. Lund and E. Kvaavik. 2011. "Hardcore Smokers in Norway 1996-2009." Nicotine \& Tobacco Research : Official Journal of the Society for Research on Nicotine and Tobacco 13(11):1132-1139.

Maryland Resource Center for Quitting Use \& Initiation of Tobacco. ND. "Older Adults." Maryland Department of Health, Retrieved July 3, 2018. (https://mdquit.org/special-populations/older-adults).

Mead, Nicola and Peter Bower. 2000. "Patient-Centredness: A Conceptual Framework and Review of the Empirical Literature." Social Science \& Medicine 51(7):10871110. 
Moyer, Virginia A. 2014. "Screening for Lung Cancer: U.S. Preventive Services Task Force Recommendation Statement." Annals of Internal Medicine 160(5):330-338.

National Comprehensive Cancer Network. 2012. National comprehensive cancer network: Nccn guidelines on lung cancer screening.

Ney, T., A. Gale, RB Coambs, L. T. Kozlowski and R. G. Ferrence. 1989. "The Future of Tobacco Use and Smoking Research." Pp. 337-348 in Smoking and Human Behavior., edited by T. Ney and A. Gale. New York, NY: Wiley \& Sons Ltd.

Nicki, R. M., R. E. Remington and G. A. MacDonald. 1984. "Self-Efficacy, Nicotinefading/self-Monitoring and Cigarette-Smoking Behaviour." Behaviour Research and Therapy 22(5):477-485.

Prochaska, J. O. and C. C. DiClemente. 1984. "Self Change Processes, Self Efficacy and Decisional Balance Across Five Stages of Smoking Cessation." Progress in Clinical and Biological Research 156:131-140.

Samet, Jonathan M., Richard Crowell, Jose E. San, Cynthia Rand, Albert A. Rizzo and Rex Yung. 2012. American lung association: Providing guidance on lung cancer screening to patients and physicians.

Siegel, Rebecca L., Kimberly D. Miller and Ahmedin Jemal. 2016. "Cancer Statistics, 2016." CA: A Cancer Journal for Clinicians 66(1):7-30. 
Simpson, Michael, Robert Buckman, Moira Stewart, Peter Maguire, Mack Lipkin, Dennis Novack and James Till. 1991. "Doctor-Patient Communication: The Toronto Consensus Statement." BMJ: British Medical Journal 303(6814):1385.

Strecher, V. J., M. H. Becker, J. P. Kirscht, S. A. Eraker and R. P. Graham-Tomasi. 1985. "Psychosocial Aspects of Changes in Cigarette-Smoking Behavior." Patient Education and Counseling 7(3):249-262.

Strecher, Victor J., Brenda DeVellis McEvoy, Marshall H. Becker and Irwin M. Rosenstock. 1986. "The Role of Self-Efficacy in Achieving Health Behavior Change." Health Education Quarterly 13(1):73-92.

Thoits, Peggy A. 2011. "Mechanisms Linking Social Ties and Support to Physical and Mental Health." Journal of Health and Social Behavior 52(2):145-161.

Weiland, Anne, de K. Van, Annette H. Blankenstein, Van Saase, Jan L. C. M., der M. Van, Wichor M. Bramer, Alexandra M. Van Dulmen and Lidia R. Arends. 2012. "Encounters between Medical Specialists and Patients with Medically Unexplained Physical Symptoms; Influences of Communication on Patient Outcomes and use of Health Care: A Literature Overview." Perspectives on Medical Education 1(4):192206. 
Weiss, Robert S. 1974. "The Provisions of Social Relationships."in Doing unto Others: Joining, Molding, Conforming, Helping, Loving., edited by Z. Rubin. Englewood Cliffs, NJ: Prentice Hall.

Wender, Richard, Elizabeth T. H. Fontham, Ermilo Barrera, Graham A. Colditz, Timothy R. Church, David S. Ettinger, Ruth Etzioni, Christopher R. Flowers, G. Scott Gazelle, Douglas K. Kelsey, Samuel J. LaMonte, James S. Michaelson, Kevin C. Oeffinger, Ya-Chen T. Shih, Daniel C. Sullivan, William Travis, Louise Walter, Andrew M. D. Wolf, Otis W. Brawley and Robert A. Smith. 2013. "American Cancer Society Lung Cancer Screening Guidelines: American Cancer Society Lung Cancer Screening Guidelines." CA: A Cancer Journal for Clinicians 63(2):106-117. 


\section{Chapter 5. Conclusion}

Lung cancer remains an important public health concern, since deaths from lung cancer makes up to $25 \%$ of all cancer deaths in the U.S. (American Cancer Society 2020).Cigarette smoking is one of the major contributing factors for lung cancer. Therefore, although lung cancer screening (LCS) has been emphasized in an attempt to identify an early detection of lung cancer, practically, reducing smoking prevalence is often considered the best way to combat morbidity and mortality from lung cancer. Smoking cessation is difficult but can considerably improve health outcomes (CDC 2020a).

The Centers for Medicare and Medicaid (CMS) mandated the LCS decisionmaking discussion when they initially approved LCS for funding in 2015 . This mandate occurred since decision-makers at the CMS believed in the importance of addressing harms and benefits of screening. They also believed that the decision-making discussion should help people understand the relevant risk factors of lung cancer, like smoking, ensuring those eligible understand "the relevant risk factors and are engaged with the shared responsibility regarding the decision to proceed or not" with the low-dose computed tomography (LDCT) scan (Jensen et al. 2015). The LCS decision-making discussion brings about an important opportunity for researchers to describe the population offered LCS and also find out the importance of communication about smoking within the decision-making discussion. It is unknown what factors are important for improving smoking cessation among patients offered LCS. 
This dissertation research was designed to add to the literature of health associated with smoking behaviors and contribute to applications of foundational theories about smoking behaviors, smoking cessation, and hardened smokers offered LCS. This dissertation addressed three specific research questions. First, what are the differences in traditionally well-correlated socioeconomic and sociodemographic factors between patients who were able to successfully achieve smoking cessation and those who were not able to successfully achieve smoking cessation prior to the LCS decision-making discussion?? Second, is patient-clinician communication (assessed by patient's perceptions of the presence of communication about smoking) during the LCS decisionmaking discussion associated with smoking cessation? The first two questions were answered by quantitative analyses of patients involved in LCS decision-making discussions. Through these analyses I was able to describe and compare factors associated with successful smoking cessation using traditionally well-correlated socioeconomic, sociodemographic, and psychosocial factors. Third, how do clinicians and patients communicate about smoking within the LCS decision-making discussion? This question was answered by undergoing a qualitative analysis of patient and clinician interviews designed to elicit information on communication during the LCS decisionmaking discussion. Through this analysis I was able to further understand the use of the LCS decision-making discussion as an opportunity to encourage smoking cessation.

I was able to use existing data from a longitudinal, observational, mixed-methods cohort study of patients offered LCS in three institutions; VA Portland Health Care System (VAPORHCS), Portland, OR; Minneapolis VA Medical Center, Minneapolis, 
MN; and Duke University Medical Center, Durham, NC. Given the unknowns thus far about smoking behaviors in patients offered an LDCT for LCS, mixed-methods studies may be particularly informative and useful (Creswell et al. 2011) since mixed-methods can facilitate a rich and thorough understanding of unknown areas. Additionally, we selected a mixed-methods design for the overall study in order to continually engage patient and clinician stakeholders throughout the research process. The decision to use a mixed-methods design improved the analytic plan and increased the potential to identify tools and processes that could be broadly replicated.

\section{Socioeconomic and Sociodemographic Factors, and Smoking Cessation}

My first analysis answered the question: what are the differences in traditionally well-correlated socioeconomic and sociodemographic factors between patients who were able to successfully achieve smoking cessation and those who were not able to successfully achieve smoking cessation prior to the LCS decision-making discussion? I described characteristics of hardened smokers to add to the knowledge base about this population and determine which socioeconomic and sociodemographic factors were associated with former or current smoking. Then I compared these factors based on smoking status (i.e., former vs. current smoker) at the time of the baseline survey. All individuals were considered hardened smokers based on their smoking history - a population that did not receive much scholarly attention in previous literature. My findings showed that patients offered LCS, also considered hardened smokers, differed in important social characteristics based on their smoking status at baseline. For example, income was significantly lower for participants who currently smoked compared to 
participants who formerly smoked. Men were less likely to currently smoke than women, and non-Hispanic whites were less likely to currently smoke than other races.

Cigarette smoking is more common among individuals with lower incomes and consequently, they are disproportionately affected by smoking-related diseases (CDC 2020b). Findings from this study support prior research documenting the importance of income as fundamental cause linked with health. Studies have shown that those who are in poverty, when measured by income, are more likely to currently smoke (i.e., not successfully quit). Not only do individuals below the poverty line attempt cessation less often and are less successful at cessation, but low-income neighborhoods are more often targets of tobacco advertising campaigns (CDC 2020b). Income provides key resources like the ability to access safer and less targeted housing, purchase health care and more nutritious foods (Adler and Newman 2002). Income also allows for greater access to health information via technology like the internet. These types of amenities lead those with higher incomes to greater levels of access to health information, which helps in utilizing preventive medicine appropriately and avoid health risks, like smoking. Our findings suggest that the link with poverty and continuation of smoking holds for Veterans and civilians alike (Golden et al. 2018; Marmot and Wilkinson 2006). The largest contributors to health are from a person's behavior and their lifestyle (Adler and Newman 2002), and income as part of SES impacts both of these contributors. My findings add to the supporting evidence. Regarding behavior, people with lower income may feel more socially isolated and lack in social support (Adler and Newman 2002). These resources lead to more stress and worse health behaviors, like smoking. Those with 
limited income may not be able to live in locations that are conducive to health. For instance, lower income may equate to worse environmental exposures like houses with lead or asbestos. Income, indeed, as a fundamental cause affects many pathways toward health.

Bruce Link and Jo Phelan (1995) described fundamental causes as social factors that have four key elements. The first is that the mechanisms by which the factor influences health may change, while the associations remain. This element highlights the importance of a persistent connection in order to define a social variable as a "fundamental cause." The second element is that the factors must involve "access to resources that can be used to avoid risks or to minimize the consequences of disease once it occurs" (Link and Phelan 1995:87). The third key element is that the social factor must influence multiple disease outcomes. That is, diseases ranging from cardiovascular disease to lung cancer to HIV can be affected. Finally, the fourth element is that the factor must affect diseases through multiple risk factors. Income determines the availability of a good education, cleanliness and safety of the living environment, as well as access to preventive health care. Fundamental causes, therefore, are the root of how individuals are affected by disease and health.

My research also found that compared to women, men were less likely to be currently smoking. One reason f may be the large sample of Veterans, who are mostly men, enrolled in VA health care. Veterans enrolled in VA health care may have access to more resources to aid in smoking cessation after military service than their civilian 
counterparts. Therefore men in our study may have more access to resources to help them quit than women. Reasons for smoking initiation in the military are multifactorial including stress relief, sanctioned regular smoking breaks, and peer pressure (Haddock et al. 2009). Reasons for initiation may also be related to other military-specific factors such as exposure to traumatic events or increased stress of deployment. A previous paper found that sociodemographic factors associated with smoking status in Veterans were similar to those observed in civilian populations. But there are also military-specific findings suggesting that exposure to dead/dying/wounded soldiers, service era, duration of service, service-connected disability status, and enrollment in VA care all influence smoking in Veterans (Golden et al. 2018). Although these important variables were not considered in the present study due to a limited sample size, they should be included in future research to tease out the role of socioeconomic, sociodemographic, and militaryspecific variables in smoking cessation.

In addition, while smoking prevalence is generally lower for females, so is successful cessation. Certainly, males have been found to have higher cessation rates after participating in several randomized control trials of cessation interventions (Wetter $t$ al. 1999). It is possible that cessation interventions are more likely to help males, since there are biological and/or social gender-specific issues that are not typically incorporated into cessation intervention trials or therapies (Bottorff et. al 2014). In fact, there are studies suggesting that certain interventions may work better for women. For example, a study by Torchalla et al. (2012) found that cessation interventions that addressed weight gain and weight concerns were most effective for women who wanted to quit smoking. 
Also, gender-specific interventions like psycho-pharmacologically differentiated medications or psychiatric treatment focused on trauma-related substance abuse (Smith et al. 2016), may be helpful for women. In contrast, more standard, gender-neutral interventions, like counseling or use of medications like Wellbutrin (Botorff et al. 2014), showed similar abstinence rates for both men and women.

The last statistically significant finding from this research question was that nonHispanic whites were less likely to currently smoke, consistent with previous research. One study found that non-Hispanic blacks and other non-Hispanic youth were more susceptible to smoking initiation compared to non-Hispanic whites (El-Toukhy, Sabado, and Choi 2016) African-Americans who smoke menthol cigarettes (the most common type of cigarette for African-Americans) have been found to have a more difficult time successfully quitting (Stahre et al. 2010) despite more quit attempts (CDCb 2020). Many differences in smoking rates can be explained by SES differences (Nollen, Mayo, and Sanderson Cox et al. 2019). But additionally, institutional racism may interact with cognitive biases of clinicians when faced with someone of a different racial or ethnic group to affect their behavior and decisions (van Ryn et al. 2011), such as the decision to offer cessation counseling during a clinician visit (Bailey et al. 2018; Reed and Burns 2008).

By understanding how and why people are exposed to risk factors and illness, as well as how social factors are related to individual risk and disease, we can identify and support the evidence for social factors (i.e., fundamental causes) that influence health even after controlling for other mechanisms. For example, being homeless or 
experiencing discrimination based on race may provide the social context for encouraging continued smoking, which may lead to development of lung cancer. That is, it is important to realize the social factors leading to an individual's homelessness or discrimination (i.e., understanding how and why people are exposed to risk factors and illness) as well as realize the mechanism of the behavior and disease. Power, prestige, knowledge, money, and other interpersonal resources are significant players in the fundamental cause theory of health and disease. These resources available to those in higher SES levels or in majority races, for instance, are just so "extensive and wideranging" (Link and Phelan 1995) as to justify these factors as fundamental causes. Resources are obtained and used in various ways, with the outcome being that they directly shape individual health behaviors by influencing people's access, knowledge, and support about health behaviors.

Another more recent study found evidence supporting the fundamental cause theory by looking at socioeconomic disparities in patients with lung cancer compared to patients with pancreatic cancer. Lung cancer is a disease that is increasingly seen as preventable due to the knowledge about smoking and increased focus on prevention and cessation, whereas pancreatic cancer has a natural history that is largely unknown and currently largely unpreventable. The authors wanted to test the fundamental cause theory and hypothesis brought about by Link and Phelan that preventable diseases are more sensitive to changes in social factors. The authors found that even though lung cancer mortality rates were initially higher in counties with higher SES, "by 1980 persons in 
lower SES counties were at greater risk and by 2009 the difference in mortality between counties with SES one SD above compared to one SD below average was 33 people per 100,000." They also found a small but significant inverse SES gradient in pancreatic cancer mortality, and that did not change over the time period studied. This supports the hypothesis that social conditions more strongly influence preventable diseases and that health inequalities occur due to differences in social conditions, like SES (Rubin, Clouston, and Link 2014).

Interestingly, I did not find that education or employment status differed between the two groups of hardened smokers, despite the evidence supporting these factors as fundamental causes. Feldman et al. (1989) and Preston \& Elot (1995) found that smoking cessation rates increase with increased educational attainment. Education increases the chances of having social support and develops human capital, which is an internal sense of capital that can contribute to self-efficacy and confidence. Both social support and human capital contribute to making positive health changes (Mirowsky and Ross 2015:299). In the Whitehall studies, Marmot examined a cohort of civil servants in the United Kingdom, all with equal access to health care, stable jobs, and relatively free from environmental hazards. Instead of finding that the seemingly similar occupational conditions equated to similar health outcomes for this cohort, the researchers found that there was a stark contrast in mortality between the top and bottom grades of civil workers (Marmot et al. 1991). These findings support the theory that there must be resources and 
other positive characteristics of the workplace available only to those in higher ranks that equate to better health (Burgard and Lin 2013; Mirowsky and Ross 2007).

Given the relatively older age of this sample (recruitment targeted those 55 and older) and retirement status of this group, it is likely that factors such as education and employment status may be less relevant with respect to smoking behavior. Since our sample had been smoking for many years prior to being offered LCS and participation in our study, the effects of these characteristics on smoking behaviors may have waned while other characteristics became more prominent, such as more graphic warning labels as deterrents (Azagba and Sharaf 2013; Shang et al. 2017), fear of withdrawal symptoms, or desire for continued stress reduction (Baker, Brandon, and Chassin 2004).

Instituting universal health care for all would be a major way to reduce health inequalities based on fundamental causes but is unlikely to occur in the US any time soon. Marmot and Wilkinson (2006) suggest improving the "built environment" to encourage more social interactions on a smaller scale, but policy recommendations often include large-scale changes like improved social equity, equal access to education, gender rights, state or federal investments in public health (Wright and Perry 2010), and reduction of lobbying in government. Luckily, studies have shown that small, easy to implement interventions are the most likely to reduce health inequalities (Phelan et al. 2010), so those are a good starting point for intervention. My findings can lead exploration of possible mechanisms for these differences, and importantly, determine mechanisms that might help with cessation. For example, it is possible that screening for 
income, race, and gender, prior to LCS decision-making discussions could be possible in order to provide extra, or different, cessation strategies.

Based on these findings, I suggest that smoking cessation programs could tailor their approach to patients while considering system- or individual- level characteristics that influence smoking status, and smoking cessation. To address disparities between income levels, gender, and race there may need to be 1) more global approaches to equitably distributing key factors associated with positive health behaviors, such as national system-level interventions to encourage income and racial inequality, and 2) recognition and implementation of the gendered aspects of smoking cessation in cessation interventions to address individual-level characteristics, like gender.

\section{Communication and Smoking Cessation}

The second question asked whether patient-clinician communication (assessed by patient's perceptions of the presence of communication about smoking) during the LCS decision-making discussion is associated with smoking cessation. I used longitudinal data to examine the association of communication about smoking within the LCS decisionmaking discussion with smoking cessation at one-year follow-up. I used valid and reliable instruments to measure my variables of interest. I first summarized the descriptive data for all measures for participants and performed bivariate statistics. I then employed a logistic regression analysis to determine the association of presence of patient-clinician communication with smoking status at one-year follow-up. I combined the No discussion and Could Not Recall responses for our analysis. I was not able to utilize a question more specific to the quality of communication since 53\% of participants 
in this sample either could not recall or reported no, they did not have a decision-making discussion. They, therefore, skipped the rest of the instrument and this would have greatly reduced our sample size. However, even brief communication regarding smoking cessation can have an impact on patient health behaviors (Lancaster and Stead 2004), and arguably, the presence of communication is the first step in providing high quality communication (IOM 2013).

It appears that communication about smoking within the LCS decision-making discussion was not positively associated with successful smoking cessation. Instead, while not statistically significant, it seems that individuals who could not recall or did not report discussing smoking behaviors may be more likely to successfully quit smoking after one year. My findings suggest that communication in the LCS decision-making discussion about smoking was not effective as intended. Effective patient-clinician communication has many benefits for both the health care system and the patient. But patients may lack the necessary skills to ask relevant questions and to advocate for themselves and their health. Clinicians also may lack necessary communication skills (D'Agostino et al. 2017) that incorporate all domains of patient-centered communication. All of the domains are amenable to training though, (D'Agostino et al. 2017) through seven main pathways (Street et al. 2009) that can lead to better health outcomes, like smoking cessation,. The seven main pathways are: increased access to care, improved patient knowledge, higher quality medical decisions, patient understanding (therapeutic alliance), increased social support, patient agency and empowerment, and better management of emotions. Importantly, high quality patient-centered communication 
utilizing all domains will subsequently lead to improvements in all seven pathways that can then lead to improved health behaviors.

A meta-analysis has shown that any type of communication within a cessation intervention is more effective than self-help or no communication (Hollis et al. 2000). These findings underscore that when clinicians ask patients about their smoking at any encounter, it has been shown to lead to reduced smoking (Bailey et al. 2018; U.S. Preventive Services Task Force 2017). Indeed, communication has been shown to lead to improved smoking cessation. For example, Lindson-Hawley and colleagues found that motivational interviewing is one form of communication that has been shown to lead to improved smoking cessation (2015).

It is possible that all patients may have subconsciously picked up on the importance of smoking cessation. More likely, they may have focused more on the fact they were at high risk of lung cancer and realized that smoking cessation was the best way to reduce their chance of being diagnosed with lung cancer. Additionally, anxiety and distress, age, and perceived importance of medical information can all create recollection issues, but even without these factors, "memory for medical information is often poor and inaccurate" (Kessels 2003).But importantly, below my Research Question 3 shows that patients already realize that smoking causes lung cancer and want to make the decision to quit personally (Golden et al. 2020). There seem to be other aspects of smoking, social factors, and personal beliefs that more strongly influence smoking behaviors, as evidenced by the findings to Research Questions 1 and 3. 
I found that study site location was significant in this analysis, however, which indicates that there is something different about individuals at Duke University compared to the VAPORHCS. Study site location can be seen as a proxy for SES. Even though our SES variables did not show a significant association with the outcome, our sites were chosen purposively to collect data from diverse socioeconomic and sociodemographic populations,Indeed, those with a lower SES are more often current smokers when compared to those with a higher SES (Marmot and Wilkinson 2006). Duke University, for instance, may have more private-pay patients, indicating that their patients may have more resources available to quit smoking. Private-pay patients typically have higher employment and may subsequently have higher economic resources overall. Those with a lower SES are more often current smokers when compared to those with a higher SES (Marmot and Wilkinson 2006), and those with a higher SES tend to have more resources to utilize when they try to quit smoking. Low health literacy, indeed, effects an estimated $36 \%$ (80 million adults) of the US population (Kutner, Greenberg, and Baer 2006) and it disproportionately impacts people from socioeconomically disadvantaged groups (Mantwill, Monestel-Umana, and Schulz 2015; Hayward et al. 2000).

Study site location is also a proxy for willingness to quit smoking since Duke University participants were recruited from a dedicated smoking cessation clinic. That is, they proactively enrolled into a smoking cessation counseling clinic where LCS was discussed within their smoking cessation clinical encounter. Participants at Duke, therefore, were likely more motivated to quit smoking compared to the other sites since they opted into a smoking cessation counseling clinic. 


\section{Smoking during the LCS Decision-Making Discussion}

My Research Question 3 asked: How do clinicians and patients communicate about smoking within the LCS decision-making discussion? I performed qualitative semistructured interviews and conventional content analysis of both patients and clinicians. These interviews focused on communication regarding smoking, the perceived importance of discussing smoking and screening together, and perceived patient challenges to cessation. I learned that clinicians and patients differed on their views about LCS decision-making discussions as an opportunity to communicate about smoking cessation.

My qualitative findings in Research Question 3 supported my quantitative results that communication about smoking during the LCS decision-making discussion is unlikely to influence smoking behavior. I found through the qualitative interviews that, even though clinicians seemed to mostly adhere to the 5A framework, there are other more meaningful factors related to smoking cessation for patients. For instance, patients mentioned personal reasons like finances or family as reasons to quit smoking rather than the risks of lung cancer or other health problems. These factors are not currently being leveraged by current clinician communication practices to motivate positive behavioral change.

While clinicians varied in their report of the use of the 5A's during LCS decisionmaking discussion, most described using at least parts of the 5A framework every time. All clinicians reported it was important to discuss smoking, some particularly within the LCS decision-making discussion. In contrast, patients described talk about smoking as 
"expected," but it did not influence their desire to quit or abstain from smoking. They did not see the difference between communication about smoking during the LCS decisionmaking discussion compared to during other clinical encounters. Patients emphasized personal feelings of readiness and self-efficacy.

Notably, lack of self-efficacy can lead to poorer management of stress, which can then lead to poorer health behaviors, like smoking. We know from the abundance of research done on the impact of stress on the allostatic load and health, that chronic stress in particular can increase the incidence of heart disease, stroke, arterial disease, infection, and even mortality (Marmot and Wilkinson 2006). Higher senses of self-efficacy also lead to less smoking relapse (Baer, Holt, and Lichtenstein 1986; Condiotte and Lichtenstein 1981; O'Leary 1985), general positive health behavior changes (Strecher et al. 1986), and other health benefits like improved pain experience and management, and better adherence to preventive programs and recovery from heart conditions (O'Leary 1985). A motivated and self-efficacious patient will likely be more empowered to be an activated patient involved in their health, but they will also be more likely to be able to make healthy changes on their own, like quitting smoking (Bandura 1997). Indeed, other studies have shown health outcomes affected by levels of self-efficacy such as in overall ratings of health (Grembowski et al. 1993), engagement in cancer screenings (Seyde, Taal, and Wiegman 1990), and alcohol use (Christiansen, Vik, and Jarchow 2002). Since patients offered LCS may be more engaged patients given they are interacting with the health care system to discuss LCS, they may have more self-efficacy. Higher self- 
efficacy may account for the finding that patients felt empowered to seek out assistance for smoking cessation if and when they were ready.

Clinicians can boost self-efficacy to help patients quit smoking through continued, and repeated, use of the 5A's during every clinical encounter, especially via Assessing and Advising their patients. One finding showed that clinicians do not consider discussion of risks of disease as a required component of the Advise aspect of the 5A's. Consequently, although clinicians seemed aware of the 5A's, more education may be necessary or desired to garner the desired impact. One possibility might be to use a computer-facilitated 5A's delivery model that has recently been shown to improve the fidelity of the 5A framework within primary care (Satterfield et al. 2018). There are other online variations that illustrate the impact the 5A's can have on patients (Martinez et al. 2019) as well that may be helpful.

Further, clinicians could not only continue to use the 5A's, but they could maximize their impact. For instance, since patients reported that they already knew they were at a higher risk of lung cancer compared to people who never smoked clinicians might educate patients about risks of other smoking-related diseases like rheumatoid arthritis or obstructive lung disease (Gath et al. 2018; Parkes et al. 2008) instead of emphasizing lung cancer risk as motivation for cessation. . Another option might be to pair the 5A's with a personal motivator like financial incentives, if possible (Olson, Boardman, and Johnson 2019).

\section{Strengths and Contributions}


Some strengths of this dissertation include the available data. I was able to use a unique, available dataset that provided information on patients offered LCS within three diverse LCS programs. We used valid and reliable surveys as well as widely used measures of health outcomes which supported the scientific integrity of the study. In addition, this study was novel as there has never been a mixed-methods study in this area. It is also novel since the population of hardened smokers has never been described and compared, and there has been little research on the association of smoking outcomes with communication in the context of LCS decision-making discussions. Longitudinal studies are beneficial because they can account for static subject characteristics that may influence cross-sectional research leading to spurious results. The focus is timely as LCS is still in the early stages of implementation and smoking rates remain high in the United States.

\section{Limitations}

This dissertation is not without limitations. First, while the inclusion of multiple sites increases the generalizability of the study, there remains a limitation due to the majority of the cohort being Veterans. Veterans are more likely to be male and Caucasian. We oversampled for minorities and women in the qualitative interviews to address this limitation. Second, I was not able to compare people offered LCS versus those who were not offered LCS given the parameters of the original study. I was also not able to examine individuals who had never smoked for their thoughts on smoking since they are not currently offered LCS. By not including those not offered LCS and those who never smoked I was not able to capture their thoughts and responses to see if they 
were affected differently by the LCS decision-making discussion. The discussion itself could have greatly impacted smoking cessation, or even never smokers' thoughts on smoking and/or LCS. It would be useful to incorporate these groups in future research.

Third, this study suffers from reporting bias, in that those who participate may be more likely to report higher incidence or quality of communication. This may have impacted our findings to show a bias towards presence of communication. Future research in this area could benefit from audio or visual confirmation of communication about smoking occurring during the LCS decision-making discussion. The fourth limitation is selection bias. We found that patients unwilling to undergo the LDCT were also unwilling to participate in our research study, limiting our ability to document those who decline screening. Participants agreeing to undergo the LDCT will likely have significant differences compared to participants who decline to undergo the LDCT and should be investigated further. However, our previous qualitative work among Veterans and non-Veterans has uncovered similar themes about deficits in patient-centered care (Golden et al. 2016). Fifth, this study suffers from recall bias; it is possible that participants may not recall, or want to recall, certain items. Participants might say what they think the researchers want to hear, also called moderator acceptance bias. Timing may not capture overall feelings since each survey and interview captures just one snapshot in time. Finally, I did not investigate specific mechanisms in this dissertation. Even so, it remains imperative to first determine the association of perceived communication with a health outcome, which will be a foundation for future studies about proximal and intermediate outcomes. 
Future studies can be guided by the findings presented in this dissertation. For instance, health promotion literature indicates that targeting specific subgroups of people with health-related messages may work better than large-scale canvassing (Latimer, Salovey, and Rothman 2007). Therefore, talking to specific groups of patients who smoke may influence them more than other types of cessation advertising or recommendations. By targeting those within LCS and using cessation-related messages that are tailored to their specific subgroup or characteristics, we may be able to help certain populations successfully quit smoking in future studies designed to develop interventions.

\section{Conclusions and Implications}

To conclude, findings of this dissertation drive three conclusions. First, hardened smokers offered lung cancer screening differed in important social factors based on their smoking status at baseline. Smoking cessation programs may need to tailor their approach to patients offered LCS who may have other individual- or system- level characteristics that influence the association between socioeconomic and sociodemographic factors, smoking status, and smoking cessation. Second, discussing smoking cessation during the LCS decision-making discussion may not lead to successful smoking cessation at least in the short term. There may be other more important aspects that affect smoking cessation, like encouragement from family and friends or financial reasons. Lastly, in support of previous findings, communication about smoking during the LCS decision-making discussion is unlikely to influence smoking behavior. Importantly, these findings add to the knowledge base and sociological theory about 
fundamental causes, unique populations, like hardened smokers, and patient-clinician communication.

Despite the fact that there is no evidence base for the shared decision-making mandate for LCS, there has been encouragement from Wender et al. (2013) on behalf of the American Cancer Society and others regarding use of shared decision-making for cancer screenings in general (Joosten et al. 2008). For example, the Institute of Medicine published a report promoting incorporation of patient-centered care, of which shared decision-making is a key piece (2013). Shared decision-making, certainly, is a component of high-quality communication (Mead and Bower 2000). A review in the New England Journal of Medicine explained that shared decision-making may be especially useful for ensuring patient-centered care within cancer screening discussions where there is no clear "right" answer (Barry and Edgman-Levitan 2012). It may be, though, that the mandate and implementation of the LCS decision-making discussion to include communication about smoking is not being conducted as intended or not having the effect expected. Broader implications from this dissertation show that other, more personalized approaches may need to be used during clinical encounters in order to help patients abstain or quit smoking such as motivational interviewing or counseling. This finding may affect the smoking component of the shared decision-making mandate for LCS itself. 


\section{References}

Adler, N. E. and K. Newman. 2002. "Socioeconomic Disparities in Health: Pathways and Policies." Health Affairs (Project Hope) 21(2):60-76.

American Cancer Society. 2020. "Key Statistics for Lung Cancer." Atlanta, GA:

American Cancer Society, Retrieved 09/18, 2020.

(https://www.cancer.org/cancer/lung-cancer/about/key-

statistics.html\#: :text=The\%20American\%20Cancer\%20Society's\%20estimates,men \%20and\%2063\%2C220\%20in\%20women)).

Antonisse, Larisa and Rachel Garfield. 2018. The relationship between work and health: findings from a literature review. Kaiser Family Foundation.

Azagba, S. and M. F. Sharaf. 2013. "The Effect of Graphic Cigarette Warning Labels on Smoking Behavior: Evidence from the Canadian Experience." Nicotine \& Tobacco Research : Official Journal of the Society for Research on Nicotine and Tobacco 15(3):708-717.

Baer, J. S., C. S. Holt and E. Lichtenstein. 1986. "Self-Efficacy and Smoking Reexamined: Construct Validity and Clinical Utility." Journal of Consulting and Clinical Psychology 54(6):846-852. 
Bailey, Steffani R., Victor J. Stevens, Stephen P. Fortmann, Stephen E. Kurtz, Mary A. McBurnie, Elisa Priest, Jon Puro, Leif I. Solberg, Rebecca Schweitzer, Andrew L. Masica and Brian Hazlehurst. 2018. "Long-Term Outcomes from Repeated Smoking Cessation Assistance in Routine Primary Care." Am J Health Promot:0890117118761886.

Baker, Timothy B., Thomas H. Brandon and Laurie Chassin. 2004. "Motivational Influences on Cigarette Smoking." Annual Review of Psychology 55(1):463-491.

Bandura, Albert. 1997. Self-Efficacy: The Exercise of Control.USA: W.H. Freeman and Co.

Barry, M. J. and S. Edgman-Levitan. 2012. "Shared Decision Making--Pinnacle of Patient-Centered Care." The New England Journal of Medicine 366(9):780-781.

Bottorff, J. L., R. Haines-Saah, M. T. Kelly, J. L. Oliffe, I. Torchalla, N. Poole, L. Greaves, C. A. Robinson, M. H. Ensom, C. T. Okoli and J. C. Phillips. 2014. "Gender, Smoking and Tobacco Reduction and Cessation: A Scoping Review." International Journal for Equity in Health 13:114-014-0114-2.

Burgard, Sarah A., and Katherine Y. Lin. "Bad jobs, bad health? How work and working conditions contribute to health disparities." American Behavioral Scientist 57, no. 8 (2013): 1105-1127. 
Centers for Disease Control and Prevention. 2020a. "Smoking \& Tobacco Use.", Retrieved 03/08, 2018. (https://www.cdc.gov/tobacco/data_statistics/fact_sheets/fast_facts/index.htm).

Centers for Disease Control and Prevention. 2020b. "Tobacco-Related Disparities.", Retrieved 01/06, 2017. (https://www.cdc.gov/tobacco/disparities/).

Christiansen, M., P. W. Vik and A. Jarchow. 2002. "College Student Heavy Drinking in Social Contexts Versus Alone." Addictive Behaviors 27(3):393-404.

Condiotte, M. M. and E. Lichtenstein. 1981. "Self-Efficacy and Relapse in Smoking Cessation Programs." Journal of Consulting and Clinical Psychology 49(5):648-658.

Creswell, John W., Ann C. Klassen, Vicki L. Plano Clark and Katherine C. Smith. 2011. "Best Practices for Mixed Methods Research in the Health Sciences." Bethesda, MD: National Institutes of Health 10.

D'Agostino, T. A., T. M. Atkinson, L. E. Latella, M. Rogers, D. Morrissey, A. P. DeRosa and P. A. Parker. 2017. "Promoting Patient Participation in Healthcare Interactions through Communication Skills Training: A Systematic Review." Patient Education and Counseling 100(7):1247-1257.

El-Toukhy, S., M. Sabado and K. Choi. 2019. "Trends in Susceptibility to Smoking by Race and Ethnicity." Pediatrics 144(3):e20191894. doi: 10.1542/peds.2019-1894. 
Feldman, J. J., D. M. Makuc, J. C. Kleinman and J. Coronary-Huntley. 1989. "National Trends in Educational Differences in Mortality." American Journal of Epidemiology 10:214-223.

Gath, M. E., L. K. Stamp, P. Aimer, S. Stebbings and G. J. Treharne. 2018.

"Reconceptualizing Motivation for Smoking Cessation among People with Rheumatoid Arthritis as Incentives and Facilitators." Musculoskeletal Care 16(1):139-146.

Golden, S. E., S. S. Ono, A. Melzer, J. Davis, S. B. Zeliadt, J. L. Heffner, H. Kathuria, G. Garcia-Alexander and C. G. Slatore. 2020. "'I Already Know that Smoking Ain'T Good for Me": Patient and Clinician Perspectives on Lung Cancer Screening Decision-Making Discussions as a Teachable Moment." Chest 158(3):1250-1259.

Golden, S. E., C. R. Thomas Jr, M. E. Deffebach, M. S. Sukumar, P. H. Schipper, B. H. Tieu, A. Y. Kee, A. C. Tsen, C. G. Slatore and Early Stage Lung Cancer Comparative Effectiveness Research Consortium. 2016. "'Even if I Don'T Remember, I Feel Better". A Qualitative Study of Patients with Early-Stage NonSmall Cell Lung Cancer Undergoing Stereotactic Body Radiotherapy Or Surgery." Annals of the American Thoracic Society 13(8):1361-1369.

Golden, Sara E., Sujata Thakurta, Hyeyoung Woo, Christopher G. Slatore and Donald R. Sullivan. 2018. "Military Factors Associated with Smoking in Veterans." Mil Med 183(11-12):e402-e408. 
Grembowski, D., D. Patrick, P. Diehr, M. Durham, S. Beresford, E. Kay and J. Hecht. 1993. "Self-Efficacy and Health Behavior among Older Adults." Journal of Health and Social Behavior 34(2):89-104.

Haddock, C. K., J. E. Taylor, K. M. Hoffman, W. S. Poston, A. Peterson, H. A. Lando and S. Shelton. 2009. "Factors which Influence Tobacco use among Junior Enlisted Personnel in the United States Army and Air Force: A Formative Research Study." American Journal of Health Promotion : AJHP 23(4):241-246.

Hayward, Mark D., Toni P. Miles, Eileen M. Crimmins and Yu Yang. 2000. "The Significance of Socioeconomic Status in Explaining the Racial Gap in Chronic Health Conditions." American Sociological Review 65(6):910-930.

Hollis, J. F., R. Bills, E. Whitlock, V. J. Stevens, J. Mullooly and E. Lichtenstein. 2000. "Implementing Tobacco Interventions in the Real World of Managed Care." Tobacco Control 9 Suppl 1:I18-24.

IOM (Institute of Medicine). 2013. "Delivering High-Quality Cancer Care: Charting a New Course for a System in Crisis.".

Jensen, Tamara S., Joseph Chin, Lori Ashby, Jamie Hermansen and Joseph D. Hutter. 2015. Decision Memo for Screening for Lung Cancer with Low Dose Computed Tomography (LDCT). 
Joosten, E. A. G., L. DeFuentes-Merillas, G. H. de Weert, T. Sensky, der S. van and C. A. J. de Jong. 2008. "Systematic Review of the Effects of Shared Decision-Making on Patient Satisfaction, Treatment Adherence and Health Status." Psychotherapy and Psychosomatics 77(4):219-226.

Kessels, Roy P. C. 2003. "Patients' Memory for Medical Information." Journal of the Royal Society of Medicine 96(5):219-222.

Kutner, Mark, Elizabeth Greenberg and Justin Baer. 2006. National assessment of adult literacy (NAAL): A first look at the literacy of America's adults in the 21st century. NCES.

Lancaster, T. and L. Stead. 2004. "Physician Advice for Smoking Cessation." The Cochrane Database of Systematic Reviews (4):CD000165. doi(4):CD000165.

Latimer, A. E., P. Salovey and A. J. Rothman. 2007. "ThThe Effectiveness of GainFramed Messages for Encouraging Disease Prevention Behavior: Is all Hope Lost?" Journal of Health Communication 12(7):645.

Lindson-Hawley, N., T. P. Thompson and R. Begh. 2015. "Motivational Interviewing for Smoking Cessation." The Cochrane Database of Systematic Reviews (3):CD006936. doi(3):CD006936. 
Link, Bruce G. and Jo C. Phelan. 1995. "Social Conditions as Fundamental Causes of Disease." Journal of Health and Social Behavior (Extra):80-94.

Mantwill, S., S. Monestel-Umaña and P. J. Schulz. 2015. "The Relationship between Health Literacy and Health Disparities: A Systematic Review." PloS One 10(12):e0145455.

Marmot, Michael and Richard G. Wilkinson. 2006. Social Determinants of Health. Oxford, UK: Oxford University Press.

Marmot, M. G., G. D. Smith, S. Stansfeld, C. Patel, F. North, J. Head, I. White, E. Brunner and A. Feeney. 1991. "Health Inequalities among British Civil Servants: The Whitehall II Study." Lancet (London, England) 337(8754):1387-1393.

Martínez, C., Y. Castellano, A. Andrés, M. Fu, A. Feliu, L. Antón, M. Ballbè, P. Fernández, S. Cabrera, A. Riccobene, E. Gavilan, A. Baena, M. Margalef, O. Tigova, N. Quirós, O. Guillen, A. Company and E. Fernández. 2019. "Impact of an Online Training Program in Smoking Cessation Interventions in Hospitals." Journal of Nursing Scholarship : An Official Publication of Sigma Theta Tau International Honor Society of Nursing 51(4):449-458.

Mead, Nicola and Peter Bower. 2000. "Patient-Centredness: A Conceptual Framework and Review of the Empirical Literature." Social Science \& Medicine 51(7):10871110. 
Mirowsky, John, and Catherine E. Ross. "Creative work and health." Journal of Health and Social Behavior 48, no. 4 (2007): 385-403.

Mirowsky, J. and C. E. Ross. 2015. "Education, Health, and the Default American Lifestyle." Journal of Health and Social Behavior 56(3):297-306.

Montgomery, A. A., J. Harding and T. Fahey. 2001. "Shared Decision Making in Hypertension: The Impact of Patient Preferences on Treatment Choice." Family Practice 18(3):309-313.

Nollen, N. L., M. S. Mayo and Sanderson Cox, L. et al. 2019. "Factors that Explain Differences in Abstinence between Black and White Smokers: A Prospective Intervention Study." Jnci 111(20):1078-1087.

O'Leary, Ann. 1985. "Self-Efficacy and Health." Behaviour Research and Therapy 23(4):437-451. doi: https://doi.org/10.1016/0005-7967(85)90172-X.

Olson, A. L., M. B. Boardman and D. J. Johnson. 2019. "Smoke-Free Moms: Financial Rewards for Smoking Cessation by Low-Income Rural Pregnant Women." American Journal of Preventive Medicine 56(6):852-859.

Ong, L. M., J. C. de Haes, A. M. Hoos and F. B. Lammes. 1995. "Doctor-Patient Communication: A Review of the Literature." Social Science \& Medicine (1982) 40(7):903-918. 
Parkes, G., T. Greenhalgh, M. Griffin and R. Dent. 2008. "Effect on Smoking Quit Rate of Telling Patients their Lung Age: The Step2quit Randomised Controlled Trial." BMJ (Clinical Research Ed.) 336(7644):598-600.

Phelan, Jo C., Bruce G. Link, and P. Tehranifar. 2010. "Social Conditions as Fundamental Causes of Health Inequalities: Theory, Evidence, and Policy Implications." Journal of Health and Social Behavior 51(1 suppl):S28-S40.

Preston, S. H. and I. T. Elot. 1995. "Are Educational Differentials in Adult Mortality Increasing in the United States?" Journal of Aging and Health 7(4):476-496.

Reed, M. B. and D. M. Burns. 2008. "A Population-Based Examination of Racial and Ethnic Differences in Receiving Physicians' Advice to Quit Smoking." Nicotine \& Tobacco Research : Official Journal of the Society for Research on Nicotine and Tobacco 10(9):1487-1494.

Rimondini, M., L. Del Piccolo, C. Goss, M. Mazzi, M. Paccaloni and C. Zimmermann. 2006. "Communication Skills in Psychiatry Residents-- how do they Handle Patient Concerns? an Application of Sequence Analysis to Interviews with Simulated Patients." Psychotherapy and Psychosomatics 75(3):161-169.

Rubin, Marcie S., Sean Clouston, and Bruce G. Link. 2014. “A Fundamental Cause Approach to the Study of Disparities in Lung Cancer and Pancreatic Cancer in the United States.” Social Science and Medicine 100:54-61. 
Satterfield, J. M., S. E. Gregorich, S. Kalkhoran, P. J. Lum, J. Bloome, N. Alvarado, R. F. Muñoz and M. Vijayaraghavan. 2018. "Computer-Facilitated 5A's for Smoking Cessation: A Randomized Trial of Technology to Promote Provider Adherence." American Journal of Preventive Medicine 55(1):35-43.

Savage, R. and D. Armstrong. 1990. "Effect of a General Practitioner's Consulting Style on Patients' Satisfaction: A Controlled Study." BMJ (Clinical Research Ed.) 301(6758):968-970.

Seyde, Erwin, Erik Taal and Oene Wiegman. 1990. "Risk-Appraisal, Outcome and SelfEfficacy Expectancies: Cognitive Factors in Preventive Behaviour Related to Cancer." Psychology \& Health 4(2):99-109.

Shang, C., J. Huang, K. W. Cheng, Y. He and F. J. Chaloupka. 2017. "The Association between Warning Label Requirements and Cigarette Smoking Prevalence by Education-Findings from the Global Adult Tobacco Survey (GATS)." International Journal of Environmental Research and Public Health 14(1):10.3390/ijerph14010098.

Smith, P. H., A. J. Bessette, A. H. Weinberger, C. E. Sheffer and S. A. McKee. 2016. "Sex/Gender Differences in Smoking Cessation: A Review." Preventive Medicine 92:135-140. 
Stahre, M., K. S. Okuyemi, A. M. Joseph and S. S. Fu. 2010. "Racial/Ethnic Differences in Menthol Cigarette Smoking, Population Quit Ratios and Utilization of EvidenceBased Tobacco Cessation Treatments." Addiction (Abingdon, England) 105 Suppl $1: 75-83$

Strecher, Victor J., Brenda McEvoy DeVellis, Marshall H. Becker and Irwin M. Rosenstock. 1986. "The Role of Self-Efficacy in Achieving Health Behavior Change." Health Education Quarterly 13(1):73-92.

Street, Richard L., Gregory Makoul, Neeraj K. Arora and Ronald M. Epstein. 2009. "How does Communication Heal? Pathways Linking Clinicianâ€"patient Communication to Health Outcomes." Patient Education and Counseling 74(3):295301.

Torchalla, I., C. T. Okoli, J. L. Bottorff, A. Qu, N. Poole and L. Greaves. 2012. "Smoking Cessation Programs Targeted to Women: A Systematic Review." Women \& Health $52(1): 32-54$

Towle, A. and W. Godolphin. 1999. "Framework for Teaching and Learning Informed Shared Decision Making." BMJ (Clinical Research Ed.) 319(7212):766-771.

U.S. Preventive Services Task Force. 2017. Final Recommendation Statement: Tobacco Smoking Cessation in Adults, Including Pregnant Women: Behavioral and Pharmacotherapy Interventions. Rockville, MD: USPSTF Program Office. 
van Ryn, M., D. J. Burgess, J. F. Dovidio, S. M. Phelan, S. Saha, J. Malat, J. M. Griffin, S. S. Fu and S. Perry. 2011. "The Impact of Racism on Clinician Cognition, Behavior, and Clinical Decision Making." Du Bois Review : Social Science Research on Race 8(1):199-218.

Wender, Richard, Elizabeth T. H. Fontham, Ermilo Barrera, Graham A. Colditz, Timothy R. Church, David S. Ettinger, Ruth Etzioni, Christopher R. Flowers, G. Scott Gazelle, Douglas K. Kelsey, Samuel J. LaMonte, James S. Michaelson, Kevin C. Oeffinger, Ya-Chen T. Shih, Daniel C. Sullivan, William Travis, Louise Walter, Andrew M. D. Wolf, Otis W. Brawley and Robert A. Smith. 2013. "American Cancer Society Lung Cancer Screening Guidelines: American Cancer Society Lung Cancer Screening Guidelines." CA: A Cancer Journal for Clinicians 63(2):106-117.

Wetter, David W., Susan L. Kenford, Stevens S. Smith, Michael C. Fiore, Douglas E. Jorenby and Timothy B. Baker. 1999. "Gender Differences in Smoking Cessation." Journal of Consulting and Clinical Psychology 67(4):555-562.

Wright, Eric R. and Brea L. Perry. 2010. "Medical Sociology and Health Services Research: Past Accomplishments and Future Policy Challenges.” Journal of Health and Social Behavior 51(1 suppl):S107-S119. 


\section{Appendix A. VA Decision Aid}

https://www.prevention.va.gov/docs/LungCancerScreeningHandout.pdf 


\section{Appendix B. Duke University Decision Aid}

https://radiology.duke.edu/wp-content/uploads/2020/08/Lung-Cancer-Screening-Shared-

Decision-Making.pdf 


\section{Appendix C. Published Study Protocol}

(Published 2017. Annals of the American Thoracic Society 14(10):1581-1590)

Rationale and Design of the Lung Cancer Screening Implementation: Evaluation of PatientCentered Care Study

Leah S. Miranda, MPH ${ }^{\mathrm{a}}$, Santanu Datta, $\mathrm{PhD}^{\mathrm{b}}$, Anne C. Melzer, MD, $\mathrm{MS}^{\mathrm{c}, \mathrm{d}}$, Renda Soylemez Wiener, MD, MPH ${ }^{\mathrm{e}, \mathrm{f}}$, James M. Davis, MD ${ }^{\mathrm{g}, \mathrm{h}, \mathrm{i}}$, Betty C. Tong, MD, MHS ${ }^{\mathrm{j}}$, Sara E. Golden, $\mathrm{MPH}^{\mathrm{a}}$, Christopher G. Slatore, MD, $\mathrm{MS}^{\mathrm{a}, \mathrm{k}, 1}$

a. Health Services Research \& Development, VA Portland Health Care System; Portland, OR, USA

b. Division of General Internal Medicine, Duke University, Durham, NC, USA

c. Minneapolis VA Health Care System; Minneapolis, MN, USA

d. Center for Chronic Disease Outcomes Research; Minneapolis, MN, USA

e. Center for Healthcare Organization \& Implementation Research, Edith Nourse Rogers Memorial VA Hospital; Bedford, MA, USA

f. The Pulmonary Center, Boston University School of Medicine; Boston, MA, USA

g. Duke Center for Smoking Cessation, Duke University; Durham, NC, USA

h. Duke Smoking Cessation Program, The Duke Cancer Institute at Duke University;

Durham, NC, USA

i. Duke Regional Hospital, Duke University; Durham, NC, USA

j. Department of Surgery, Duke University Medical Center; Durham, NC, USA

k. Department of Medicine, Oregon Health \& Science University; Portland, OR, USA

1. Section of Pulmonary \& Critical Care Medicine, VA Portland Health Care System;

Portland, OR, USA

Corresponding Author at

Leah S. Miranda, MPH

3710 SW US Veterans Hospital Rd. R\&D 66

Portland, OR 97239, USA

Telephone: 503-220-8262, Fax: 503-273-5367, leah.miranda@va.gov

Running Title: Lung cancer screening patient-centered outcomes

Funding: This study is supported by an award from the American Cancer Society 128737-RSG155-01-CPPB, Lung Cancer Screening Implementation: Evaluation of Patient-Centered Care. It was also supported by resources from the VA Portland Health Care System, Portland, OR and the Edith Nourse Rogers Memorial VA Hospital, Bedford, MA.

The Department of Veterans Affairs did not have a role in the conduct of the study, in the collection, management, analysis, interpretation of data, or in the preparation of the manuscript. The views expressed in this article are those of the authors and do not 
necessarily represent the views of the Department of Veterans Affairs or the U.S. Government.

Authorship Statement: All authors have made substantial contributions to the 1) conception and design, acquisition of data, or analysis and interpretation of data; 2) have contributed to drafting the article for important intellectual content; and 3) have provided final approval of the version to be published. Leah Miranda takes responsibility for the content of the manuscript, including data and analysis.

All authors declare no conflicts of interest with the work presented in this manuscript. Keywords: lung cancer screening, patient-centered outcomes research, patient-clinician communication

Link to full article: https://www.atsjournals.org/doi/10.1513/AnnalsATS.201705378SD?url_ver=Z39.88-

2003\&rfr_id=ori\%3Arid\%3Acrossref.org\&rfr_dat=cr_pub++0pubmed\& 


\section{Appendix D. Selected Surveys}

\section{About You}

This section is about your background. Please check one box unless otherwise indicated.

1. What is the highest level or grade of school you have completed?
$1^{\text {st }}-8^{\text {th }}$ grade
$\square$ Some college or vocational work
$9^{\text {th }}-11^{\text {th }}$ grade
$\square$ College graduate
High school graduate $\left(12^{\text {th }}\right.$ grade $) /$ GED
$\square$ Post-graduate work
Refused

2. Are you currently employed? Check all that apply.

$\square$ Employed full time (35+ hrs/wk) $\square$ Retired

$\square$ Employed part time, regular work $\quad \square$ Disabled

Employed part time, irregular work $\square$ Currently not working

$\square$ Unemployed, looking for work $\quad \square$ Volunteer work

$\square$ Student

$\square$ Other, specify:

Refused

3. How would you describe your current marital status?

$\begin{array}{ll}\square \text { Never married } & \square \text { Separated } \\ \square \text { Married } & \square \text { Widowed } \\ \square \text { Divorced } & \square \text { Refused }\end{array}$


4. How would you describe your racial/ethnic background?
American Indian/Alaska Native
$\square$ Black/African American
Asian
$\square$ White/Caucasian
Native Hawaiian/Other Pacific Islander
$\square$ More than one race
Other, specify:
$\square$ Refused

5. Are you Spanish, Hispanic, or Latino? $\square$ Yes $\square$ No $\square$ Refused

6. What is the average total yearly income for your household? (Include all income)
Less than $\$ 10,000$
$\$ 40,000-49,999$
$\$ 10,000-19,999$
$\$ 50,000-59,999$
$\$ 20,000-29,999$
$\$ 60,000-69,999$
$\$ 30,000-39,999$
$\$ 70,000-79,999$
$\$ 80,000$ or more
Refused

8. With which gender do you identify? $\square$ Male $\square$ Female $\square$ Refused

\section{Tobacco Use}

1. How would you describe your cigarette smoking?

\begin{tabular}{|l|l|l|}
\hline $\begin{array}{l}\square \text { Never smoked (less than 100 c } \square \text { Past smoker (quit } \\
\text { in your lifetime) }\end{array}$ & $\begin{array}{l}\square \text { Current smoker (any smoking, eve } \\
7 \text { days ago) }\end{array}$ & within the past 7 days) \\
\hline
\end{tabular}

For current smokers:

\section{Screening and Smoking (If no/can't recall to discussion, skip to section 13)}

1. Did the person who talked with you most about screening discuss quitting smoking [electronic cigarettes] with you?

$\square$ Yes $\quad \square$ No (skip to section 13) $\quad \square$ Can't recall $\square$ Does not apply 


\section{PATIENT INITIAL INTERVIEW}

Lung Cancer Screening Implementation: Evaluation of Patient-Centered Care Qualitative Study

\section{Study ID}

Interview Date $1 \quad 1$

Interviewer(s)

Smoking

- How does lung cancer screening (LCS) make you think about your smoking and health? Are there effects of smoking besides lung cancer?

- How did your clinician communicate about smoking during your discussion?

$\circ$ What were your reactions

- What are your thoughts on screening as a substitute for cessation?

- Probe for barriers to cessation, personal risks.

- Does a negative test mean you don't have bad effects from smoking?

- If the PCP asked, advised, assessed, assisted (counseling, talking, recommending meds, etc.) and arranged f/u for smoking, would that help?

- How do you feel about former smokers being offered LCS?

$\circ$ Get thoughts on smoking status during screening (providers more willing to discuss, does/should it matter, etc.)?

- How important is it that everyone at the [your institution] is offered screening if they're eligible vs. just leaving it up to the individual PCP and patient decisions?

$\circ$ That is, what would happen if there were no clinical reminders?

- Do you think doctors "push" lung cancer screening for their patients?

- Do you think their personal views on smoking influence their decisions to offer screening to their patients?

$\circ$ Why? 
- Do you feel like your smoking status affects how health care providers treat you?

- How does your smoking status affect your care or choices offered to you? 


\section{CLINICIAN INTERVIEW}

Lung Cancer Screening Implementation: Evaluation of Patient-Centered Care Qualitative Study

\section{Study ID}

Interview Date 1

Interviewer(s)

Smoking

- How do you address smoking cessation during screening or after the CT?

- What would help you to do a better job?

- How do you feel this process influences your patient's desire to quit?

- How do you think patients understand smoking and health? (e.g. Do they understand other effects beside lung cancer?)

- Do you generally recommend screening for most patients who meet criteria?

- Do you think stigma against smokers influences your or other clinicians' opinions?

- Tell me about how you address a patient's concerns and worries after the LDCT.

- How do screening results typically affect your patients?

$\circ$ Does it matter if the results are negative or positive? 
Appendix F. Human Subjects Approvals

Portland State University Mail - Re: Waive oversight request

Portland Statg

Sara Golden <sloboy@pdx.edu>

Re: Waive oversight request

Comedy Millar <comedy@pdx.edu>

Fri, Mar 16, 2018 at 1:26 PM

To: Sara Golden <sloboy@pdx.edu>

Hi Sara.

It's ok! Technically. PSU is not "engaged in research" in this situation. Also, no study data or research activities will occur at PSU. You are a VA employee, and their IRB has approved your engagement on the study. as well as the PI of the study. This study is covered under an approved IRB.

Our office is aware that you are using this research to satisfy your dissertation requirements. The Office of Graduate Studies will require you submit proof that you have gone through PSU's Office of Research Integrity and the IRB. You may submit this email to OGS when you apply for graduation. I have worked with Roxanne Treece at OGS in very similar situations in the past.

Let me know if you have any additional questions.

Cheers.

Comedy Millar

[Cuoted lext hidden]

https://mail.google.com/mail/u/0/?ui=2\&ik=1040b9739e\&jsver=jIbIdzeP9wE.en.\&view=p... 4/12/2018 
Institutional Review Board \#1

VA Portland Health Care System

Portland, OR

\section{IRB APPROVAL - Continuing Review}

Date: August 3, 2017

From: Alex Mitchell, MS

Investigator: Christopher G. Slatore, MD, MS

Protocol: *Lung Cancer Screening Implementation: Evaluation of Patient-Centered Care

Sponsor: 9805 = American Cancer Society - Admin: 06 = Portland VA Research Foundation

ID: 03482 Prom\#: 0019 Protocol\#: N/A

The following items were reviewed and approved through Expedited Review:

- Abstract (06/28/2017;07/10/2017 rcvd)

- Contimuing Review (07/24/2017;07/24/2017 rcvd)

- CRQ Attachment, question 9.4.2 (07/10/2017 rcvd)

- Protocol (06/02/2017;06/14/2017rcvd)

- Waiver of Documentation (04/18/2017;04/19/2017 rcvd)

- Screening/Recruitment Waiver (04/18/2017;04/19/2017 rcvd)

- Research Information Sheet - Research Information Sheet - Aim 1 (patient) (04/15/2017; 07/10/2017 rcvd)

- Research Information Sheet - Research Information Sheet - Aim 2a (patient) (04/14/2017; 07/10/2017 rcvd)

- Research Information Sheet - Research Information Sheet - Aim 2b (clinician) (10/20/2016; 07/10/2017

rcvd)

Expedited Approval [Expedited under:

Federal Regulation: 45 CFR 46.110(b)(1)(5) / VA Regulation: 38 CFR 16.110(b)(1)(5)

Federal Regulation: 45 CFR 46.110(b)(1)(6) / VA Regulation: 38 CFR 16.110(b)(1)(6)

Federal Regulation: 45 CFR 46.110(b)(1)(7) / VA Regulation: 38 CFR 16.110(b)(1)(7)] was granted on 08/03/2017 for a period of 12 months and will expire on 08/02/2018. The reviewer was Eileen Wilbur, R.Ph. Your Continuing Review is scheduled for 09/06/2017. This Expedited review will be rep

The protocol was approved to consent a maximum of 720 human subjects.

The protocol was approved to enroll a maximum of 600 human subjects.

Electronic data is approved for VA storage at the following network location: IUR01PORHSM03|Services\ResearchlSlatore 3482 Screening।

Approval for study contimuation is contingent upon your compliance with the requirements of the Research Service for the conduct of studies involving human subjects.

The Portland VAMC IRB is not connected with, has no authority over, and is not responsible for human research conducted at any other institution, except where a Memorandum of Understanding specifies otherwise Separate consent forms, initial reviews, continuing reviews, amendments, and reporting of serious adverse events are required if the same study is conducted at multiple institutions. 